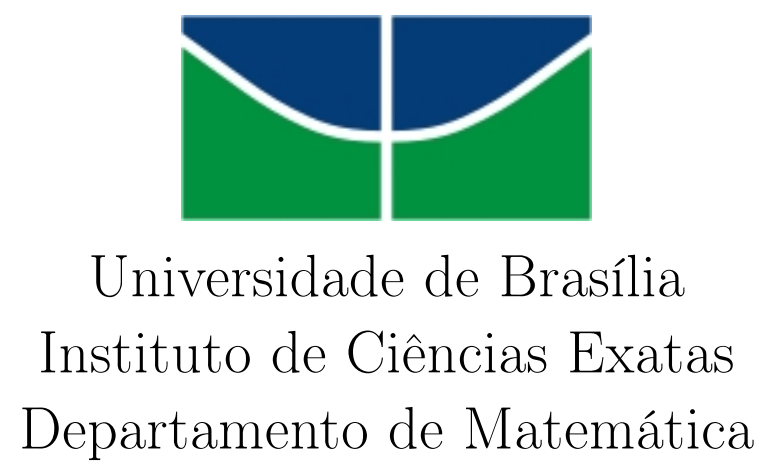

\title{
Matemática Financeira na Educação Básica: um novo olhar
}

$$
\text { por }
$$

Iuri de Souza Simões Ferreira 
Universidade de Brasília

Instituto de Ciências Exatas

Departamento de Matemática

\section{Matemática Financeira na Educação Básica: um novo olhar.}

\section{por \\ IURI DE SOUZA SIMÕES FERREIRA*}

Dissertação apresentada ao Departamento de Matemática da Universidade de Brasília, como parte dos requisitos do "Programa" de Mestrado Profissional em Matemática em Rede Nacional - PROFMAT, para obtenção do grau de

\section{MESTRE}

Brasília, 03 de julho de 2015.

Comissão Examinadora:

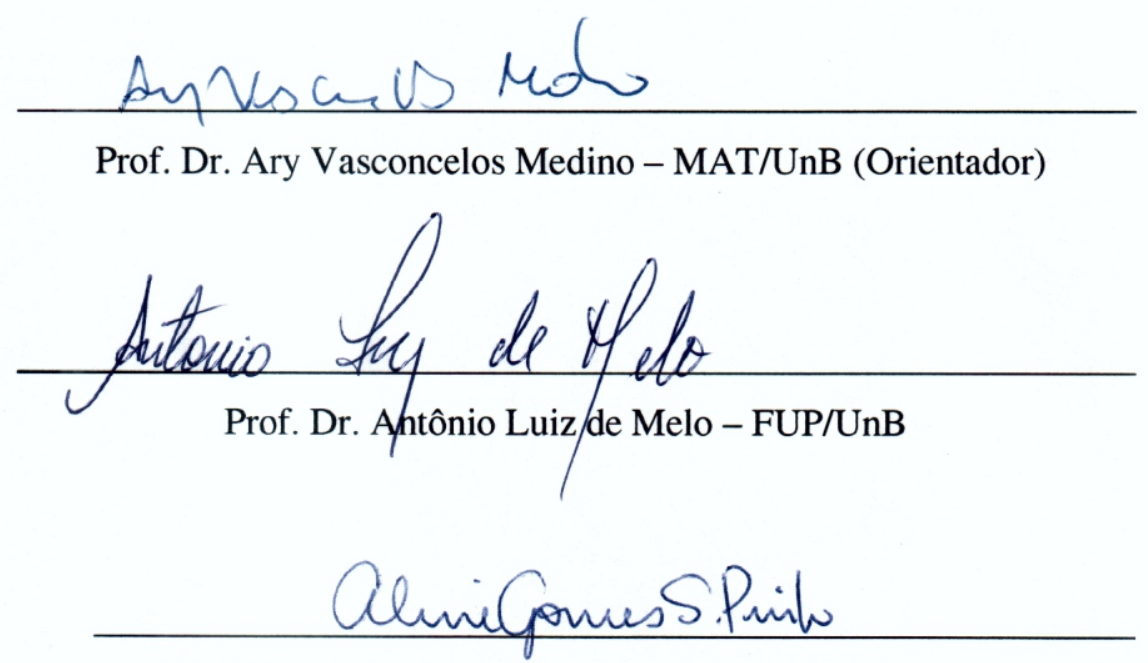

Prof. Dra. Aline Gomes da Silva Pinto - MAT/UnB

* O autor foi bolsista CAPES durante a elaboração desta dissertação. 
Ficha catalográfica elaborada automaticamente, com os dados fornecidos pelo(a) autor(a)

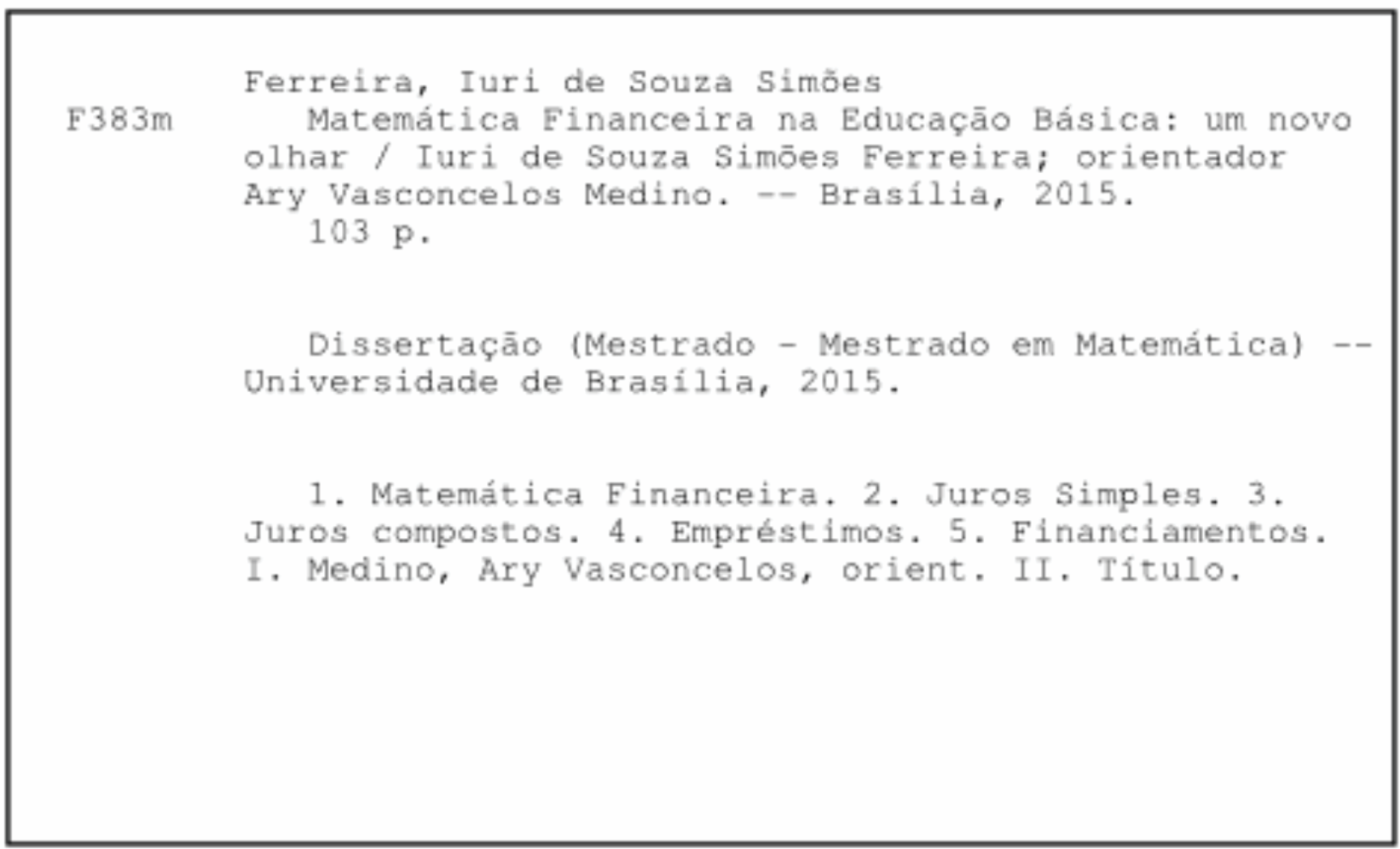


Este trabalho é dedicado à minha esposa Kessy Corrêa B. de Lima Simões Ferreira que sempre esteve ao meu lado, principal responsável pela minha formação acadêmica. Companheira inseparável sem a qual este trabalho como tantas outras vitórias não seriam possíveis. Também dedico a outras duas fontes de inspiração: meus filhos Rafael e Gustavo de Lima Simões Ferreira. 


\section{Agradecimentos}

Agradeço, primeiramente, a Deus, que sempre me abençoou, possibilitando a conclusão deste curso, tão importante para minha formação acadêmica.

Aos meus amigos e familiares, em especial meus sogros José Ferreira de Lima e Castorina Corrêa Balduino de Lima, cujo apoio e ajuda foram fundamentais para a realização deste curso.

À minha família, minha esposa Kessy Corrêa Balduino de Lima Simões Ferreira e meus filhos Rafael de Lima Simões Ferreira e Gustavo de Lima Simões Ferreira, razão de minha dedicação e crescimento, da busca em tornar-me um ser humano melhor, esposo e pai à altura do amor que sinto.

Ao meu orientador, Ary Vasconcelos Medino, pelas correções, conselhos, orientações e contribuições fundamentais para este trabalho.

Aos professores do Departamento de Matemática, em especial àqueles que ministraram cursos para a turma de 2013, bem como aos colegas de curso, que de alguma forma estiveram envolvidos com o Programa de Mestrado ProfMat.

Agradeço o apoio financeiro fornecido pela CAPES na realização deste curso.

Enfim, a todos que direta ou indiretamente, contribuíram para a conclusão deste trabalho.

Enfim, a todos que de alguma forma, mesmo que indireta, contribuíram para a conclusão deste trabalho. 
"A diferença entre o poeta e o matemático é que o poeta tenta elevar sua mente aos céus, enquanto o matemático tenta levar os céus para dentro de sua mente." - G. K. Chesterton. 


\section{Resumo}

Este trabalho apresenta uma visão diferenciada sobre o Ensino da Matemática Financeira na Educação Básica, tendo como objetivo fazer com que o aluno seja capaz de aplicar o conhecimento em seu cotidiano de forma consciente e crítica. Para isso, são utilizados os conteúdos de razão, proporção, progressões aritméticas e geométricas, funções afim, exponencial e logarítmicas, reveladas como aplicações eficazes para a resolução de problemas, uma abordagem pouco usada no ensino regular. Além disso, sugere a inclusão do tema empréstimos e financiamentos, algo que pode contribuir de maneira relevante na vida prática dos alunos.

Palavras-Chaves: Matemática Financeira; Razão; Proporção; Progressão Aritmética; Progressão Geométrica; Juros Simples; Juros Compostos; Empréstimos; Financiamentos. 


\section{Abstract}

This work proposes a different view on teaching Financial Mathematics in the High School and Elementary School. It has as goal to make that students be able to apply this knowledge in their daily lives in a consciously and critical way. For this purpose, we use the concepts of ratio, proportion, arithmetic sequence, geometric sequence, affine function, exponential and logarithmic function. This approach is rarely used in High School and Elementary School and shows effective applications in problem solving. It also suggests the inclusion of the topics Loans and Financing in this level of education and this can contribute in a significant way in the practical life of the students.

Keywords: Financial Mathematics; ratio; proportion; arithmetic sequence; Geometric sequence; compound Interest; loans; financing. 


\section{Notação}

Este trabalho utiliza a seguinte notação:

$A^{*}$ : Conjunto de todos os elementos não nulos de um conjunto A;

$A_{+}$: Conjunto de todos os elementos não negativos de um conjunto A;

$A_{-} \quad$ : Conjunto de todos os elementos não positivos de um conjunto A;

$A_{+}^{*}$ : Conjunto de todos os elementos positivos de um conjunto A;

$A_{-}^{*}$ : Conjunto de todos os elementos negativos de um conjunto A;

$\mathbb{N}$ : Conjunto dos números naturais, considerando apenas os inteiros positivos;

$\mathbb{Z}:$ Conjunto dos números inteiros;

$\mathbb{Q}$ : Conjunto dos números racionais;

$\mathbb{R}:$ Conjunto dos números reais. 


\section{Sumário}

Introdução 1

1 Matemática Financeira Básica 3

1.1 Razão . . . . . . . . . . . . . . . . . . . . . . . . 3

1.2 Proporção . . . . . . . . . . . . . . . . . . . . . . . 8

1.3 Acréscimo e Desconto . . . . . . . . . . . . . . . . . . . . . . 11

1.3.1 Abordagens básicas . . . . . . . . . . . . . . . . . . 11

1.3.2 Fatores de Correção . . . . . . . . . . . . . . . . . . 13

1.3.3 Aumentos e Reduções sucessivas . . . . . . . . . . . . . . . . . 15

1.4 Outros Conceitos Básicos . . . . . . . . . . . . . . . . . . . . . . . . . 19

1.4.1 Inflação, Deflação e Desinflação . . . . . . . . . . . . . . . . . . . . 19

1.4.2 Taxas Nominais ou Aparentes e Taxas Reais . . . . . . . . . . . . . 19

1.5 Usando a calculadora simples . . . . . . . . . . . . . . . . . . 21

1.5.1 Botões de uma calculadora simples . . . . . . . . . . . . . . 22

1.5 .2 Botão $[\mathrm{CE}]$ e $[\mathrm{C}] \ldots \ldots \ldots \ldots$

1.5.3 As teclas de Memória . . . . . . . . . . . . . . . . . . . . 23

1.5.4 A tecla porcentagem ..................... 24

1.6 Estudo de caso . . . . . . . . . . . . . . . . . . . . . . 26

2 Fundamentação Teórica $\quad 29$

2.1 Progressões Aritméticas: PA . . . . . . . . . . . . . . . . . . . . . . . 29

2.1.1 Termo Geral de uma PA . . . . . . . . . . . . . . . . . 31

2.1.2 Progressão Aritmética e a Função afim . . . . . . . . . . . . . . . . 32

2.1.3 Soma dos termos de uma PA . . . . . . . . . . . . . . . . 32

2.2 Progressões Geométricas: PG . . . . . . . . . . . . . . . . . . . . 33

2.2.1 Taxa de Crescimento e Fator de Correção . . . . . . . . . . . . . . . 33 
2.2 .2 Progressões Geométricas . . . . . . . . . . . . . . . . . 35

2.2 .3 Termo Geral de uma PG . . . . . . . . . . . . . . . . 38

2.2.4 Progressão Geométrica e a função exponencial . . . . . . . . . . . 39

2.2.5 Soma dos termos de uma $\mathrm{PG} \ldots \ldots \ldots \ldots$

2.2.6 Soma dos infinitos termos de uma PG decrescente . . . . . . . . . 41

3 Matemática Financeira no Ensino Médio 43

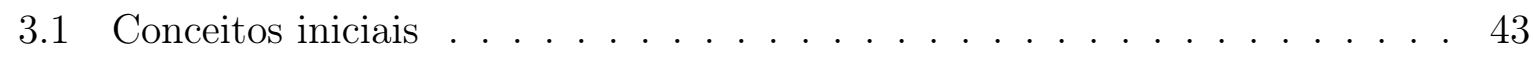

3.2 Regime de Capitalização Simples (Juros Simples) . . . . . . . . . . . 45

3.2 .1 Juros Simples e Progressões Aritméticas . . . . . . . . . . . . 46

3.2 .2 Juros simples e funções . . . . . . . . . . . . . . . . . . . . 48

3.3 Regime de Capitalização Composta (Juros Compostos) … . . . . . . 52

3.3.1 Juros Compostos, PG e funções exponenciais . . . . . . . . . . 55

3.3.2 Capitalização composta com taxa de juros variáveis . . . . . . . . 58

3.3.3 Taxas Proporcionais x Taxas Equivalentes _... . . . . . . . . 59

3.4 Estudo de Casos . . . . . . . . . . . . . . . . . . . . . 62

3.4 .1 Cartão de crédito . . . . . . . . . . . . . . . . . . 62

3.4 .2 Cheque Especial . . . . . . . . . . . . . . . . . . . 65

4 O dinheiro no tempo: empréstimos e financiamentos 68

4.1 Valor Atual e Valor Futuro . . . . . . . . . . . . . . . . . . . 69

4.2 Financiamentos . . . . . . . . . . . . . . . . 71

4.2.1 Sistema de Amortização Constante(SAC) . . . . . . . . . . . . 74

4.2.2 Sistema Francês de Amortização (Tabela Price) . . . . . . . . . . 80

4.3 Estudo de casos . . . . . . . . . . . . . . . . . . . . . . . . 89

4.3 .1 À vista ou a prazo? . . . . . . . . . . . . . . . . . . . . 89

4.3 .2 Empréstimo Pessoal . . . . . . . . . . . . . . . . . . . . 91

4.3.3 Custo Efetivo Total (CET) . . . . . . . . . . . . . . . . 92

4.3.4 Financiamento de Carros: leasing ou financiamento . . . . . . . . . 94

4.3 .5 Financiamento Imobiliário . . . . . . . . . . . . . . . . 97

$\begin{array}{ll}\text { Conclusão } & 103\end{array}$

$\begin{array}{ll}\text { Referências Bibliográficas } & 104\end{array}$ 


\section{Introdução}

De modo geral, o ensino da Matemática Financeira na Educação Regular não é devidamente valorizado. O primeiro contato do aluno com este assunto de forma mais efetiva se dá no sétimo ano do Ensino Fundamental (em um currículo de 9 anos), após o estudo de razão, proporção e regra de três. Infelizmente, a introdução do assunto geralmente ocorre de forma artificial, o professor muitas vezes recorre à regra de três, o que prejudica o aprofundamento posteriormente.

Finalizado o primeiro contato, o aluno tende a dar continuidade a este conteúdo na primeira série do Ensino Médio, dependendo do currículo. Tem a ideia de juros simples e compostos, com uma abordagem segmentada de outros conteúdos da Matemática. Aprende um conjunto de fórmulas e se vê obrigado a utilizá-las para resolução de problemas moldados para esta forma de solucionar.

Portanto, o objetivo principal deste trabalho é sugerir uma reflexão sobre o Ensino da Matemática Financeira na Educação Regular, a ponto de apresentar conceitos e problemas deste conteúdo durante o ensino de diversos tópicos da Matemática, vinculando, assim, a Matemática Financeira a vários assuntos, contextualizando, fazendo o aluno perceber que estão intimamente relacionados entre si.

Outra contribuição essencial é a apresentação de problemas reais, que fazem parte do cotidiano do aluno, auxiliando, assim, no principal ponto desta reflexão que é o objetivo do Ensino da Matemática Financeira: que ela possa preparar o aluno para tomada de decisões, ou seja, a partir dos conceitos aprendidos ele tenha consciência financeira, condições de tomar decisões sensatas, utilizando a noção matemática.

Além disso, é apresentada, de forma breve uma noção sobre empréstimos e financiamentos, que é hoje uma realidade em potencial de qualquer cidadão. São elucidadas noções de construção de planilhas e, principalmente, a partir de progressões, apresentação, a possibilidade de se estudar empréstimos e financiamentos com uma abordagem que não aparece em livros que tratam deste assunto. São enunciados e demonstrados teoremas 
e corolários como opção para abordar o tema sem a necessidade de planilhas.

Vale ressaltar que não há intenção de criticar ou apontar um modelo ideal, mas contribuir de forma efetiva a uma ponderação sobre a importância do conteúdo e como está sendo ministrado na escola.

As referências usadas para elaboração deste trabalho contam com livros específicos de Matemática Financeira (referências [4], [7], [8] e [9] ), assim como livros-textos de conteúdos da Matemática do Ensino Médio (referências [5], [6] e [7]) e do portal do Banco Central do Brasil na Internet (referências [1], [2] e [3]). 


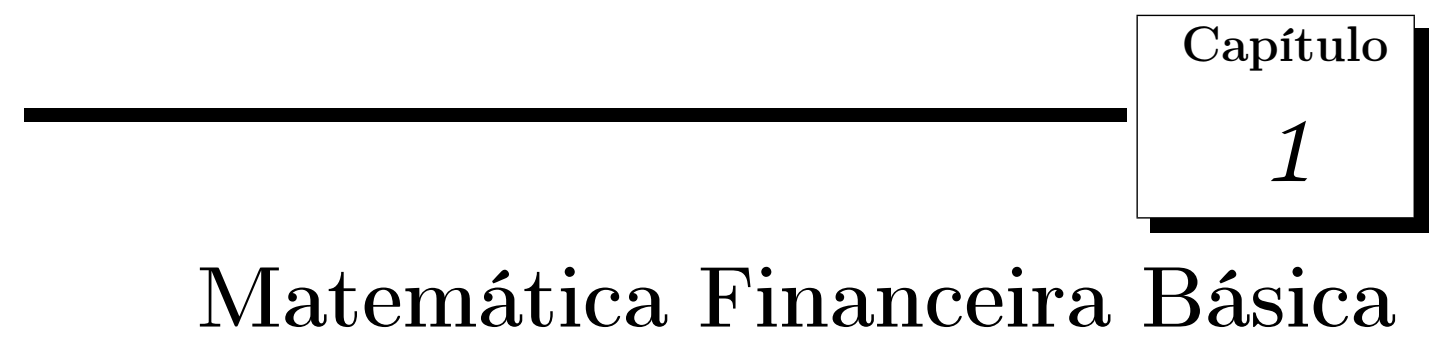

Neste capítulo, serão explorados os conceitos fundamentais da Matemática Financeira. Em alguns livros, este assunto é denominado Matemática Comercial, por se tratar de uma forma simples, aplicada ao cotidiano, retomando alguns conceitos básicos.

A maior parte deste capítulo, senão sua totalidade, destina-se à aplicação da Matemática no Ensino Fundamental, essencial para a formação satisfatória de um aluno que tenha base para um bom curso de Matemática Financeira em anos posteriores. Serão apresentados os conceitos fundamentais com exemplos de abordagens que podem ser utilizadas e estratégias de resolução de problemas.

\subsection{Razão}

No ano de 2012 a editora Livrobom teve um lucro de 200 mil reais e no ano seguinte 300 mil reais. Estes valores podem ser comparados fazendo a diferença: houve um aumento de 100 mil reais nas vendas. No entanto, não apresenta uma ideia relativa do crescimento.

Uma forma muito mais precisa de comparação seria dividir o lucro do ano de 2013 pelo obtido no ano de 2012, isto é, 300 : 200 que é igual a 1,5, ou seja, o lucro de 2013 foi 1,5 vezes maior que o de 2012. Esta última forma de comparação é denominada de razão.

Definição 1.1 (Razão). É chamada razão entre dois números reais a e $b(\operatorname{com} b \neq 0) a$ expressão: $\frac{a}{b}$. O número a é chamado de antecedente e $b$ é denominado consequente.

É um conceito fundamental, pois constitui a melhor forma de comparação entre dois valores. Pode ser representada de três formas: fracionária, decimal ou percentual. 
Exemplo 1.1. Observe na tabela abaixo a representação da razão na forma fracionária e decimal.

\begin{tabular}{|l|l|c|c|}
\hline & Expressão & Forma fracionária & Forma decimal \\
\hline (i) & razão entre 3 e 4 & $\frac{3}{4}$ & $3: 4=0,75$ \\
\hline \multirow{2}{*}{ (ii) } & razão entre $\frac{3}{5}$ e $\frac{7}{10}$ & $\frac{\frac{3}{5}}{\frac{7}{10}}=\frac{6}{7}$ & $6: 7 \approx 0,85714286$ \\
\hline (iii) & razão entre 1,2 e 0,3 & $\frac{1,2}{0,3}=\frac{4}{1}$ & $400: 100=4,0$ \\
\hline
\end{tabular}

Tabela 1.1: Formas de uma razão

Uma razão também pode ser exibida na forma de porcentagem.

Definição 1.2 (Porcentagem). Uma razão de denominador 100 é chamada de razão centesimal, taxa percentual ou simplesmente de porcentagem. Para representar uma porcentagem utiliza-se o símbolo \% em substituição ao denominador 100.

Exemplo 1.2. Observe as razões percentuais:

\begin{tabular}{|c|c|c|c|}
\hline razão & $\frac{31}{100}$ & $\frac{72,5}{100}$ & $\frac{0,015}{100}$ \\
\hline porcentagem & $31 \%$ & $72,5 \%$ & $0,015 \%$ \\
\hline
\end{tabular}

Tabela 1.2: razões percentuais

Observação 1.1 (Escrevendo a razão na forma percentual à partir da fracionária). Para escrever uma razão da forma fracionária para a percentual, basta transformar o consequente para 100 (multiplica-se antecedente e consequente pelo número conveniente).

Observação 1.2 (Escrevendo a razão na forma percentual à partir da decimal). Tendo a forma decimal de uma razão, basta multiplicá-la por $\frac{100}{100}$ ou $100 \%$ (note que $\frac{100}{100}=$ $100 \%=1$, assim, o produto por 1 não altera o valor da razão apenas insere a porcentagem: $\%)$

Exemplo 1.3 (Revisitando o exemplo 1.1). Observe que as razões serão escritas na forma percentual.

Exemplo 1.4 (Cálculo Simples). Como visto anteriormente, uma razão pode ser apresentada nas formas fracionária, decimal ou percentual. Represente a razão entre 11 e 20 na forma percentual. 


\begin{tabular}{|l|c|c|}
\hline Expressão & Forma fracionária & Forma decimal \\
\hline razão entre 3 e 4 & $\frac{3}{4}=\frac{3 \cdot 25}{4 \cdot 25}=\frac{75}{100}=75 \%$ & $0,75 \cdot \frac{100}{100}=\frac{75}{100}=75 \%$ \\
\hline razão entre $\frac{3}{5}$ e $\frac{7}{10}$ & $\frac{\frac{3}{7}}{\frac{7}{10}}=\frac{6}{7}$ & $\approx 0,85714286 \cdot 100 \% \approx 85,71 \%$ \\
\hline razão entre 1,2 e 0,3 & $\frac{1,2}{0,3}=\frac{4 \cdot 100}{1 \cdot 100}=\frac{4 \cdot 100}{1 \cdot 100}=400 \%$ & $4,0 \cdot 100 \%=400 \%$ \\
\hline
\end{tabular}

Tabela 1.3: Escrevendo na forma percentual

\begin{tabular}{|c|c|}
\hline Usando a forma fracionária & Usando a forma decimal \\
\hline$\frac{11}{20}=\frac{11 \cdot 5}{20 \cdot 5}=\frac{55}{100}=55 \%$ & $11: 20=0,55=55 \%$ \\
\hline
\end{tabular}

Tabela 1.4: Escrevendo uma razão na forma decimal e fracionária

\section{Solução.}

Observação 1.3. Note que a forma fracionária é mais prática de usar quando a forma fatorada do denominador possui apenas os fatores 2 e 5 , ou seja, é possível transformar em uma potência de 10.

Observação 1.4. A forma decimal pode ser escrita diretamente na forma percentual, basta "andar" duas casas decimais. Uma explicação possível é lembrar que a multiplicação por 1 não altera o resultado: $0,55 \cdot 1=0,55 \cdot \frac{100}{100}=0,55 \cdot 100 \%=55 \%$

Como a porcentagem é uma razão de consequente 100, para usá-la deve-se eleger um valor como principal (que equivale a 100\%). Observe os exemplos a seguir.

Exemplo 1.5 (Escrevendo um valor na forma de porcentagem). Um smartphone custa $R \$ 800,00$ e Rildo possui $R \$$ 700,00. Que porcentagem representa a quantia possuída em relação ao valor do produto?

\section{Solução.}

Comparando a quantia de Rildo e o valor da mercadoria (valor principal: 100\%), tem-se:

$$
\frac{700}{800}=\frac{7}{8}=0,875
$$

ou seja, $87,5 \%$.

Exemplo 1.6 (Escrevendo uma porcentagem na forma de valor monetário). Um celular custa $R \$ 800,00$. O vendedor, percebendo que Rildo não possuía toda a quantia, aplicou um desconto, cobrando apenas $80 \%$ do valor do produto. Que quantia minima Rildo precisa para adquirir o celular? 


\section{Solução.}

Note que se deseja descobrir que valor monetário que representa o percentual de $80 \%$. Lembre-se: o valor principal aqui é $\mathrm{R} \$ 800,00$. Neste caso, deseja-se descobrir $80 \%$ de $\mathrm{R} \$$ 800,00 .

$$
\begin{aligned}
80 \% \text { de } 800 & =80 \% \cdot 800 \\
& =0,8 \cdot 800=640
\end{aligned}
$$

Assim, o valor cobrado pelo celular é de $\mathrm{R} \$ 640,00$.

Como a razão é a melhor forma de comparar valores, esta torna-se uma ferramenta fundamental para a tomada de decisões simples do dia a dia. Seguem alguns exemplos.

Exemplo 1.7 (aumento virtual de preços). Uma caixa de bombons custava $R \$$ 7,20 há um ano. Para surpresa de Bernardo, a caixa de bombons continua custando o mesmo valor. No entanto, ao verificar a embalagem constatou-se que a massa da caixa, que era de $400 \mathrm{~g}$ passou para $300 \mathrm{~g}$. Pode-se afirmar que houve aumento de preço?

\section{Solução.}

Em um breve cálculo, Bernardo verificou que o produto sofreu aumento de preço. Observe o raciocínio adotado por ele. Fazendo a razão entre massa do produto e valor, obtém-se o valor pago por grama. Por exemplo: verificando o valor de um ano atrás, tem-se

$$
\frac{400 g}{R \$ 7,20}=\frac{400: 400}{7,2: 400}=\frac{1}{0,018}
$$

Interpretando o resultado, cada grama custa $\mathrm{R} \$ 0,018$ (menos de 2 centavos de real). A mesma comparação feita hoje:

$$
\frac{300 g}{R \$ 7,20}=\frac{300: 300}{7,2: 300}=\frac{1}{0,024} \quad \text { (mais de dois centavos de real cada grama) }
$$

A diferença parece irrisória, no entanto a comparação entre o valor novo e antigo é surpreendente:

$$
\frac{0,024}{0,018}=\frac{24}{18}=\frac{4}{3}=1,333 \cdots
$$

A expressão equivale a aproximadamente $133,33 \%$, ou seja, houve um aumento de $33,33 \%$, embora o valor cobrado seja o mesmo.

Como o valor cobrado não sofreu alteração, seria possível chegar à mesma conclusão simplesmente fazendo a razão entre a massa usada anteriormente e a atual:

$$
\frac{400}{300}=\frac{4}{3} \approx 133,33 \%
$$


Exemplo 1.8 (Tomando a melhor decisão: embalagem x preço). Um grupo de quatro alunos encontra seu professor de Matemática em um supermercado. Curioso, o professor verifica que no carrinho dos alunos há quatro latas de refrigerante de $350 \mathrm{ml}$ (custando $R \$$ 3,00 cada), quatro pacotes de salgadinhos de $60 \mathrm{~g}$ (custando $R \$ 1,60$ cada) e 4 tabletes de chocolate de $30 \mathrm{~g}$ (custando $R \$ 1,50$ cada).

Andando pelas seções do mercado anotaram os preços na tabela 1.5, dada a seguir. Faça uma análise do caso.

\begin{tabular}{|l|c|r|}
\hline Produto & Embalagem & Valor \\
\hline Refrigerante & 2 litros & $\mathrm{R} \$ 5,00$ \\
\hline Salgado & $120 \mathrm{~g}$ e $250 \mathrm{~g}$ & $\mathrm{R} \$ 2,40$ e $\mathrm{R} \$ 4,00$ \\
\hline Chocolate & $170 \mathrm{~g}$ & $\mathrm{R} \$ 4,50$ \\
\hline
\end{tabular}

Tabela 1.5: Pesquisa no mercado, exemplo 1.8.

\section{Solução.}

Em um breve cálculo, o professor mostrou aos alunos como a razão é uma ferramenta fundamental para comparar valores e finalmente tomar decisões corretas.

Note que as mercadorias do carrinho são: 4 latas de refrigerante de $350 \mathrm{ml}(4 \cdot 3=12)$, 4 pacotes de salgadinhos de $60 \mathrm{~g}(4 \cdot 1,60=6,40)$ e 4 tabletes de chocolate de $30 \mathrm{~g}$ $(4 \cdot 1,50=6,00)$. Totalizando um gasto de $\mathrm{R} \$ 24,40$.

Andando nas seções do supermercado, o professor mostrou aos alunos que a comparação entre quantidade (g ou ml) e valor ( $\mathrm{R} \$$ ) ajuda a tomar a melhor decisão.

Uma garrafa de refrigerante de 2 litros atende os alunos que estão levando 1,4 litros de refrigerante. Como a garrafa de 2 litros custa no mesmo mercado $\mathrm{R} \$ 5,00$, a economia será de $\mathrm{R} \$ 7,00$, com $600 \mathrm{ml}$ a mais de refrigerante.

O supermercado oferece pacotes de salgadinhos de 120 g e $250 \mathrm{~g}$, com valores de $\mathrm{R} \$$ 2,40 e $\mathrm{R} \$ 4,00$. Assim, levando um pacote de $250 \mathrm{~g}$, o valor pago será de $\mathrm{R} \$ 4,00$, com 10 gramas a mais de salgadinho, gerando uma economia de $\mathrm{R} \$ 2,40$ (suficiente para levar outro pacote de $120 \mathrm{~g}$ ).

Uma barra de chocolate de 170 g custa no mesmo mercado $\mathrm{R} \$ 4,50$, uma economia de $\mathrm{R} \$ 1,50$, levando $20 \mathrm{~g}$ a mais de chocolate.

Assim, os alunos poderiam levar mais mercadorias por $\mathrm{R} \$ 13,50$, uma economia de $\mathrm{R} \$$ 10,90 .

Fazendo-se a comparação em cada caso, pela razão, é possível determinar um resultado comparativo.

No caso do refrigerante, pode-se comparar valor e capacidade: $\frac{R \$ 3,00}{350 m l}$ e $\frac{R \$ 5,00}{2000 m l}$. 
Simplificando cada fração por seu respectivo denominador, tem-se $\frac{3: 3}{350: 3}=\frac{1}{116,66} \mathrm{e}$ $\frac{5: 5}{2000: 5}=\frac{1}{200}$. Significa que $\mathrm{R} \$ 1,00$ equivale a aproximadamente 116,66 mililitros na compra da latinha e $200 \mathrm{ml}$ na garrafa de 2 litros.

Analisando os diferentes pacotes de salgadinhos, as razões com seus respectivos valores são dados na tabela:

\begin{tabular}{|c|c|c|}
\hline $60 \mathrm{~g}$ & $120 \mathrm{~g}$ & $250 \mathrm{~g}$ \\
\hline$\frac{R \$ 1,60}{60}=\frac{R \$ 1,60: 1,6}{60: 1,6}=\frac{1}{37,5}$ & $\frac{R \$ 2,40}{120}=\frac{R \$ 2,40: 2,4}{120: 2,4}=\frac{1}{50}$ & $\frac{R \$ 4,00}{250}=\frac{R \$ 4,00: 4}{250: 4}=\frac{R \$ 1}{62,5}$ \\
\hline
\end{tabular}

Tabela 1.6: apoio para resolução do exemplo 1.8

Uma barra de chocolate de 170 g custa no mesmo mercado $\mathrm{R} \$ 4,50$, uma economia de $\mathrm{R} \$ 1,50$, levando $20 \mathrm{~g}$ a mais de chocolate.

\subsection{Proporção}

Considerando a mesma editora, Livrobom, suponha que o lucro de 2014 seja de 400 mil reais e o lucro de 2015 seja 600 mil. Note que as comparações entre os lucros de 2015 e 2014 (600:400 = 3:2) e de 2013 e 2012 (300:200 = 3:2) são iguais. Esta igualdade entre as duas razões denomina-se proporção.

Definição 1.3. Dadas as razões $\frac{a}{b} e \frac{c}{d},\{a, b, c, d\} \subset \mathbb{R}$, sendo $b, d \neq 0$, a igualdade

$$
\frac{a}{b}=\frac{c}{d}
$$

é chamada proporção. Os valores a e d são denominados extremos e b e c são chamados meios.

Define-se, ainda, que quatro valores $a, b, c$ e $d$ são, nessa ordem, proporcionais se for possível escrever uma proporção nessa ordem.

A proporção tem atrelada ao seu uso uma propriedade fundamental, utilizada em praticamente todos os casos.

Propriedade 1.1 (Propriedade Fundamental da Proporção). Considerando a proporção $\frac{a}{b}=\frac{c}{d}$, com $b$ e d diferentes de zero, vale a propriedade:

$$
\frac{a}{b}=\frac{c}{d} \Longrightarrow a \cdot d=b \cdot c
$$


Demonstração. Dada a igualdade $\frac{a}{b}=\frac{c}{d}$, multiplique ambos os membros da igualdade por $b \cdot d$.

$$
\begin{array}{r}
b \cdot d \cdot \frac{a}{b}=\frac{c}{d} \cdot b \cdot d \\
a \cdot d=b \cdot c
\end{array}
$$

Exemplo 1.9. Uma livraria doa seus livros a duas bibliotecas comunitárias $A$ e $B$, respectivamente, na razão de 2 para 5. Sabendo que a biblioteca deseja doar 400 livros para a biblioteca A, qual o número de livros que devem ser doados para a biblioteca B?

\section{Solução.}

Como a razão de livros de A para B é de 2:5, chamando a quantidade de livros doados para a biblioteca $\mathrm{B}$ de $x$, então:

$$
\begin{aligned}
\frac{2}{5} & =\frac{400}{x} \\
2 x & =5 \cdot 400 \\
x & =1000
\end{aligned}
$$

Logo, a biblioteca $B$ deve receber 1.000 livros.

Exemplo 1.10. Dois sócios, Lima e Lena investiram para a abertura de uma empresa as quantias de $R \$ 12.000,00$ e $R \$ 15.000,00$, respectivamente. Depois de cinco anos receberam uma oferta de $R \$ 360.000,00$. Se a proposta for aceita quanto cada um deve receber?

\section{Solução.}

O valor total deve ser dividido na mesma proporção que os sócios investiram, ou seja, a razão entre os valores da venda que Lima e Lena receberão deve ser igual à razão entre os valores investidos de cada um. Desta forma, denominando o valor recebido por lima de $v$, o valor recebido por Lena será $360000-v$ :

$$
\begin{aligned}
\frac{12000}{15000} & =\frac{v}{360000-v} \\
\frac{4}{5} & =\frac{v}{360000-v} \\
5 v & =4 \cdot(360000-v) \\
v & =160000
\end{aligned}
$$


Logo, o valor a ser recebido por Lima, caso o negócio seja concretizado, é de $\mathrm{R} \$$ 160.000,00 e por Lena é de $\mathrm{R} \$ 200.000,00$.

Neste trabalho, a notação de proporção será limitada à resolução de situações-problema específicas. Seu uso para cálculo de porcentagens gera um vício, os alunos e mesmo professores passam a usá-la como única estratégia para resolução de todos os problemas de porcentagem e ignoram sua definição, o que limita muito o aluno, prejudicando-o na resolução de problemas mais complexos em anos posteriores.

Embora, segundo os alunos, a resolução por razão seja mais trabalhosa, com a prática percebe-se uma evolução significativa e melhor fixação da aprendizagem, facilitando conceitos futuros.

Exemplo 1.11. Em uma compra de $R \$ 256,00$, um cliente verificou o cupom fiscal $e$ identificou um gasto de $R \$ 64,00$ com impostos. Qual a taxa percentual de impostos?

\section{Solução.}

Para uso deste recurso, utiliza-se a ideia de Valor Principal, representando 100\%, como o valor monetário de $\mathrm{R} \$ 256,00$. Pode-se construir uma proporção fazendo duas razões equivalentes ou usando a regra de três, que é uma proporção na forma de esquema. Veja as duas formas de resolução.

Regra de três Simples

$$
\begin{aligned}
& \text { Valor } \\
& \begin{array}{rc}
256 & \text { Porcentagem } \\
64 & 100 \\
256 x & =100 \cdot 64 \\
x & =\frac{6400}{256} \\
x & =25
\end{array}
\end{aligned}
$$

Proporção

Fazendo a razão entre valor e porcentagem, considere $v_{0}$ : valor principal e $p_{0}$ : porcentagem do valor principal (100\%). A partir da propriedade fundamental da proporção,

$$
\frac{v_{0}}{p_{0}}=\frac{v_{1}}{p_{1}} \Rightarrow v_{0} \cdot p_{1}=v_{1} \cdot p_{0}
$$


Usando a fórmula (1.2),

$$
\begin{aligned}
\frac{256}{100} & =\frac{64}{x} \\
256 x & =64 \cdot 100 \\
x & =\frac{6400}{256} \\
x & =25
\end{aligned}
$$

Assim, 64 representa 25\% de 256 .

Agora, usando razão, basta comparar o valor com o total e transformar a razão para a forma percentual:

$$
\frac{64}{256}=\frac{1}{4}=\frac{1 \cdot 25}{4 \cdot 25}=25 \%
$$

\subsection{Acréscimo e Desconto}

Para definição de acréscimo e desconto, serão conceituados outros termos que servirão de base para o estudo.

Definição 1.4 (Valor Principal ou Capital). Nome dado ao valor que será usado em uma aplicação financeira. Geralmente o valor inicial, principal, dependendo do contexto adotado.

Definição 1.5 (Acréscimo e Desconto). O acréscimo é o valor que é somado ao valor principal. Operação financeira que representa aumento no valor do Capital, enquanto o desconto representa o valor que será subtraído do capital.

\subsubsection{Abordagens básicas}

Serão apresentados a seguir exemplos de abordagens básicas envolvendo os conceitos de acréscimo e desconto.

Exemplo 1.12 (Resolução direta). Em um produto que custa $R \$ 120,00$, será dado um desconto de $R \$ 15,75$. Qual será o valor final do produto?

\section{Solução.}

O valor final será: $120-15,75$, ou seja, $\mathrm{R} \$ 104,25$.

Exemplo 1.13 (Resolução direta). Uma boutique de roupas adquire uma camisa com o preço de custo de $R \$$ 28,00. Para atingir o lucro desejado, a loja aumenta o valor do produto em $R \$ 18,25$. Qual será o valor final do produto? 


\section{Solução.}

O valor final será: $28+18,25$, ou seja, $\mathrm{R} \$ 46,25$.

Exemplo 1.14 (Uso da porcentagem ). Abilio recebia um salário de $R \$$ 3.200,00. A partir de fevereiro de 2015 sua remuneração sofreu um aumento de 12\%. Qual o novo valor do salário?

\section{Solução.}

$1^{\circ}$ Método (Regra de três / Proporção)

Infelizmente este é hoje o método mais utilizado. Embora não seja o mais didático, por não usar a própria definição de porcentagem, é o mais cômodo para o professor, ou mesmo para os alunos por não exigir muito raciocínio. Um método automatizado é geralmente uma preferência do aluno que opta, na maioria das vezes, pelo caminho que exige menos raciocínio.

$$
\begin{aligned}
& \text { Valor } \\
& \begin{array}{cc}
3200 & \text { Porcentagem } \\
x & 100 \\
100 \cdot x=3200 \cdot 12 \\
x=384
\end{array}
\end{aligned}
$$

O salário de $R \$ 3.200,00$ com o aumento de $R \$ 384,00$ passou a ser de $R \$ 3.584,00$.

\section{$2^{\circ}$ Método (Unidade de Porcentagem)}

Uma forma intuitiva, muitas vezes sugerida pelo próprio aluno, é a estratégia de encontrar o equivalente a $1 \%$ do valor principal e, em seguida, calcular a porcentagem desejada. O aluno que faz este tipo de sugestão deve ser instigado, pois possui um raciocínio interessante para a Matemática.

Sabe-se que $1 \%$ de 3200 é o mesmo que 32 ( faça $\frac{3.200}{100}=32$ ). Assim, $12 \%$ é o mesmo que $12 \cdot 1 \%$, ou seja, $12 \cdot 32=384$. Logo, o salário é de $\mathrm{R} \$ 3.584,00$

\section{$3^{\circ}$ Método (Fração de Quantidade)}

No $6^{\circ}$ Ano do Ensino Fundamental, o aluno tem um trabalho intensivo com frações e um dos tópicos trabalhados é o de frações de quantidade, ou seja, calcular a fração de qualquer valor. Nos anos subsequentes, esta ideia não é bem explorada. Este recurso é o ponto de partida para a adoção do fator de correção, estratégia que será amplamente explorada neste trabalho.

Como $12 \%$ é o mesmo que $\frac{12}{100}, 12 \%$ de 3.200 é o mesmo que $\frac{12}{100} \cdot 3.200=0,12 \cdot 3.200$. Desta forma, o aumento será de $\mathrm{R} \$ 384,00$ e o salário será de $\mathrm{R} \$ 3.584,00$. 


\subsubsection{Fatores de Correção}

Na Matemática é chamado fator o termo que está envolvido em uma multiplicação. Assim, usando a ideia de fração de quantidade abordada na seção anterior, resolvem-se de maneira mais simples e eficaz problemas, que neste primeiro momento, abordam a ideia de desconto e acréscimo.

Observação 1.5. O valor principal equivale a 100\% que é o mesmo que 1. Considere, uma taxa percentual $i_{d}$ de desconto ou uma taxa percentual $i_{a}$ para aumento. No caso do aumento o fator de correção será: $1+i_{a}$. No caso do desconto o fator de correção será: $1-i_{d}$.

Considera-se que o valor principal equivale a $100 \%$ ou 1 inteiro. Assim, qualquer porcentagem de desconto ou acréscimo será aplicado diretamente na porcentagem. Para ilustrar, será usado o exemplo 1.14.

$4^{\circ}$ Método (Fator de Correção)

Como Abílio recebeu um aumento de 12\%, seu salário, definido como valor principal $(100 \%)$ passa a ser de $112 \%$. Desta forma, deseja-se calcular $112 \%$ de 3.200 . Como $112 \%=1,12$, tem-se que com o aumento o salário passa a ser de $112 \%$ ou 1,12 do Valor Principal;

$$
\begin{aligned}
112 \% \text { de } 3.200 & =1,12 \cdot 3.200 \\
& =3.584,00
\end{aligned}
$$

Logo, o salário será de $\mathrm{R} \$ 3.584,00$.

Note que o cálculo é único e direto. Este raciocínio será adotado daqui em diante, facilitando e otimizando consideravelmente os cálculos que serão realizados.

Exemplo 1.15 (Aplicando fatores de correção). Com a troca de patrocinador esportivo, o São Paulo Futebol Clube realiza a venda de sua camisa oficial, que custava $R \$ 180,00$, com um desconto de 35\%. Qual será o novo valor da camisa?

\section{Solução.}

Como houve um desconto de $35 \%$, o valor relativo da camisa, em relação ao valor principal passa a ser de $65 \%$.

O valor final da camisa, é $65 \%$ de 180 :

$$
0,65 \cdot 180=117
$$


O valor final da camisa será de $\mathrm{R} \$ 117,00$.

Exemplo 1.16 (Valor em porcentagem). Após a final da Copa do Mundo, uma loja de artigos esportivos realizou uma liquidação dos produtos que restaram do tema. Uma bola que custava $R \$ 64,00$ passou a custar $R \$ 51,20$. Qual a porcentagem de desconto efetuada pela loja?

\section{Solução.}

Como se conhece da definição de porcentagem, uma razão de denominador 100 equivalente a uma comparação entre dois valores (Neste caso, comparação entre valor final e valor principal):

$$
\begin{aligned}
\frac{\text { desconto }}{\text { valor Principal }} & =\frac{51,20}{64} \\
& =\frac{512}{640} \\
& =0,8
\end{aligned}
$$

Note que o fator de correção é 0,8. Desta forma, foi atribuído um desconto de $20 \%$.

Considerando o valor principal como sendo o valor inicial $\left(V_{i}\right)$, atribuindo um desconto ou acréscimo, encontra-se o valor final $\left(V_{f}\right)$ e que este valor final equivale à multiplicação entre o valor inicial e o fator de correção $(F)$ :

$$
V_{f}=V_{i} \cdot F \Longleftrightarrow F=\frac{V_{f}}{V_{i}}
$$

Exemplo 1.17. O valor de um produto comprado por um cliente em um supermercado tem custo de $R \$ 12,25$. Com a incorporação dos impostos é cobrado o valor de $R \$ 17,15$. Qual o fator de correção e qual a taxa de impostos cobrada?

Solução. Compara-se o valor final e inicial, neste caso, a razão entre 17,15 e 12,25.

$$
\left.\frac{17,15}{12,25}=1,4 \text { (equivalente a } 140 \%\right)
$$

Encontrado o fator de correção: 1,4 (equivalente a 140\%), encontra-se a porcentagem de aumento de $40 \%$.

Observe que o fator de correção referente a um aumento deve ser maior que 1, enquanto o desconto tem fator de correção menor que 1. 


\subsubsection{Aumentos e Reduções sucessivas}

Quando se pensa no valor do dinheiro no tempo, deve-se levar em consideração que um aumento pode ser periódico, assim como um desconto, como uma caderneta de poupança, descontos sucessivos de uma loja ensaiando uma liquidação, mesmo um empréstimo ou tantas outras situações comuns.

Infelizmente esta é uma abordagem não empregada no Ensino Fundamental, por se tratar de uma ideia de juros compostos (assunto que nunca é abordado no Ensino Fundamental). A não empregabilidade deste conteúdo é uma grande oportunidade perdida no Ensino Fundamental, que explora apenas situações que envolvem juros simples, criando para o aluno uma ilusão.

Deseja-se mostrar nesta seção que é possível abordar este assunto que é tão real e presente no cotidiano de um cidadão. Usando recursos da realidade do aluno, serão apresentados alguns exemplos a seguir.

Para ilustrar esse raciocínio, verifique o exemplo:

Exemplo 1.18. ${ }^{1}$ Em um jogo de azar, o jogador dobra sua quantia se vencer e perde a metade se não vencer a aposta. Érick, começou com $R \$ 64,00$, venceu três e perdeu três dessas apostas, o que acontece no final?

(A) Depende da ordem das apostas;

(B) ganhou dinheiro;

(C) nem ganhou nem perdeu dinheiro;

(D) ganhou ou perdeu dinheiro, dependendo da ordem em que se sucederam suas vitórias e derrotas;

(E) perdeu $R \$ 27,00$.

Solução. Fazendo simulações, considere inicialmente as possíveis sequências (entenda-se V: vitória e P: perda): VPPVPV e VVVPPP.

Pelas simulações, é possível chegar a uma conclusão e encontrar a resposta correta do problema, letra (C). No entanto, pode-se chegar à mesma conclusão por uma simples multiplicação. Basta lembrar de uma propriedade básica da Aritmética: a ordem dos fatores não altera o produto. No contexto, os fatores equivalem a fatores de correção. simulação 1)

$$
64 \cdot 2 \cdot \frac{1}{2} \cdot \frac{1}{2} \cdot 2 \cdot \frac{1}{2} \cdot 2=64 \cdot \frac{8}{8}=64
$$

\footnotetext{
${ }^{1}$ Adaptado de [6], pág.27
} 


\begin{tabular}{|c|c|}
\hline Simulação 1 & Simulação 2 \\
\hline VPPVPV & VVVPPP \\
\hline Vitória: $R \$ 64,00 \cdot 2=128$ & Vitória: $R \$ 64,00 \cdot 2=128$ \\
\hline Perda: $R \$ 128,00 \cdot \frac{1}{2}=64$ & Vitória: $R \$ 128,00 \cdot 2=256$ \\
\hline Perda: $R \$ 64,00 \cdot \frac{1}{2}=32$ & Vitória: $R \$ 256,00 \cdot 2=512$ \\
\hline Vitória: $R \$ 32,00 \cdot 2=64$ & Perda: $R \$ 512,00 \cdot \frac{1}{2}=256$ \\
\hline Perda: $R \$ 64,00 \cdot \frac{1}{2}=32$ & Perda: $R \$ 256,00 \cdot \frac{1}{2}=128$ \\
\hline Vitória: $R \$ 32,00 \cdot 2=64$ & Perda: $R \$ 128,00 \cdot \frac{1}{2}=64$ \\
\hline
\end{tabular}

Tabela 1.7: Simulações para resolução do exemplo 1.18

simulação 2)

$$
64 \cdot 2 \cdot 2 \cdot 2 \cdot \frac{1}{2} \cdot \frac{1}{2} \cdot \frac{1}{2}=64 \cdot \frac{8}{8}=64
$$

Ou seja, em uma situação de aumentos e/ou descontos sucessivos, basta efetuar a multiplicação uma vez, não importando a ordem dos fatores.

Exemplo 1.19. A gasolina custava $R \$ 3,08$ e sofreu dois reajustes consecutivos, de $2,5 \%$ e $9,5 \%$.

\section{Solução.}

Se um produto sofre aumento de $2,5 \%$ pode-se calcular pelo fator 1,025 , assim como o fator 1,095 para aumento de 9,5\%.

$3,08 \cdot 1,025 \cdot 1,095=3,08 \cdot 1,122375=3,456915$

O valor da gasolina após os reajustes será de $\mathrm{R} \$ 3,456$.

Exemplo 1.20. Qual a variação percentual causada por dois aumentos sucessivos de $20 \%$ ?

\section{Solução.}

Um aumento de $20 \%$ equivale ao fator de correção 1,2, ou seja, dois aumentos sucessivos equivalem à multiplicação pelo fator de correção 1,2 por duas vezes.

Note que para resolução deste problema não é preciso ter um valor inicial, pois deseja-se conhecer apenas a variação percentual. Desta forma, considere um capital C.

$$
C \cdot 1,2 \cdot 1,2=1,44 \cdot C
$$

Comparando com C, o capital inicial, o valor final é 1,44 vezes maior, o que equivale dizer que o valor final é $144 \%$ de C, ou seja o aumento foi de $44 \%$. 
Exemplo 1.21. Um investidor aplicou $R \$ 800,00$ em um investimento que após 2 meses, à taxa mensal de juros constantes, resultou em um montante de 832,32. Qual foi a taxa de juros do investimento?

\section{Solução.}

Descobrindo o fator de correção, é possível descobrir a taxa de juros do investimento. O Capital inicial sofreu duas vezes o mesmo fator de correção que será definido como $x$. Encontrando o valor de $x$, pode-se determinar a taxa de juros.

$$
\begin{aligned}
800 \cdot x \cdot x & =832,32 \\
800 x^{2} & =832,32 \\
x^{2} & =\frac{832,32}{800} \\
x^{2} & =1,0404 \\
x & =1,02
\end{aligned}
$$

Logo, a taxa de juros foi de 1,02-1, ou seja $2 \%$ a.m.

Exemplo 1.22 (O comerciante mal intencionado). Um comerciante preocupado com as vendas, que não estavam boas, pensou em uma estratégia que a princípio parecia uma possibilidade de melhora para seu estabelecimento. Decidiu aumentar todo o seu estoque em $15 \%$ e depois oferecer uma grande liquidação em toda a sua mercadoria, de $15 \%$. Será que esta estratégia será vantajosa para o comerciante, que na verdade não pretende oferecer nenhum desconto?

\section{Solução.}

Ao promover um aumento de $15 \%$, o comerciante utiliza o fator de correção 1,15 (equivale a $100 \%+15 \%$ ). Em seguida, o desconto de $15 \%$ equivale a multiplicar o valor da mercadoria pelo fator de correção 0,85 (100\% - 15\%).

Considere um produto de valor $v$. Configurando o caso de aumento e desconto sucessivos, equivale à expressão: $v \cdot 1,15 \cdot 0,85$. Logo, tem-se: $v \cdot 0,9775$.

Ou seja, o valor final equivale a $97,75 \%$ do valor inicial. Assim, o comerciante vai vender suas mercadorias com $2,5 \%$ de desconto. Vale ressaltar que, ele queria vender pelo mesmo preço inicial.

Note que, neste caso, se uma mercadoria custa $\mathrm{R} \$ 100,00$ e aplica-se um desconto de $15 \%$, o valor de desconto será de $\mathrm{R} \$ 15,00$. No entanto, se for tomada como referência o valor de $\mathrm{R} \$ 115,00$ (já com aumento de 15\%), o desconto será de R\$17,25. Assim, o valor de venda será de 115 - 17, 25 e não 115 - 15, como imaginava o comerciante com intenções duvidosas. 
Para a mercadoria de $\mathrm{R} \$ 115,00$ sofrer uma redução para $\mathrm{R} \$ 100,00$, multiplica-se por um fator $f$ :

$$
\begin{aligned}
115 \cdot f & =100 \\
f & =0,8696
\end{aligned}
$$

Este fator de correção equivale a 13,04\% (faça 1-0,8696 = 0,1304).

Imagine agora uma situação muito comum, vivenciada no cotidiano.

Exemplo 1.23. Uma loja de eletrônicos anuncia uma Smart TV no valor de R\$2.500,00, nas seguintes condições:

Condição 1: Preço à vista: $R \$ 2.500,00$

Condição 2: Preço à prazo: $R \$ 1.500,00+R \$ 1.500,00$

Quanto um cliente que opta pela compra em duas vezes, deve pagar de juros?

\section{Solução}

Observe as duas resoluções a seguir.

Resolução Incorreta

A primeira resolução que vem à cabeça é a seguinte:

Pagando em duas vezes o valor final será de $\mathrm{R} \$ 3.000,00, \mathrm{R} \$ 500,00$ a mais que o valor à vista.

Comparando o valor dos juros ao valor inicial, tem-se:

$$
\frac{500}{2500}=\frac{1}{5}
$$

Assim, a taxa percentual de juros é de 0,2, ou seja, $20 \%$.

Note que este raciocínio está incorreto. Os juros estão sendo comparados ao valor inicial, este é o erro. Como se sabe, ao pagar o valor à vista, não se pagam juros. No entanto, o valor não foi pago totalmente a prazo:

Resolução Correta

Como R\$ 1.500,00 foram pagos à vista, eles não sofrem juros. Assim, deve-se pagar juros apenas no prazo, ou seja, referente ao valor de $\mathrm{R} \$ 1.500,00$.

Comparando o valor da segunda parcela ao restante do valor à vista $(\mathrm{R} \$ 1.000,00)$

$$
\frac{1500}{1000}=\frac{3}{2}
$$

Assim, a taxa percentual de juros é de 1,5, ou seja, um aumento de $50 \%$.

Veja que o erro cometido na primeira resolução é comum. Quando se paga o valor de 
uma mercadoria a prazo, os juros nunca são cobrados sobre o valor à vista. Assim, o valor é cobrado sobre o valor a prazo.

\subsection{Outros Conceitos Básicos}

Para finalizar a parte inicial, fundamental da Matemática Financeira, serão apresentados alguns conceitos complementares que justificam situações que serão abordadas futuramente.

\subsubsection{Inflação, Deflação e Desinflação}

Para entender o que é Inflação, Deflação e Desinflação, verifique os conceitos a seguir.

Definição 1.6 (Cesta Básica). A cesta básica é um conjunto de produtos que constituem as condições minimas de sobrevivência de um brasileiro ${ }^{2}$.

Definição 1.7 (Inflação e Deflação). Um conjunto de cálculos realizados sobre a Cesta Básica, uma combinação entre médias simples e ponderadas caracterizam o que se chama de Inflação, quando há crescimento nessas taxas calculadas.

No caso de indices negativos, tem-se caracterizada a Deflação.

Definição 1.8 (Desinflação). A desinflação ocorre se houver uma diminuição do crescimento da inflação.

Entre os cálculos para determinação do índice da inflação estão os principais índices usados para o cálculo da inflação: IPC (Índice de Preços ao Consumidor), IPCA (Índice de Preços ao Consumidor Amplo), INPC (Índice Nacional de Preços ao Consumidor) e IGP (Índice Geral de Preços).

Estas definições e as próximas servem para entender o porquê da desvalorização do dinheiro e o porquê de algumas situações que surgirão em breve.

\subsubsection{Taxas Nominais ou Aparentes e Taxas Reais}

Ao analisar uma aplicação financeira ou a comparação de valores monetários em períodos distintos, deve-se corrigir essa taxa, dita nominal, pela taxa real (inserida em seu cálculo a inflação do período).

\footnotetext{
${ }^{2}$ Para definições mais técnicas e específicas, vide [8]
} 
Exemplo 1.24. Em 2014, o salário mínimo era de $R \$$ 724,00. Em janeiro de 2015 passou a ser de $R \$$ 788,00. Sabe-se que a inflação acumulada de 2014 foi aproximadamente $6,5 \%$.

(a) Qual a taxa nominal de correção?

(b) Qual a taxa real se considerarmos a inflação acumulada de 6,5\%?

\section{Solução.}

Observe a seguir a resolução, ilustrando os conceitos apresentados.

(a) Para o cálculo nominal, desconsideram-se fatores externos como inflação, verificando apenas o capital e o valor final.

Para determinar a taxa de crescimento, encontra-se o fator de correção, comparando o valor final com o inicial:

$$
\text { Fator }=\frac{\text { ValorFinal }}{\text { Capital }}=\frac{788}{724} \approx 1,08839
$$

Logo, a taxa nominal é de aproximadamente 8,839\%.

(b) Para o cálculo da taxa real consideram-se fatores externos, como a inflação, por exemplo. Assim, o salário corrigido pela inflação (que seria o aumento mínimo natural) seria de:

$$
724 \cdot 1,065=771,06
$$

Assim, o fator de correção de aumento real deve ser a razão entre o novo salário e o salário real (corrigido pela inflação):

$$
\text { Fator }=\frac{788}{771,06} \approx 1,02197
$$

Ou seja, 2,197\% (lembre-se: 1,02197 - 1=0,02197) é a taxa real de aumento.

Ainda seria possível calcular a taxa de aumento comparando o valor do aumento em relação ao corrigido. Observe as soluções alternativas:

(a) O valor do aumento é de $\mathrm{R} \$ 64,00$. Comparando ao valor inicial, tem-se $\frac{64}{724} \approx 8,839 \%$.

(b) O valor do aumento real (comparando ao valor corrigido pela inflação) seria de $\frac{16,94}{771,06} \approx 2,197 \%$. 
Note que é possível padronizar este tipo de cálculo. Verifique o exemplo dado, identificando o salário inicial como $V_{0}$ (Valor Inicial), $V_{c}$ (Valor Final Corrigido), o salário final como $V_{f}$ (Valor Final), taxa nominal $i_{n}$, taxa de correção $i_{c}$ (no exemplo a taxa da inflação), taxa real $i_{r}$ e fator de correção real $f_{r}$. Considere uma forma genérica para a resolução de (b).

$$
\begin{aligned}
f_{r} & =\frac{V_{f}}{V_{c}} \\
& =\frac{V_{0}+V_{0} \cdot i_{n}}{V_{0}+V_{0} \cdot i_{c}} \\
& =\frac{V_{0} \cdot\left(1+i_{n}\right)}{V_{0} \cdot\left(1+i_{c}\right)} \\
& =\frac{1+i_{n}}{1+i_{c}}
\end{aligned}
$$

Para encontrar a taxa, basta calcular:

$$
i_{r}=f_{r}-1=\frac{1+i_{n}}{1+i_{c}}-1
$$

Assim,

$$
i_{r}=\frac{1+i_{n}}{1+i_{c}}-1
$$

onde $i_{r}$ é a taxa real, $i_{n}$ é a taxa nominal ou aparente e $i_{c}$ é a taxa de correção.

Assim, resolvendo (b) do exemplo 1.24 pela fórmula 1.3,

$$
\begin{gathered}
i_{r}=\frac{1+i_{n}}{1+i_{c}}-1 \\
i_{r}=\frac{1,08839}{1,065}-1 \approx 0,02197=2.197 \%
\end{gathered}
$$

\subsection{Usando a calculadora simples}

Como visto na resolução da maioria dos exemplos, foram elaborados cálculos simples, porém trabalhosos. Desta forma, alguns exemplos serão retomados para resolução com uso de calculadora. Antes, observe os botões de uma calculadora simples e suas respectivas funções. 


\subsubsection{Botões de uma calculadora simples}

Observe na tabela abaixo uma breve descrição dos principais botões de uma calculadora simples.

\begin{tabular}{|c|c|}
\hline Botão & Descrição \\
\hline$c$ & Zera o visor e a operação \\
\hline CE & Zera o visor mas mantém a operação \\
\hline $\mathrm{M}+$ & Adiciona o valor do visor à memória \\
\hline M- & Subtrai o valor do visor do contido na memória. \\
\hline MS & Substitui o valor da memória pelo que aparece no visor. \\
\hline MR & Recupera o valor da memória. \\
\hline
\end{tabular}

Tabela 1.8: teclas de uma calculadora comum

Usando algumas situações comuns como exemplo, acompanhe o uso de algumas teclas, muitas vezes desconhecidas pelos alunos.

\subsubsection{Botão [CE] e [C]}

Como descrito, o botão [CE] apaga o número que aparece no visor, no entanto mantém a operação caso esteja iniciada. O botão [C], reinicia toda a operação.

Exemplo 1.25. Ao efetuar a operação: $356+567$, o usuário erra o segundo número, digitando 566. Para apagar o último número, basta pressionar o botão [CE].

Observe a realização da operação na calculadora 


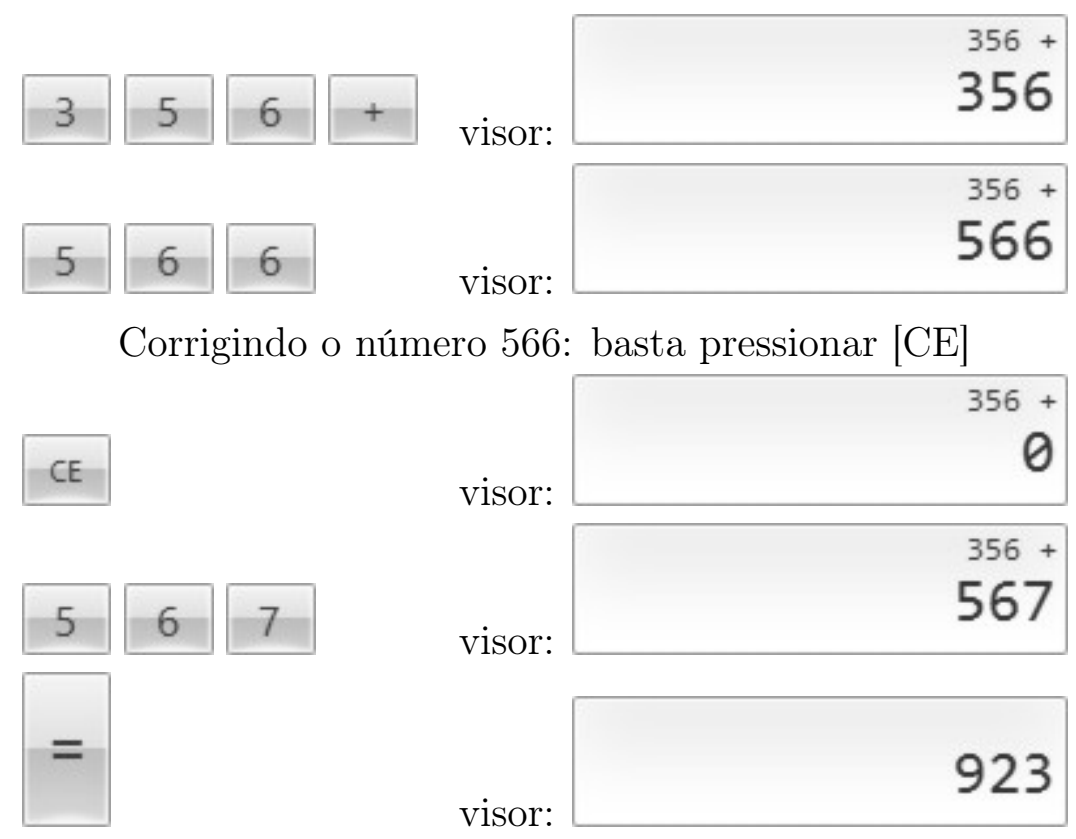

Repetindo toda a operação anterior, pressionando [C] no lugar de [CE], o processo será reiniciado.

\subsubsection{As teclas de Memória}

Muitos desconhecem o uso das teclas de memória: [M+], [M-], [MC], [MS], [MR]. Exemplo 1.26. Considere a operação: $12 \cdot 12+3 \cdot 5$. Observe a sequência de operações realizadas a seguir.

A seguir serão efetuados dois procedimentos na calculadora: no primeiro os caracteres serão digitados na ordem que aparece. Na segunda a expressão será resolvida na forma correta. 


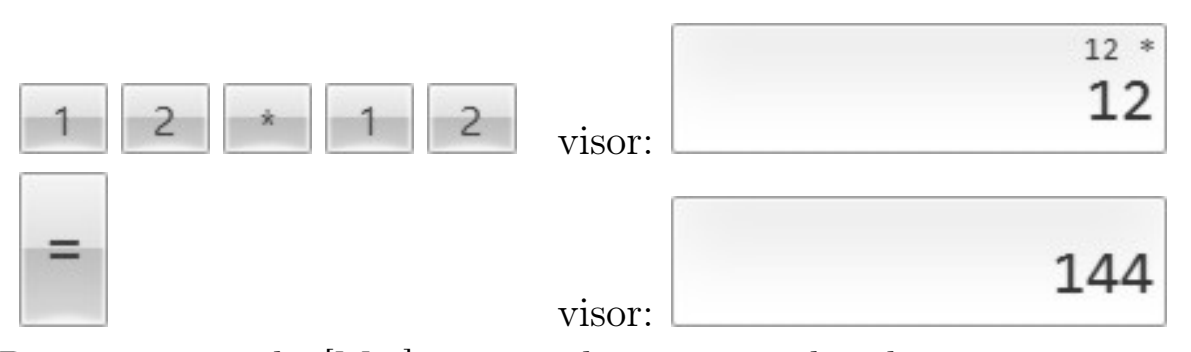

Pressione a tecla $[\mathrm{M}+]$ : para adicionar o valor do visor ao que estiver na memória. A tecla [M-] é usada para subtrair.
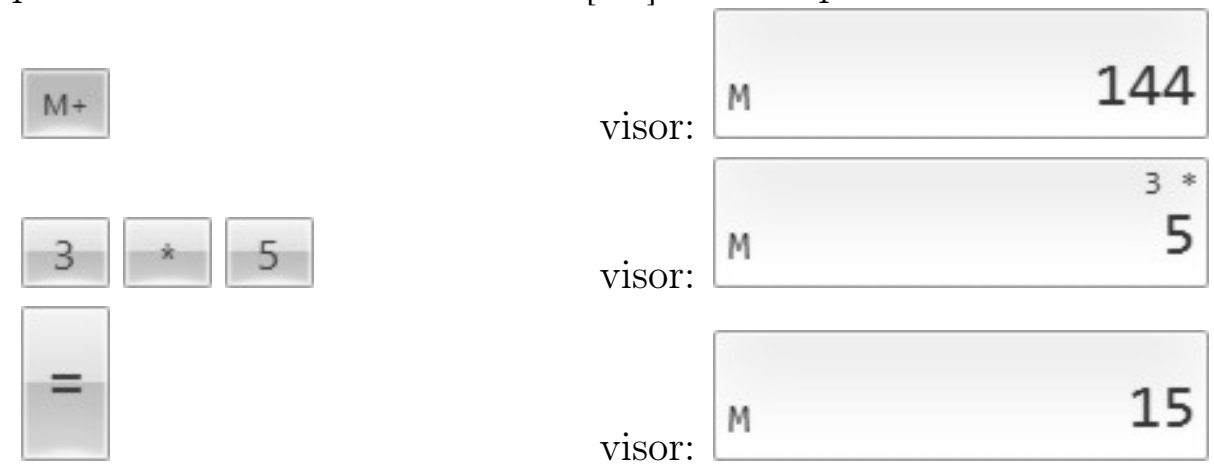

Pressione a tecla $[\mathrm{M}+]$ para adicionar o valor à memória que é 144
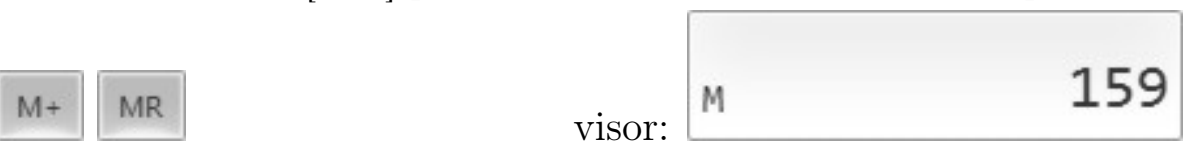

Recuperando a memória, pressionando $[\mathrm{MR}] \ldots$

\subsubsection{A tecla porcentagem}

Um dos maiores empecilhos para utilização da calculadora para cálculos de Matemática Financeira está no uso correto da tecla [\%]. Para uso da calculadora como mero apoio para cálculos simples o botão referente a porcentagem deve ser desconsiderado. No entanto, deve-se ensinar ao aluno como se dá seu uso.

Como exemplo, acompanhe a resolução do exemplo 1.14, da página 12.

Exemplo 1.27 (Revisitiando o exemplo 1.14). Abilio recebia um salário de $R$ \$ 3.200,00 e recebeu um aumento de 12\%. Deseja-se saber o novo salário.

\section{Solução com o uso de uma calculadora simples}

Como visto, sendo o Principal o salário antigo de Abílio (100\%), acrescentando o aumento de $12 \%$, passa a ser de $112 \%$. Ou seja, basta multiplicar o salário antigo pelo fator de correção: 1,12. Observe a seguir o uso da calculadora. 

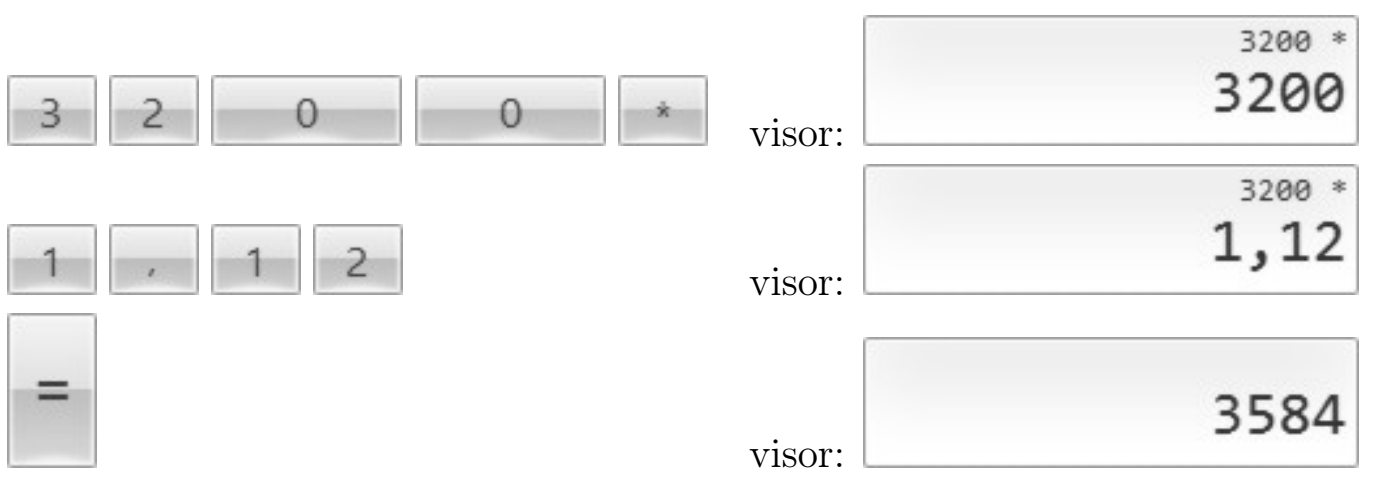

\section{A tecla porcentagem [\%]}

A tecla porcentagem leva em consideração o usuário leigo, que não tem domínio de cálculos com porcentagem. Assim, a tecla porcentagem é usada após uma soma ou diferença, calculando automaticamente a porcentagem do valor que aparece no visor.

Veja a seguir o uso deste botão para resolver o mesmo exemplo resolvido anteriormente, em seguida serão apresentados outros exemplos.
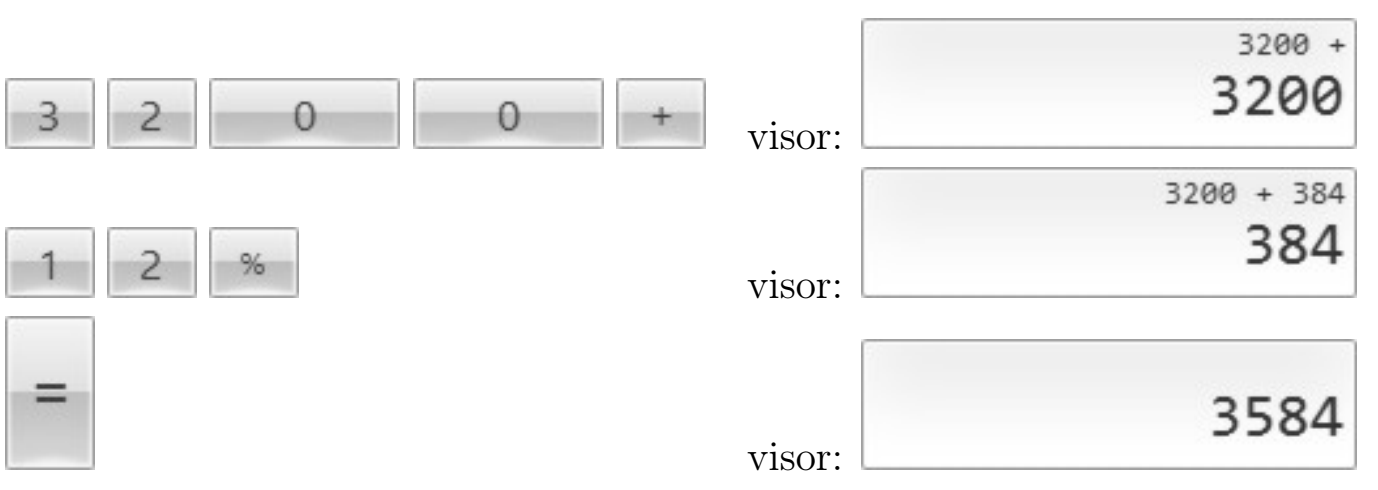

Note que ao clicar na tecla porcentagem aparece o valor referente a $12 \%$ de $\mathrm{R} \$ 3.200,00$. Ao clicar na tecla $[=]$, aparece o resultado do valor inicial somado ao aumento.

Observe o exemplo a seguir.

Exemplo 1.28. Calcule o valor de $250+25 \%$.

Efetuando a resolução fielmente matemática, terá:

$$
250+0,25=250,25
$$

No entanto, ao reproduzir a expressão da mesma forma que está apresentada na calculador, ou seja, [2][5][0][+][2][5][\%]=312,50. Ou seja, a calculadora "entende" que o cálculo desejado é: $250+25 \%$ de 250 , ou seja,

$$
250+25 \% \cdot 250=250+62,5=312,50
$$


Exemplo 1.29. Resolva, com uso da calculadora, o exemplo 1.15, da página 13. Recapitulando, um clube de futebol deseja vender sua camisa de $R \$ 180,00$ com desconto de $35 \%$.

\section{Resolvendo com a calculadora}

Sem utilizar a tecla de porcentagem basta realizar a multiplicação de 180 pelo fator de correção 0,65 (equivalente a 65\%, após retirar 35\% de desconto). Assim, reproduzindo a situação na calculadora encontra-se a resposta dada a seguir.

$$
180[*] 0,65=117
$$

Usando a tecla de porcentagem utiliza-se a sequência a seguir:

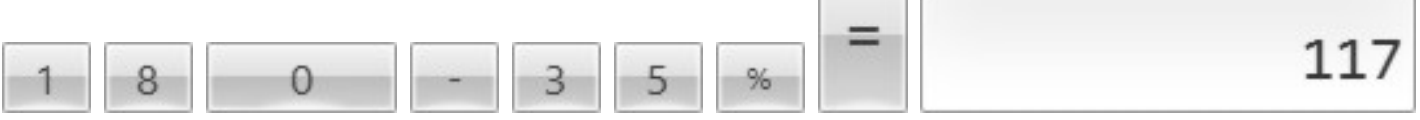

\subsection{Estudo de caso}

Veja um estudo de caso, uma situação problema envolvendo conceitos e raciocínios usados neste capítulo. O estudante deve dominar as técnicas envolvidas, no entanto, é fundamental o uso de calculadora para cálculos com números maiores, assim o exercício não fica cansativo.

Exemplo 1.30. Rafael deseja comprar um notebook de última geração. Recebeu, em seu e-mail, o anúncio de uma site de e-commerce. Verifique a veracidades das informações.

(i) Desconto à vista;

(ii) Desconto no boleto;

(iii) Compra no cartão (acréscimo real);

(iv) Compra no cartão parcelado em duas vezes.

(i) Desconto que consta no anúncio

O valor do notebook era de $\mathrm{R} \$ 2.399,00$. Sofrendo o desconto indicado pelo site, o valor do notebook passou a ser de $\mathrm{R} \$ 1760,23$. Assim, considerando o valor de 2.399,00 como principal, a comparação do novo valor e o principal é dado por:

$$
\frac{1760,23}{2399} \approx 0,7337
$$




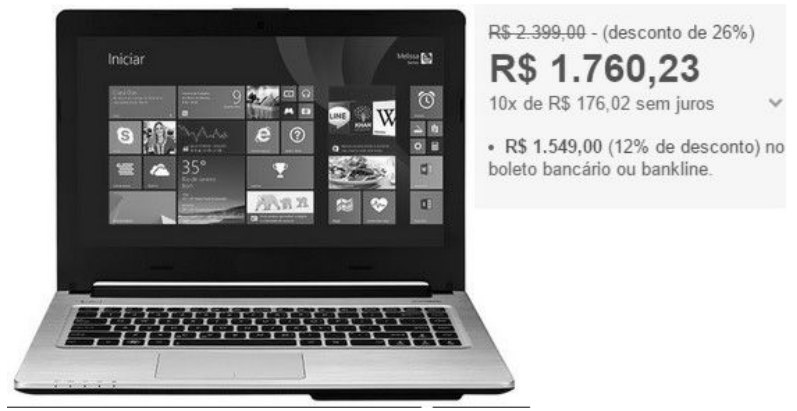

Figura 1.1: anúncio de e-commerce

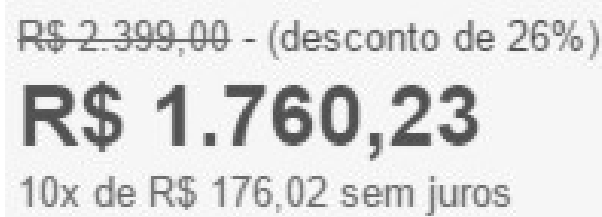

Figura 1.2: Desconto oferecido pelo site

Como o fator de correção é 0,7337 (como houve desconto, é menor que 1), o valor do desconto é dado por:

$$
1-0,7337=0,2663
$$

Assim, o desconto foi de 26,63\%, coerente com o anúncio.

(ii) Desconto no boleto bancário

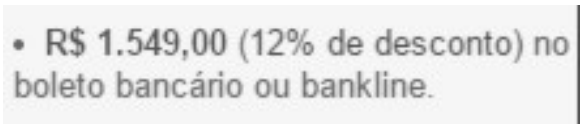

Figura 1.3: desconto à vista, no boleto

Para verificar o desconto basta verificar o valor à vista e o valor ofertado pelo notebook.

$$
\frac{1549}{1760.23} \approx 0,87999
$$

Novamente o chamado desconto é coerente com o anúncio. O que realmente não é coerente é a nomenclatura, usada para distrair o cliente. Em uma compra o valor considerado como principal é o valor à vista (neste caso, atribuído na compra por boleto).

Desta forma, o valor principal adotado deve ser o valor à vista, ou seja, para realmente entender a situação calcula-se o percentual de aumento para a compra no 
cartão de crédito.

(iii) Calculando o aumento na compra à cartão

Na compra com o cartão de crédito o valor pago é de $\mathrm{R} \$ 1760,23$. Considerando o valor à vista como principal $(\mathrm{R} \$ 1.549,00)$. Note que o valor do aumento é de $\mathrm{R} \$$ 211,23, para calcular o percentual de aumento tem-se:

$$
\frac{211,23}{1549} \approx 0,1363
$$

Ou seja, na compra com cartão o acréscimo é superior a $13 \%$.

Como analisado anteriormente o percentual de aumento fica maior quando se compara o valor dividido.

(iv) Compra no cartão à prazo

Se o cliente dividir em duas vezes, paga a metade do valor do cartão à vista e depois de 30 dias a outra metade, que é de $R \$ 880,11$. Assim, o aumento que é de $R \$$ 211,23 incide sobre a segunda parcela que não foi paga à vista.

$$
\frac{211,23}{880,11} \approx 0,24
$$

Ou seja, o acréscimo neste caso é de $24 \%$.

Observe como uma decisão aparentemente simples envolve cálculos muitas vezes impensáveis e como um anúncio pode ser "maquiado" atendendo ao comércio. 


\section{Capítulo 2 Fundamentação Teórica}

Serão apresentados de forma breve algumas propriedades e tópicos fundamentais para o estudo da Matemática Financeira

\subsection{Progressões Aritméticas: PA}

Considere uma sequência numérica que sofre aumentos ou decréscimos constantes de um termo para seu sucessor. Esta sequência é uma PA.

Definição 2.1 (Progressões Aritméticas: PA). Uma Progressão Aritmética é uma sequência numérica na qual a diferença entre um termo e seu antecessor é sempre a mesma. Essa diferença é chamada de razão. $a_{n+1}-a_{n}=r$ para todo $n$ natural.

Definição 2.2 (PA's crescentes, decrescentes e constantes). À partir da razão, define-se o tipo de Progressão Aritmética:

- PA decrescente: razão negativa: $r<0 \Rightarrow a_{n+1}<a_{n}$

- PA constante: razão nula $r=0 \Rightarrow a_{n+1}=a_{n}$

- PA crescente: razão positiva $r>0 \Rightarrow a_{n+1}>a_{n}$

Exemplo 2.1. Considere as sequências abaixo:

$S_{1}=(1,5,9,13)$

$S_{2}=(3,3,3,3, \cdots)$

$S_{3}=(4,11,18,25, \cdots)$

$S_{4}=(120,60,30,15, \cdots)$ 
$S_{5}=(3,-1,-5,-9, \cdots)$
$S_{6}=(2,5,2,5, \cdots)$

\section{Analisando as sequências do exemplo 2.1}

(i) $S_{1}$ é uma PA finita pois a sequência tem apenas quatro termos e a diferença entre um termo e seu antecessor é sempre constante, ou seja, $5-1=9-5=13-9=4$. Destaca-se: $1^{\circ}$ termo, $a_{1}=1$, último termo, $a_{4}=4$ e razão $r=4$. Esta é uma PA dita crescente pois a razão é positiva, ou seja, se todo termo sofre sempre uma soma de um número positivo para seu sucessor;

(ii) $S_{2}$ é uma PA infinita, note que a diferença entre um termo e seu antecessor é sempre a mesma: $r=0$. Desta forma, é dita constante;

(iii) $S_{3}$ é uma PA infinita de razão $r=7$ (note que $11-4=18-11=25-18=7$ )

(iv) $S_{4}$ não é uma PA pois a diferença entre termos consecutivos apresenta valores diferentes. $(60-120=-60$ e $30-60=-30)$;

(v) $S_{5}$ é uma PA infinita decrescente, note que a razão: $r=-4$, ou seja, $a_{n+1}<a_{n}$;

(vi) $S_{6}$ não é PA, pois $a_{2}-a_{1} \neq a_{3}-a_{2}$.

Exemplo 2.2. Em uma Progressão Aritmética, para avançar um termo basta somar a razão; para avançar dois termos, basta somar duas razões etc. Assim, em uma progressão aritmética, $a_{2}=a_{1}+r, a_{9}=a_{5}+4 r$ e $a_{100}=a_{60}+40 \mathrm{r}$. Observe o esquema da figura 2.1, a seguir.

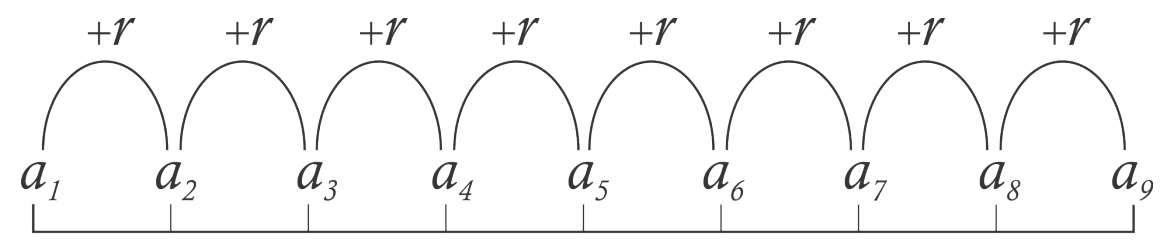

Figura 2.1: Esquema de uma P.A.

Seguindo este raciocínio é bem intuitivo encontrar uma fórmula para determinar o n-ésimo termo (chamado termo geral da PA), à partir do primeiro. Ou seja do primeiro ao n-ésimo termo "pulam-se" $(n-1)$ casas. Assim, será provado, em seguida que:

$$
a_{n}=a_{1}+(n-1) \cdot r
$$




\subsubsection{Termo Geral de uma PA}

Como a Progressão Aritmética é uma Sequência, tomando uma de primeiro termo $a_{1}$, razão $r$ e n-ésimo termo $a_{n}$, é possível encontrar uma forma geral para um termo qualquer (n-ésimo) da PA.

Teorema 2.1. Se $\left(a_{n}\right)$ é uma progressão aritmética de razão $r$, então o n-ésimo termo, para todo $n$ inteiro positivo é dado pela lei:

$$
a_{n}=a_{1}+(n-1) r
$$

Demonstração. Pela definição de progressão aritmética, tem-se:

$$
\begin{aligned}
a_{2}-a_{1} & =r \\
a_{3}-a_{2} & =r \\
a_{4}-a_{3} & =r \\
\vdots & =\vdots \\
a_{n}-a_{n-1} & =r
\end{aligned}
$$

Somando essas $n-1$ igualdades, obtém-se: $a_{n}-a_{1}=(n-1) r$. Ou seja,

$$
a_{n}=a_{1}+(n-1) r
$$

Exemplo 2.3. Um carro no valor de $R \$ 38.000,00$ desvaloriza-se com o tempo de forma constante, de maneira que daqui a 20 anos seu valor será nulo. Qual a desvalorização anual?

\section{Solução.}

Note que tem-se uma PA de $1^{\circ}$ termo $\left(a_{1}=38.000\right)$ e vigésimo termo igual a zero $\left(a_{20}=0\right)$. Assim, pela fórmula 2.1, tem-se:

$$
\begin{aligned}
a_{n} & =a_{1}+(n-1) r \\
a_{20} & =38000+(20-1) r \\
19 r & =-38000 \\
r & =-\frac{38.000}{19} \\
r & =-2.000
\end{aligned}
$$


Logo, a cada ano que passa há uma diminuição de $\mathrm{R} \$ 2.000,00$.

\subsubsection{Progressão Aritmética e a Função afim}

Considere uma grandeza $a(n)$ que sofre aumentos periódicos iguais a $r$, a cada intervalo inteiro de $n$. Observe o gráfico a seguir que associa a cada número natural $n$ o número $a_{n}$. Assim, é possível representar graficamente uma PA, observe a Figura 2.2.

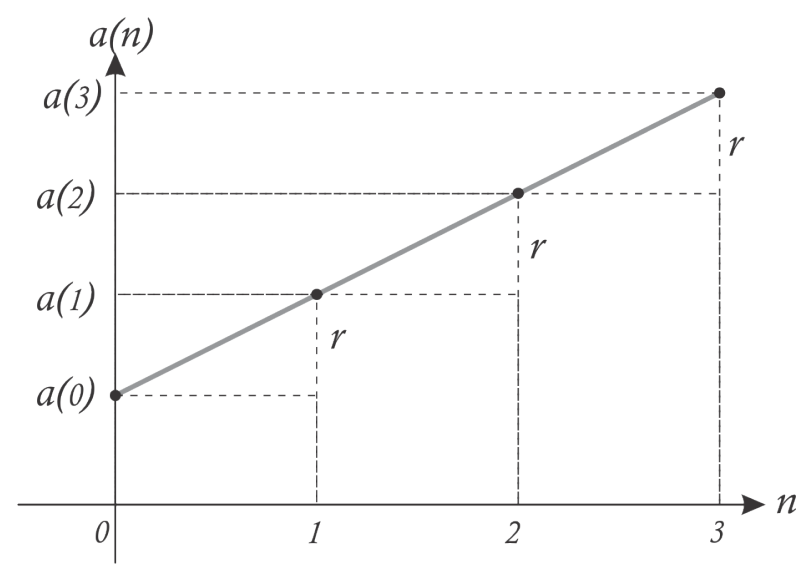

Figura 2.2: Representação gráfica de uma PA

Note que para cada acréscimo de uma unidade em $n$, tem-se uma imagem em $a(n)$, ou seja, para 3 no eixo da abscissa, encontra-se o terceiro termo $\left(a_{3}\right)$ no eixo da ordenada. Para o n-ésimo número natural na abscissa encontra-se sua respectiva imagem $(a(n))$ no eixo das ordenadas.

\subsubsection{Soma dos termos de uma PA}

É possível encontrar a soma dos $n$ primeiros termos de uma PA à partir de uma fórmula.

Teorema 2.2. A soma dos n primeiros termos da Progressão Aritmética $\left(a_{n}\right)=\left(a_{1}, a_{2}, \cdots, a_{n}\right)$ é igual a

$$
S_{n}=\frac{\left(a_{1}+a_{n}\right) n}{2}
$$

Demonstração. De fato, considere a soma dada a seguir:

$$
\begin{gathered}
+\begin{array}{l}
S_{n}=a_{1}+a_{2}+\cdots a_{n-1}+a_{n} \\
S_{n}=a_{n}+a_{n-1}+\cdots a_{2}+a_{1}
\end{array} \\
\frac{2 \cdot S_{n}}{=}\left(a_{1}+a_{n}\right)+\left(a_{2}+a_{n-1}\right)+\cdots a_{n}+a_{1}
\end{gathered}
$$


Como $a_{n}=a_{1}+(n-1) r$, então, $\left(a_{1}+a_{n}\right)=\left(a_{2}+a_{n-1}\right)=\left(a_{3}+a_{n-2}\right)=\cdots\left(a_{n}+a_{1}\right)$, observe que o primeiro elemento de cada igualdade pode ser escrito em função do primeiro termo, $a_{1}$, e o segundo elemento em função do n-ésimo termo, $a_{n}$. Assim, $2 \cdot S_{n}=\left(a_{1}+a_{n}\right) n$, ou seja,

$$
S_{n}=\frac{\left(a_{1}+a_{n}\right) n}{2}
$$

\subsection{Progressões Geométricas: PG}

Enquanto uma PA se caracteriza por um aumento (ou decréscimo) constante entre termos consecutivos, a PG caracteriza-se por uma taxa de aumento (ou decréscimo) constante.

Quando se trata de aumento usa-se a diferença entre um termo e seu antecessor. Para calcular a taxa de aumento (ou decréscimo) deve-se fazer a razão entre a diferença e o termo anterior.

\subsubsection{Taxa de Crescimento e Fator de Correção}

Antes de tratar da definição de PG convém relembrar as definições de taxa e fator de correção.

Definição 2.3 (Taxa de crescimento). A taxa de crescimento é a razão entre o aumento e o valor inicial. Quando houver aumento, o valor será superior a 1, quando houver diminuição será positivo e inferior a 1, o que caracteriza um decrescimento.

Exemplo 2.4. Qual a taxa de crescimento de uma grandeza que passa de 5 para 7 ?

Solução.

Houve um aumento de 2 unidades, $7-5=2$. Assim, a taxa de aumento é de $\frac{2}{5}$ ou 0,4 . Em percentual, pode-se afirmar que a taxa de aumento é de $40 \%$.

Definição 2.4 (Fator de Correção). Um fator de correção é a razão entre um termo e seu antecessor ou aquele que multiplica um termo resultando no seguinte. Seu valor equivale $a(1+i)$, sendo $i$ a taxa de crescimento.

Exemplo 2.5. Qual o fator de correção de uma grandeza que passou de 5 para 7? 


\section{Solução.}

Calculando a taxa de aumento $i$ tem-se:

$$
\frac{7-5}{5}=\frac{2}{5}
$$

Assim, o fator de correção será $(1+i)$, ou seja, 1,4 o mesmo que $140 \%$. Note que é o mesmo que fazer a razão entre o termo 7 e seu antecessor 5 . Logo, $\frac{7}{5}=1,4$.

Exemplo 2.6. O termo $a_{20}$ de uma sequência é igual a 15. Se o próximo termo dessa sequência vale 12, determine o aumento, a taxa de crescimento e o fator de correção.

\section{Solução.}

Tem-se $a_{20}=15$ e $a_{21}=12$.

1. aumento: $12-15=-3$ (houve decrescimento);

2. taxa de crescimento $i:-\frac{3}{15}=-\frac{1}{5}=-0,2$

3. fator de correção: $\frac{12}{15}=\frac{4}{5}=0,8$ ou, simplesmente, $1+i=1-0,2=0,8$.

Exemplo 2.7. Um cliente do banco CobraKaro tem uma divida de cheque especial no mês $n$ de $Q_{n}$. Sabe-se que a taxa cobrada pelo banco é de 9\%. Assim, no mês n, a dívida é igual à do ano anterior somada ao aumento de $9 \%$, ou seja, $Q_{n}=Q_{n-1}+0,09 \cdot Q_{n-1}=$ $Q_{n-1} \cdot(1+0,09)$, ou seja, o fator de correção é 1,09 e a taxa de crescimento é de 0,09 $=9 \%$.

Exemplo 2.8. Rildo guardou uma grande quantia em dinheiro no cofre e retira sempre a quantia de $20 \%$ do valor presente no cofre. Qual a taxa de correção neste caso?

Solução. Assim, o saldo $\left(V_{n}\right)$ da conta no mês $n$ é a mesma do mês anterior com uma retirada de $20 \%$. Pode-se representar na forma:

$$
\begin{gathered}
V_{n}=V_{n-1}-0,2 \cdot V_{n-1} \\
V_{n}=V_{n-1} \cdot(1-0,2) \\
V_{n}=0,8 \cdot V_{n-1}
\end{gathered}
$$

Como o fator de correção é 0,8 , houve uma diminuição de 0,2 , ou seja, a taxa é de $-0,2=-20 \%$. 
Teorema 2.3. A grandeza $\left(G_{n}\right)$ tem taxa de crescimento constante igual a $i$, se e só se

$$
G_{n+1}=(1+i) \cdot G_{n}
$$

para todo $n$ natural.

Demonstração. $(\Longrightarrow)$ Se a taxa de crescimento de $G_{n}$ é $i$, então

$$
\begin{aligned}
i & =\frac{G_{n+1}-G_{n}}{G_{n}} \\
G_{n+1}-G_{n} & =i G_{n} \\
G_{n+1} & =G_{n}+i G_{n} \\
G_{n+1} & =(1+i) \cdot G_{n}
\end{aligned}
$$

$(\Longleftarrow)$

$$
\begin{aligned}
G_{n+1} & =(1+i) \cdot G_{n} \\
1+i & =\frac{G_{n+1}}{G_{n}} \\
i & =\frac{G_{n+1}}{G_{n}}
\end{aligned}
$$

\subsubsection{Progressões Geométricas}

Em uma Progressão Aritmética a soma de um valor constante a um termo resulta no seu consecutivo, enquanto na Progressão Geométrica a multiplicação de um termo por um dado número resulta no consecutivo.

Definição 2.5 (Progressão Geométrica). É definida como Progressão Geométrica (PG) a sequência que determina taxas de crescimentos iguais para termos consecutivos quaisquer. Ou seja, em uma $P G$, a taxa de crescimento é constante.

A taxa de crescimento $i$ determina o fator de correção $1+i$, chamada razão (q) da PG.

Definição 2.6 (Progressão Geométrica - Definição Clássica). É chamada PG a sequência na qual a razão entre um termo, à partir do segundo, e seu antecessor é sempre constante. A esta razão dá-se o nome de razão da $P G$, representando por $q$. 
Definição 2.7 (Progressão Geométrica - Definição por recorrência). É chamada PGa sequência que segue à lei de recorrência:

$$
\left\{\begin{array}{l}
a_{1}=a \\
a_{n+1}=a_{n} \cdot q, n \in \mathbb{N}
\end{array}\right.
$$

Exemplo 2.9. Considere as sequências abaixo:

$S_{1}=(1,5,9,13)$

$S_{2}=(3,3,3,3, \cdots)$

$S_{3}=(3,6,12,24, \cdots)$

$S_{4}=(120,60,30,15, \cdots)$

$S_{5}=(64,96,144,216, \cdots)$

\section{Analisando as sequências do exemplo 2.9}

(i) $S_{1}$ não é uma $\mathrm{PG}$, pois $\frac{5}{1} \neq \frac{9}{5}$;

(ii) $S_{2}$ é uma PG infinita, note que a razão entre um termo e seu antecessor é sempre a mesma: $q=1$. Desta forma, é dita constante;

(iii) $S_{3}$ é uma PG infinita de razão $q=2\left(\right.$ dado que $\left.\frac{6}{3}=\frac{12}{6}=\frac{24}{12}=\cdots=2\right)$

(iv) $S_{4}$ é uma PG, note que a razão entre um termo e seu antecessor é sempre a mesma (ou seja, $\frac{60}{120}=\frac{30}{60}=\frac{15}{30}=\cdots \frac{1}{2}$ ), veja que é uma PG decresente se $0<q \leq 1$;

(v) $S_{5}$ é uma PG infinita crescente, note que a razão: $q=\frac{3}{2}$, ou seja, $\frac{a_{n+1}}{a_{n}}=\frac{96}{64}=$ $\frac{144}{96}=\cdots ;$

Exemplo 2.10. Progressões Geométricas de razões $q>1$ são progressões crescentes, $q=1$ constantes e $0<q<1$ são decrescentes. Assim, $P G$ 's com razões $q_{1}=1,2$, $q_{2}=0,8$ e $q_{3}=2$ equivalem, respectivamente, a taxas de crescimento de:

$$
\begin{aligned}
& q_{1}=1+i_{1}=1+0,2 \Rightarrow i_{1}=0,2=20 \% \\
& q_{2}=1+i_{2}=1-0,2 \Rightarrow i_{2}=-0,2=-20 \% \\
& q_{3}=1+i_{3}=1+1 \Rightarrow i_{3}=1=100 \%
\end{aligned}
$$

Exemplo 2.11. Em uma Progressão Geométrica, para avançar um termo basta multiplicar o termo atual pela razão q; para avançar dois termos, basta multiplicar duas vezes pela razão $q$, ou seja, multiplicar por $q^{2}$. Assim, em uma $P G, a_{2}=a_{1} \cdot q, a_{8}=a_{5} \cdot q^{3} e$ $a_{100}=a_{60} \cdot q^{40}$. Observe o esquema da figura 2.3, a seguir. 


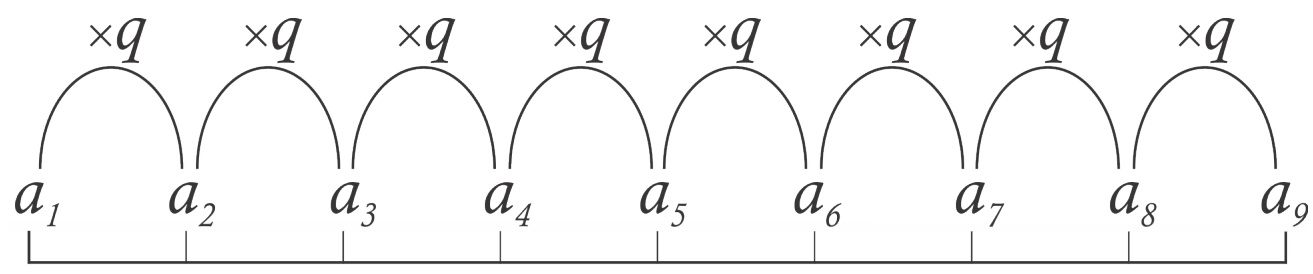

Figura 2.3: Esquema de uma P.G.

Exemplo 2.12. Em uma $P G$ o quinto termo vale 18 e o oitavo termo 486. Qual éo sétimo termo?

\section{Solução.}

Como tem-se o oitavo e quinto termos, pode-se fazer: $a_{8}=a_{5} \cdot q^{3}$ (note que "pulam-se" 3 casas do quinto para o oitavo termo), assim,

$$
\begin{aligned}
a_{8} & =a_{5} \cdot q^{3} \\
486 & =18 \cdot q^{3} \\
q & =3
\end{aligned}
$$

Logo, como deseja-se encontrar o sétimo termo, pode-se encontrá-lo à partir do quinto:

$$
\begin{aligned}
& a_{7}=a_{5} \cdot q^{2} \\
& a_{7}=18 \cdot 9 \\
& a_{7}=162
\end{aligned}
$$

Logo, o sétimo termo da PG dada é 162.

Seguindo este raciocínio pode-se formalizar que para "pular" da casa $m$ para $n(m, n \in$ $\mathbb{N}$ e $m<n)$, multiplica-se por $q$ durante $(n-m)$ vezes, ou seja, multiplica-se por $q^{n-m}$. Observe a figura 2.4. Assim,

$$
a_{n}=a_{m} \cdot q^{n-m}
$$

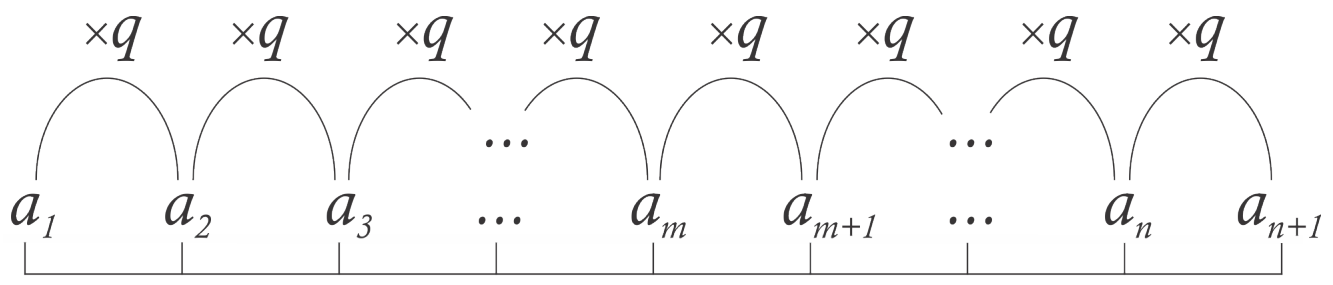

Figura 2.4: PG com termos $a_{m}$ e $a_{n}$

Pode-se, desta forma, deduzir o termo geral de uma PG, ou seja, como encontrar o n- 
ésimo termo de uma PG à partir do primeiro termo, embora esta fórmula seja demonstrada em seguida, é fácil deduzí-la.

Note que do primeiro termo até o último "pulam-se" $n-1$ casas, assim,

$$
a_{n}=a_{1} \cdot q^{n-1}
$$

\subsubsection{Termo Geral de uma PG}

Formalizando a conjectura apresentada, segue o teorema 2.4.

Teorema 2.4 (Termo Geral de uma PG). Em toda Progressão Geométrica $\left(a_{n}\right)$ de razão q, tem-se para todo natural $n$ :

$$
a_{n}=a_{1} \cdot q^{n-1}
$$

Demonstração. Sabe-se que:

$$
\begin{aligned}
\frac{a_{2}}{a_{1}} & =q \\
\frac{a_{3}}{a_{2}} & =q \\
\frac{a_{4}}{a_{3}} & =q \\
\vdots & =\vdots \\
\frac{a_{n}}{a_{n-1}} & =q
\end{aligned}
$$

Multiplicando as $n-1$ igualdades, obtem-se:

$$
\frac{a_{2}}{a_{1}} \cdot \frac{a_{3}}{a_{2}} \cdot \frac{a_{4}}{a_{3}} \cdots \frac{a_{n}}{a_{n-1}}=q^{n-1}
$$

Assim,

$$
\frac{a_{n}}{a_{1}}=q^{n-1} \Rightarrow a_{n}=a_{1} \cdot q^{n-1}
$$

Observação 2.1. Um raciocínio não muito usual é o de pensar na $P G$ de forma inversa, ou seja, em uma $P G$ de $n$ termos, considerando o n-ésimo termo como primeiro e o primeiro como n-ésimo, encontra-se uma $P G$ de razão $\frac{1}{q}$.

Revisitando o exemplo 2.12, foi citada uma PG de quinto termo igual a 18 e oitavo termo igual a 456. Descobrindo que a razão é 3 descobre-se a PG:

$$
\left(a_{n}\right)=\left(\frac{2}{9}, \frac{2}{3}, 2,6,18,54,162,456\right)
$$


Note que foi dada uma PG de 8 termos, na qual $a_{1}=\frac{2}{9}, a_{8}=456$ e $q=3$. Se escrita de forma inversa a mesma PG fica na forma:

$$
\left(a_{n}\right)=\left(456,162,54,18,6,2, \frac{2}{3}, \frac{2}{9}\right)
$$

Note que a razão da PG invertida é o inverso da PG original, ou seja, se a razão da PG invertida for $q^{\prime}$, então $q^{\prime}=\frac{1}{q}$. Deseja-se chamar a atenção para um raciocínio muito útil: se para encontrar um termo de uma $\mathrm{PG}$ multiplica-se pela razão, para encontrar o termo anterior basta dividir este termo pela mesma razão, o mesmo que multiplicar pelo inverso da razão para encontrar seu antecessor.

\subsubsection{Progressão Geométrica e a função exponencial}

Considerando o termo geral de uma PG: $a_{n}=a_{1} \cdot q^{n-1}$, pode-se afirmar que fixando o primeiro termo e a razão constantes, ou seja, variando $n$ e consequentemente $a_{n}$, pode-se usar a notação de função e escrever uma PG como uma função exponencial $a: \mathbb{N} \rightarrow \mathbb{R}$ tal que: $a(n)=a(1) \cdot q^{n-1}$, ou melhor adapta-se considerar o primeiro termo da PG como $a_{0}$ e usar a notação:

$$
a: \mathbb{N} \cup\{0\} \rightarrow \mathbb{R}, \text { sendo } a(n)=a(0) \cdot q^{n}
$$

Assim, a representação gráfica desta função é uma sequência de pontos que pertence à curva de uma função exponencial real. Observe a figura 2.5.
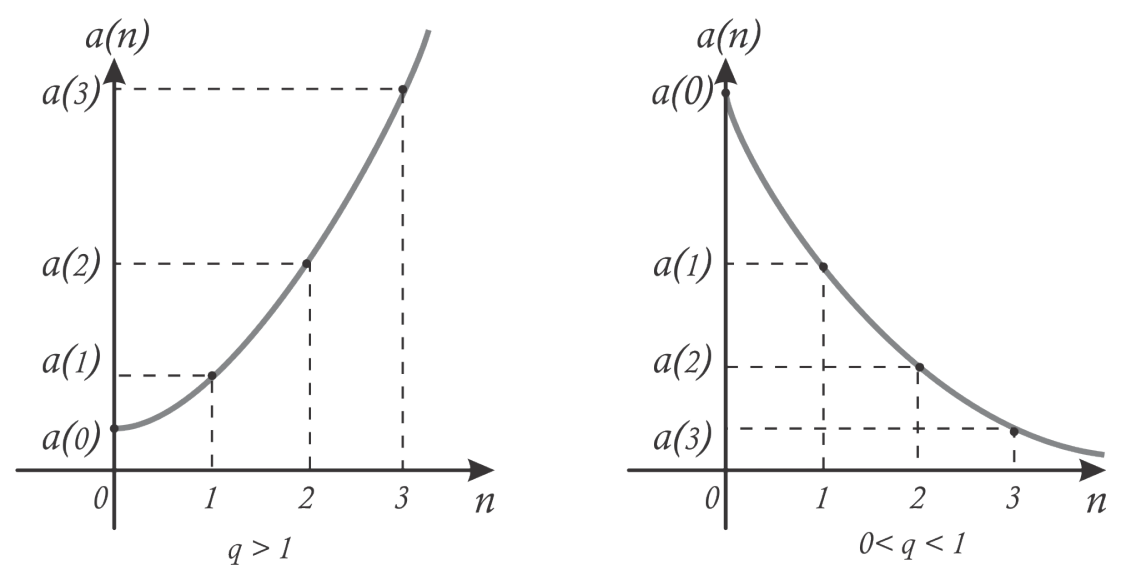

Figura 2.5: gráfico de uma PG crescente e decrescente

Logo, por se tratar de uma função exponencial pode-se afirmar que uma PG é sempre limitada inferiormente pelo primeiro termo, se a PG for crescente $(q>1)$ e pode ser limitada superior e inferiormente se $0<q<1$, pois o limite do termo geral tende a zero para $n$ tendendo ao infinito e a sequência é sempre menor ou igual a $a_{0}$ por ser decrescente. 


\subsubsection{Soma dos termos de uma PG}

Assim como é possível deduzir uma fórmula para a soma dos termos de uma PA, é possível deduzir a soma dos termos de uma PG. Observe o teorema a seguir.

Teorema 2.5 (Soma dos termos de uma PG). A soma dos n primeiros termos de uma Progressão Geométrica $\left(a_{n}\right)$ de razão $q \neq 1$ é igual a

$$
S_{n}=\frac{a_{1} \cdot\left(q^{n}-1\right)}{q-1}
$$

Demonstração. Considere $S_{n}$ a Soma dos $n$ primeiros termos de uma PG. $S_{n}=a_{1}+a_{2}+$ $a_{3}+\cdots a_{n}$ e considere ainda a igualdade obtida ao multiplicar ambos os membros por $q$, fazendo a diferença: $q S_{n}-S_{n}$, e observando que $a_{k} \cdot q=a_{k+1}, k \in \mathbb{N}$, obtém-se:

$$
\begin{gathered}
q \cdot S_{n}=a_{1} \cdot q+a_{2} \cdot q+\cdots a_{n} \cdot q \\
S_{n}=a_{1}+a_{2}+\cdots a_{n-1}+a_{n} \\
\hline q \cdot S_{n}-S_{n}=a_{n} \cdot q-a_{1}
\end{gathered}
$$

Como $a_{n}=a_{1} \cdot q^{n-1}$, tem-se:

$$
S_{n} \cdot(q-1)=a_{1} \cdot\left(q^{n}-1\right) \Rightarrow S_{n}=\frac{a_{1} \cdot\left(q^{n}-1\right)}{q-1}
$$

Observação 2.2 (Soma dos termos de uma PG decrescente). Note que para $q<1$, a expressão $q^{n}-1<0$, então pode-se usar uma alternativa à fórmula 2.5, multiplicando numerador e denominador da fração por -1, obtendo-se:

$$
S_{n}=\frac{a_{1} \cdot\left(1-q^{n}\right)}{1-q}
$$

Observação 2.3 (A Soma dos termos de uma PG decrescente é limitada? ). Analisando o resultado do Exemplo 2.12, percebe-se que a Soma cresce cada vez menos a ponto de deduzir-se um possível limite para ela. Note que de $S_{4}$ para $S_{8}$ o crescimento é bem maior que de $S_{8}$ para $S_{12}$.

Qual seria a soma dos 100 primeiros termos? Seria superior a 1300? E a soma dos 1000 primeiros termos? Se realmente a soma for limitada seria possivel calcular a soma dos termos de uma PG infinita? 


\subsubsection{Soma dos infinitos termos de uma PG decrescente}

Considere, com a finalidade de estudo a PG decrescente. É possível responder as perguntas levantadas na Observação 2.3? Ou melhor, é possível generalizar para toda PG decrescente?

Conjecturando, pode-se tomar a soma dos termos de uma PG decrescente, pela fórmula: $S_{n}=\frac{a_{1}\left(1-q^{n}\right)}{1-q}$. Sabendo que uma função exponencial da forma $f: \mathbb{R} \rightarrow \mathbb{R}$ com $f(n)=q^{n}$ é limitada inferiormente em zero para $0<q<1$, então, considerando a soma dos infinitos termos de uma $\mathrm{PG}$, tem-se que $\lim _{n \rightarrow \infty} q^{n}=0$ e portanto

$$
\lim _{n \rightarrow \infty} S_{n}=\frac{a_{1}}{1-q}=s
$$

Para formalizar este resultado, verifique os teoremas dados a seguir, essenciais para o resultado que se deseja provar. O primeiro deles é a célebre desigualdade de Bernoulli, devida a Jacques Bernoulli, 1654-1705, matemático suiço.

Teorema 2.6 (Desigualdade de Bernoulli). Se $h>-1$, então,

$$
(1+h)^{n} \geq 1+n h
$$

para todo natural $n$.

Demonstração. Prova-se por indução.

Se $n=0$, ambos os membros são iguais a 1 e a desigualdade é verdadeira.

Supondo agora a desigualdade verdadeira para $n=k$, mostra-se que ela é verdadeira para $n=k+1$. Se $(1+h)^{k} \geq 1+k h$, multiplicando ambos os membros por $1+h$, que é positivo, obtém-se

$$
\begin{aligned}
(1+h)^{k+1} & \geq(1+k h)(1+h) \\
& =1+k h+h+k h^{2} \\
& =1+(k+1) h+k h^{2} \geq 1+(k+1) h
\end{aligned}
$$

Teorema 2.7. Se $|q|<1, \lim q^{n}=0$.

Demonstração. Se $q=0$, escolhido $\epsilon>0$, tem-se $\left|q^{n}-0\right|<\epsilon$, para todo $n>0$. 
Se $q \neq 0$, escolhido $\epsilon>0$ e pondo $h=\frac{1}{|q|}-1, h$ será positivo e

$$
\left|q^{n}-0\right|=\frac{1}{(1+h)^{n}} \leq \frac{1}{1+n h}<\frac{1}{n h}<\epsilon
$$

se $n>\frac{1}{\epsilon h}$

Teorema 2.8 (Soma dos infinitos termos de uma PG decrescente). O limite da soma $S_{n}$ dos $n$ primeiros termos de uma progressão geométrica $\left(a_{n}\right)$, de razão q tal que $|q|<1$, é igual a

$$
S=\frac{a_{1}}{1-q}
$$

Demonstração. Escolhido $\epsilon>0$, seja $h=\frac{1}{|q|}-1$. Observe que $h>0$ e que $1-q>0$. Tem-se:

$$
\left|S_{n}-S\right|=\left|\frac{a_{1}\left(1-q^{n}\right)}{1-q}-\frac{a_{1}}{1-q}\right|=\frac{\left|a_{1}\right||q|^{n}}{1-q}
$$

Se $a_{1}=0$, tem-se $\left|S_{n}-S\right|=0<\epsilon$ para todo $n$ natural e, se $a_{1} \neq 0$,

$$
\left|S_{n}-S\right|=\frac{\left|a_{1}\right|}{1-q} \cdot \frac{1}{(1+h)^{n}} \leq \frac{\left|a_{1}\right|}{1-q} \cdot \frac{1}{1+n h}<\frac{\left|a_{1}\right|}{(1-q) h n}<\epsilon
$$

para $n>\frac{\left|a_{1}\right|}{\epsilon h(1-q)}$ 


\section{$-$ \\ Matemática Financeira no Ensino Médio}

Um dos objetivos deste capítulo é fornecer uma breve apresentação de alguns conceitos fundamentais da Matemática Financeira e suas fórmulas, usadas hoje por muitos como única ferramenta de resolução de situações-problema.

No entanto, o principal objetivo deste capítulo é a desvinculação dos conceitos às fórmulas, substituindo-as como aplicações de outros assuntos da Matemática como por exemplos os apresentados no capítulo de fundamentação teórica (capítulo 2).

O objeto de estudo da Matemática Financeira é o conjunto de procedimentos utilizados em pagamentos de empréstimos, bem como métodos de análise de investimentos em geral. Acrescenta-se, então, como objetivo principal formar um aluno que, a partir destas técnicas, esteja apto a tomar decisões relativas à sua vida financeira com embasamento matemático.

\subsection{Conceitos iniciais}

Quando uma pessoa ou instituição empresta a outra um valor monetário, durante um período temporal, essa quantia é chamada de Capital (ou Valor Principal) e é indicada nas fórmulas apresentadas a seguir por $C$.

O valor que o emprestador cobra pelo uso do dinheiro que fica emprestado durante todo o período é chamado de Juro e será indicado nas fórmulas por $J$.

A taxa percentual, que será indicada por $i$, expressa como uma porcentagem do capital é calculada em intervalos de tempos predefinidos nas formas: ao dia (a.d.), ao mês (a.m.), 
ao ano (a.a.) etc. Assim, o juro cobrado em um único período é igual ao produto da taxa pelo Capital, isto é,

$$
J=C \cdot i
$$

O tempo que o valor fica emprestado é representado pelo número de períodos e o período é uma unidade de tempo em que a taxa de juros é capitalizada (dias, meses, anos etc).

Para o cálculo dos juros em períodos diferentes de 1, deve-se saber o regime de juros adotado para seus cálculos.

Ao final do prazo do empréstimo, o tomador pagará o capital acrescido dos juros. A esta quantia dá-se o nome de montante, representado por $M$. Desta forma, tem-se:

$$
M=C+J
$$

Exemplo 3.1. Um estudante recebeu um prêmio de $R \$ 3.000,00$ e o aplicou durante 3 meses em um investimento que rende à taxa de $8 \%$ a.t. (ao trimestre). Quanto rendeu seu investimento e qual foi a quantia total retirada?

\section{Solução.}

O Capital é de $\mathrm{R} \$ 3.000,00(C=3000)$, a taxa de juros é de $8 \%$ a.t. $(i=0,08)$ e o período é de 1 trimestre. Note que a taxa de juros é capitalizada trimestralmente, assim, $J=C \cdot i=3000 \cdot 0,08 \Rightarrow J=240$.

Serão acrescidos R $\$ 240,00$ de juros. Como o Montante é o Capital acrescido dos juros, a quantia total retirada é de $\mathrm{R} \$ 3.240,00$.

Exemplo 3.2. Bete conseguiu uma renda extra de $R \$ 10.000,00$ e depositou na poupança, deixando aplicada durante 12 meses. Na retirada, sacou o valor total de $R \$ 10.616,78$. Quanto o depósito rendeu de juros e qual sua taxa anual?

\section{Solução.}

Como o valor inicial era de $\mathrm{R} \$ 10.000,00$, então $C=10000$, a taxa $i$ é desconhecida e o Montante é de R $\$ 10.616,78$, então, $M=10616,78$.

$$
\begin{aligned}
M & =C+J \\
10616,78 & =10000+10000 \cdot i \Rightarrow i=0,061678
\end{aligned}
$$

A quantia referente ao juros é de $\mathrm{R} \$ 616,78$ e sua taxa anual é de $6,1678 \%$.

Formalizando os conceitos apresentados, são dadas as definições a seguir. 
Definição 3.1 (Capital ou Valor Principal). É a quantia inicialmente emprestada ou aplicada.

Definição 3.2 (Juros). Valor que um capital rende ou acréscimo cobrado de um empréstimo.

Definição 3.3 (Período). É o intervalo de tempo considerado como unidade, usado para a capitalização da taxa de juros, o tempo da operação financeira equivale ao total de períodos.

Definição 3.4 (Taxa de juros). É a razão percentual dos juros em relação ao capital, capitalizado conforme um periodo de tempo pré-fixado (periodo).

Definição 3.5 (Montante ou Valor Final). Valor total ao final da aplicação, equivale ao Capital acrescido dos juros ao final do período.

Quando um capital fica aplicado a uma certa taxa de juros por um intervalo ou períodos de tempo, os juros e o montante serão calculados segundo duas convenções de cálculos, chamadas de regimes de capitalização: Capitalização Simples (ou Juros Simples) e Capitalização Composta (ou Juros Compostos).

Embora o modelo amplamente usado seja o de capitalização composta, o regime adotado em determinada aplicação financeira é aquele acordado entre as partes.

\subsection{Regime de Capitalização Simples (Juros Simples)}

Neste regime de capitalização, os juros gerados em cada período são constantes e se baseiam no Capital e taxa de juros. Os juros são pagos apenas ao final da aplicação.

Considere um capital $C$, aplicado a juros simples, a uma taxa $i$ por período e durante $n$ períodos de tempo. Os juros serão iguais em cada período de tempo, ou seja, indicando por $j_{1}, j_{2}, j_{3}, \cdots, j_{n}$, respectivamente, como os juros nos períodos $1,2,3, \cdots n$, tem-se:

$$
j_{1}=j_{2}=j_{3}=\cdots=j_{n}=C \cdot i
$$

Assim, os juros (total dos juros no período) são calculados como:

$$
J=C \cdot i \cdot n
$$

Como o montante equivale ao capital acrescido aos juros, tem-se

$$
M=C+J=C+C \cdot i \cdot n \Rightarrow M=(1+i n) \cdot C
$$


Assim, é dada a fórmula que relaciona montante, capital, taxa e número de períodos.

$$
M=(1+i n) \cdot C
$$

Observação 3.1. Note que o período e a capitalização da taxa de juros devem estar reduzidos à mesma unidade de tempo.

Quando se resume a Matemática Financeira a um conjunto de variáveis e fórmulas, como as apresentadas (e como aparecem nos livros didáticos de Ensino Médio), perdese uma grande oportunidade de explorar e fixar não apenas estes conceitos como outros trabalhados em diferentes momentos, ou seja, o intuito deste trabalho é mostrar que é possível abordar a Matemática Financeira não como um assunto à parte, mas como a aplicação de uma série de assuntos trabalhados na Matemática do Ensino Médio.

Para melhor ilustrar essa ideia, verificam-se os mesmos conceitos como aplicações de alguns tópicos da Matemática do Ensino Médio, apresentados na Fundamentação Teórica deste trabalho (capítulo 2).

\subsubsection{Juros Simples e Progressões Aritméticas}

Considere um Capital $\left(c_{0}\right)$ aplicado em um investimento que rende à taxa $i$ por período, gerando juro $j$. Observe que os montantes encontrados (representados por $c_{1}, c_{2}, c_{3}, \cdots c_{n}$ ) a cada período formam uma Progressão Aritmética de razão j. Observe a figura 3.1.

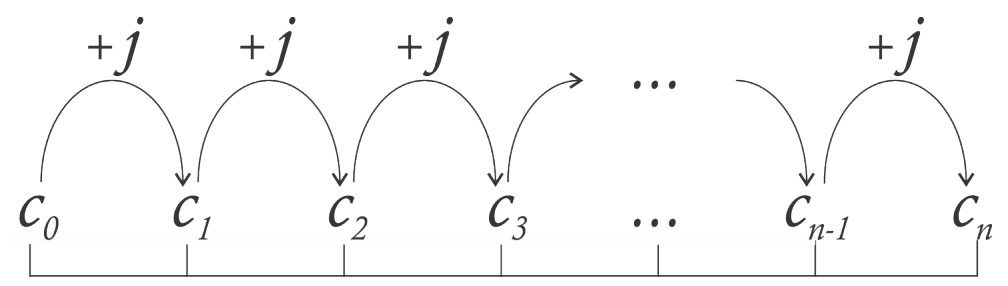

Figura 3.1: Montantes na forma de PA

Note que o Montante ao fim do primeiro mês equivale ao capital acrescido do juro, enquanto o montante ao fim do terceiro mês equivale ao capital acrescido do dobro do juro, assim como na Progressão Aritmética, pois da mesma forma que $a_{1}=a_{0}+r$ e $a_{2}=a_{0}+2 r$, tem-se $c_{1}=c_{0}+j$ e $c_{2}=c_{0}+2 j$. Então, $c_{n}=c_{0}+n \cdot j$.

No esquema apresentado na figura 3.1 fica ilustrado que o comportamento do montante em relação ao período é o mesmo que o termo geral de uma Progressão Aritmética, sendo o primeiro termo $c_{0}$ (capital: $C$ ), razão $j$ (juros de um período à taxa $i$ ) e o Montante no período $k$ como $c_{k}, k \in \mathbb{N}$. 
Como $j$ é o juro de um período, $j=C \cdot i$, então os juros $J$ (total de juros em todo o período) são calculados como: $J=n \cdot j$, ou seja,

$$
J=C \cdot i \cdot n
$$

Desta forma, lembrando o termo geral de uma PA de razão $r$, primeiro termo $a_{1}$ (ou $\left.a_{0}\right)$ e $n$ termos: $a_{n}=a_{1}+(n-1) r$ ou $a_{n}=a_{0}+n r$ e usando o esquema da figura 3.1, encontra-se $c_{n}, c_{n}=c_{0}+n \cdot j=c_{0}+c_{0} \cdot i \cdot n$. Comparando à formula do montante (3.4), tem-se:

$$
\begin{aligned}
M & =C+C \cdot i \cdot n \\
c_{n} & =c_{0}+c_{0} \cdot i \cdot n
\end{aligned}
$$

Assim, o n-ésimo termo é $c_{n}, M=c_{n}$, o primeiro termo é $c_{0}$ e $C=c_{0}$, enquanto a razão da progressão aritmética é $j=c_{0} \cdot i$.

Observação 3.2. Os problemas de juros simples podem ser resolvidos, portanto, usando a própria terminologia de PA, ou seja, $a_{n}, a_{0}$ etc.

Observe no exemplo a seguir duas abordagens diferentes usadas na resolução, a tradicional (usando as fórmulas da Matemática Financeira) e outra utilizando Progressões Aritméticas.

Exemplo 3.3. Patrícia tomou emprestado de seu irmão, a juros simples, com taxa de 2\% a.m., a quantia de $R \$$ 4.000,00 para pagar após seis meses. Qual será o valor pago ao final do período?

\section{Solução tradicional.}

O capital é de $\mathrm{R} \$ 4.000,00(C=4000)$, a taxa de juros é de $2 \%(i=0,02)$ e o período é de 6 meses $(n=6)$ e deseja-se descobrir o montante $M$. Assim,

$$
\begin{aligned}
& M=C+C \cdot i \cdot n=C \cdot(1+i \cdot n) \\
& M=4000 \cdot(1+0,02 \cdot 6)=4480
\end{aligned}
$$

O valor a ser pago por Patrícia é de $\mathrm{R} \$ 4.480,00$.

\section{Solução por PA.}

Como os montantes de uma aplicação de juros simples têm comportamento de Progressão Aritmética, de primeira termo $c_{0}$, razão $j(j=C \cdot i)$, observe o esquema da figura 3.2 .

$$
c_{6}=c_{0}+c_{0} \cdot i \cdot n=4000+4000 \cdot(0,02) \cdot 6 \Rightarrow c_{6}=4480
$$




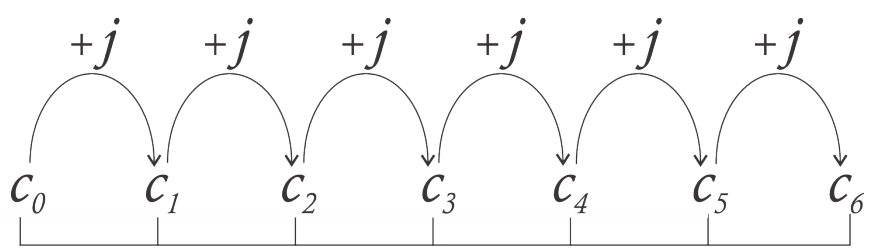

Figura 3.2: Resolução do exemplo 3.3

Assim, o pagamento (montante) após 6 meses é de $\mathrm{R} \$ 4.480,00$.

Exemplo 3.4. Qual o capital que aplicado a juros simples, à taxa de 2,5\% a.m., resulta em um montante de $R \$ 6.000,00 \mathrm{em}$ dois anos?

\section{Solução tradicional.}

O capital é desconhecido $(C=$ ?), a taxa $i$ é de $2,5 \%$ a.m $(i=0,025)$, o montante é de $\mathrm{R} \$ 6.000,00(M=6000)$ e o tempo de 2 anos equivale a 24 meses $(n=24)$.

$$
\begin{aligned}
M & =C+C \cdot i \cdot n=C \cdot(1+i \cdot n) \\
6000 & =C \cdot(1+0,025 \cdot 24) \Rightarrow C=3750
\end{aligned}
$$

\section{Solução por PA.}

Considerando a aplicação financeira como PA, o número de períodos é $n=24$, o montante é de $\mathrm{R} \$ 6.000,00\left(M=c_{24}=6000\right)$ e $j=c_{0} \cdot i=0,0125 \cdot c_{0}$. Assim, deseja-se conhecer $c_{0}$.

$$
\begin{aligned}
c_{n} & =c_{0}+n \cdot j \\
c_{24} & =c_{0}+24 \cdot 0,025 \cdot c_{0} \\
6000 & =c_{0} \cdot(1+0.6) \\
c_{0} & =3750 .
\end{aligned}
$$

Dessa forma, o capital aplicado foi de $\mathrm{R} \$ 3.750,00$.

\subsubsection{Juros simples e funções}

Como apresentado no capítulo 2, pode-se associar PA à função afim e como o regime de capitalização simples tem comportamento linear, ou seja, tem crescimento constante em intervalos de tempo iguais, então pode-se escrever a fórmula, $M=C+C i n$ usando a notação de funções $M(n)=C+C \cdot i \cdot n$, sendo $C$ e $i$ as constantes e, comparando ao modelo matemático de uma função linear: $f(x)=a x+b$, então $n=x, M(n)=f(x)$, $a=C \cdot i$ e $b=C=M(0)$. 
Assim, é possível solucionar problemas de Juros Simples usando a abordagem de funções.

Exemplo 3.5 (Revisitando o Exemplo 3.3 ). Patrícia tomou emprestado de seu irmão, a juros simples, com taxa de 2\% a.m., a quantia de $R \$$ 4.000,00 para pagar após seis meses. Qual será o valor pago ao final do período?

\section{Solução (função afim).}

Como na fórmula $M=C+C \cdot i \cdot n$ pode-se considerar o Montante como uma função do número de meses, ou seja, tome como variáveis $M(M=M(n))$ e $n$ e constantes $C=M(0)$ e $i$.

No problema dado,

$$
M(6)=4000+4000 \cdot 0,02 \cdot 6 \Rightarrow M(6)=4480
$$

O valor a ser pago por Patrícia é de $\mathrm{R} \$ 4.480,00$. Veja a representação gráfica:

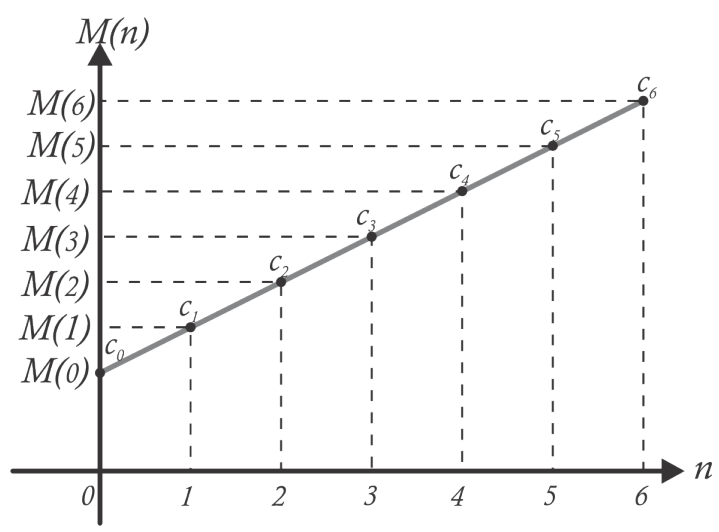

Figura 3.3: Resolução do exemplo 3.5

Note que os pontos destacados $\left(c_{0}, c_{1}, c_{2}, c_{3}, c_{4}, c_{5}\right.$ e $\left.c_{6}\right)$ são termos da PA $c_{n}=c_{0}+c_{0} \cdot j$.

Observação 3.3. O uso de Progressões Aritméticas traz uma abordagem de Matemática Discreta, ou seja, sabendo que cada termo é o montante de um perído (pontos do gráfico, vide figura 3.3), a função exibe o Montante de forma contínua, mostrando inclusive frações de períodos de tempo. Apesar disso, as duas abordagens podem ser usadas para quaisquer problemas envolvendo juros simples.

Exemplo 3.6. Uma empresa oferece aos seus funcionários empréstimo a juros simples para periodos completos inferiores a 3 anos. Sabendo que a taxa de juros praticada é de $8 \%$ a.a., em quanto tempo um funcionário que tomou um empréstimo de $R \$ 10.000,00$ demorou a pagar sua divida, sabendo que a quantia paga foi de $R \$ 11.800,00$, antes da data limite? 


\section{Solução.}

Resolvendo o problema com a notação de função, sabe-se que $n$ é desconhecido, $M(n)=11800, C=10000$ e $i=0,08$ (a taxa de juros é de $8 \%$ a.a.). Desta forma, no problema dado:

$$
\begin{aligned}
M(n) & =C+C \cdot i \cdot n \\
11800 & =10000+10000 \cdot 0,08 \cdot n \Rightarrow n=2,25
\end{aligned}
$$

O período total foi de 2,25 anos, ou seja, 2 anos e 3 meses (0,25 anos é o mesmo que $0,25 \cdot 12=3)$.

Note que nesse exemplo o período não foi um número inteiro, como ocorre com uma $\mathrm{PA}$, pois $n$ representa o número de termos em $c_{n}=c_{0}+n j$.

Embora nada impeça o uso dessa abordagem, vale lembrar que em uma PA pode-se usar problemas que tenham valores inteiros para $n$, usando a abordagem de funções para situações nas quais $n$ possa ter valor fracionário. Observe o gráfico da figura 3.4.

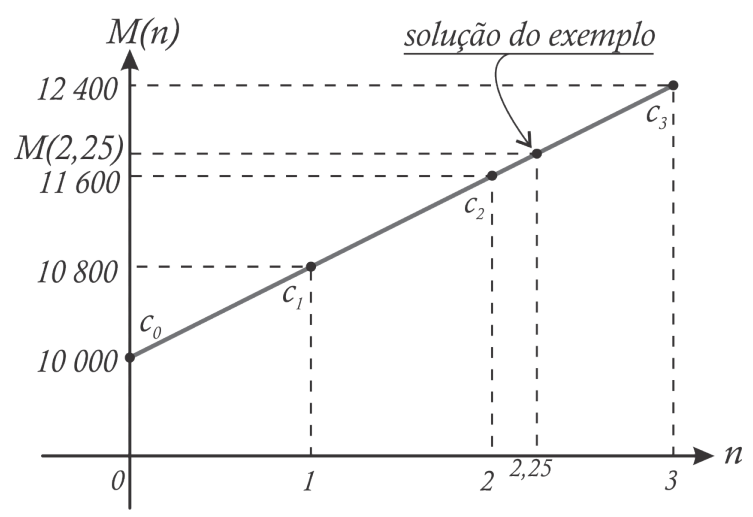

Figura 3.4: Resolução do exemplo 3.6

Desta forma, as duas abordagens de PA e função afim são interessantes e, como no currículo regular de Matemática aparecem em momentos diferentes, é uma oportunidade que o professor tem para enriquecer estes conteúdos levando conceitos e problemas da Matemática Financeira, em troca de apresentá-la de modo artificial e à parte de conteúdos significativos da Matemática.

Observação 3.4. O uso do regime de capitalização simples não é usual, os casos mais comuns de utilização deste modelo são operações de curtíssimo prazo (inferior a um periodo) e descontos simples em duplicatas.

Exemplo 3.7. Um comerciante recebe uma duplicata (boleto de pagamento) com vencimento em 12/06/2015 no valor de R\$1.280,00. No pagamento antecipado concede-se 
desconto simples de $12 \%$ a.m. Qual será o valor pago se o pagamento for efetuado em 22/05/2015?

\section{Solução.}

Como o pagamento foi efetuado em $22 / 05 / 2015$, foi antecipado em 21 dias, e a taxa proporcional em dias é dada por $\frac{12 \%}{30}=0,4 \%$ a.d. (considera-se o mês comercial de 30 dias).

Note que neste caso o juro é negativo por descontar do valor, ou seja, -0, $4 \%$ a.d., $\log \mathrm{O}$

$$
\begin{aligned}
& M=C \cdot(1-i n) \\
& M=1280 \cdot(1-0,004 \cdot 21) \\
& M=1172,48
\end{aligned}
$$

Logo, o valor pago deve ser de $\mathrm{R} \$ 1172,48$.

A preferência deste modo de capitalização para aplicações financeiras de curtíssimo prazo se deve à comparação entre a função exponencial e afim, de parâmetros idênticos.

Conforme apresentado, uma aplicação financeira do modelo de juros simples tem o comportamento de uma função afim, enquanto a aplicação no sistema de capitalização composta tem, como será apresentado na seção 3.3, o comportamento de uma função exponencial (será apresentado ainda neste capítulo).

Observe os gráficos de duas funções, referentes a aplicações de taxas financeiras iguais a $i$, submetendo um capital $C$ por $n$ períodos na figura 3.5. Considere a aplicação financeira no regime de capitalização simples representada por $M(n)=C+C i n=C \cdot(1+i n)$ e $C(n)$ representando a aplicação no regime de capitalização composta, $C(n)=C \cdot(1+i)^{n}$.

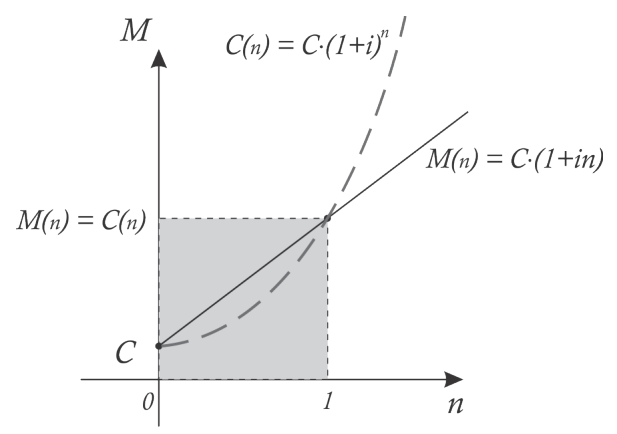

Figura 3.5: Gráfico das aplicações a juros simples e compostos na mesma taxa e capital

Note que, para os mesmos períodos, a aplicação $C(n)$ é maior que $M(n)$ a partir de um período, no entanto no intervalo de 0 a 1 para $n$, (região sombreada no plano cartesiano) 
os valores de $M(n)$ são maiores. O que justifica a preferência das instituições ao utilizar a modalidade de juros simples para prazos inferiores a um período.

Exemplo 3.8. Um cliente tem sua conta negativada em $R \$ 1.000,00$. Sabe-se qua a taxa de juros cobrada por sua instituição é de 8,9\% a.m. no regime de capitalização composta. No entanto, o cliente quitou seu débito em 15 dias. Calcule o valor cobrado de cheque especial nos dois regimes de capitalização.

\section{Solução.}

O período é de 0,5 mês, calculando no regime de capitalização simples, tem-se:

$$
\begin{aligned}
& M(n)=C \cdot(1+i \cdot n) \\
& M(n)=1000 \cdot(1+0,089 \cdot 0,5) \\
& M(n)=1044,50
\end{aligned}
$$

O valor da dívida será de $\mathrm{R} \$ 1044,50$. Enquanto no regime de capitalização composta,

$$
\begin{aligned}
& C(n)=C \cdot(1+i)^{n} \\
& C(n)=1000 \cdot(1+0,089)^{0,5} \\
& C(n)=1043,55
\end{aligned}
$$

O valor da dívida será de $\mathrm{R} \$ 1043,55$. Este resultado explicita porque se utiliza a modalidade de juros simples nessa situação.

\subsection{Regime de Capitalização Composta (Juros Compos- tos)}

Como apresentado, o Montante de uma aplicação financeira a juros simples tem um crescimento constante, ou seja, independente do tempo que o capital for aplicado, o crescimento a cada período será sempre o mesmo, uma porcentagem do capital.

Como se imagina, este não parece um modelo ideal para a Economia. Seria de maior interesse um modelo matemático que permitisse o crescimento do capital aplicado, de modo que quanto maior o número de períodos desta aplicação, o crescimento fosse relativamente maior, ou seja, um modelo matemático que tivesse um crescimento proporcional ao montante do período anterior e não apenas ao tempo, como ocorre no Regime de capitalização simples. 
Considere um Capital $C$, sofrendo periodicamente acréscimo de juros a uma taxa $i$ por período, capitalizada sobre o montante anterior, e durante $n$ períodos de tempo. Analisando o montante a cada período tem-se:

$$
\begin{aligned}
& \text { período } 0 \quad C_{0}=C \\
& \text { período } 1 \quad C_{1}=C+C \cdot i=C \cdot(1+i) \\
& \text { período } 2 \quad C_{2}=C_{1}+C_{1} \cdot i=C_{1} \cdot(1+i) \\
& =C \cdot(1+i)(1+i)=C \cdot(1+i)^{2} \\
& \text { período } 3 \quad C_{3}=C_{2}+C_{2} \cdot i=C_{2} \cdot(1+i) \\
& =C \cdot(1+i)^{2} \cdot(1+i)=C \cdot(1+i)^{3} \\
& \text { período } \mathrm{n} \quad C_{n}=C_{n-1}+C_{n-1} \cdot i=C \cdot(1+i)^{n}
\end{aligned}
$$

O montante de um período é igual ao montante do período anterior multiplicado por $1+i$ que é o fator de correção. Assim, o conjunto dos montantes dados período a período formam uma Progressão Geométrica de primeiro termo $C$ e razão $1+i$. Logo, como acontece com a PG, pode-se também associar a uma função exponencial.

Teorema 3.1. No regime de juros compostos de taxa $i$, um principal $C_{0}$ transforma-se, em $n$ periodos de tempo, em um montante igual a

$$
C_{n}=C_{0} \cdot(1+i)^{n}
$$

Demonstração. Para cada $k$, seja $C_{k}$ a dívida paga após $k$ períodos de tempo. Tem-se $C_{k+1}=C_{k}+i C_{k}=(1+i) C_{k}$. Daí, $\left(C_{k}\right)$ é uma progressão geométrica de razão $1+i$ e $C_{n}=C_{0} \cdot(1+i)^{n}$.

Desta forma, como o comportamento do montante caracteriza uma função de tipo exponencial, a fórmula 3.6 pode ser usada para qualquer valor real de $n$.

Como este é o regime de ampla predominância no mercado financeiro e mesmo nas operações financeiras do cotidiano, convenciona-se neste trabalho que o regime de capitalização padrão será o de juros compostos, ou seja, quando não estiver explícito, este será o modelo utilizado.

Exemplo 3.9. Um cliente toma no banco um empréstimo de $R \$ 2.000,00$ à taxa de $4 \%$ a.m. e deseja pagar a dívida após 6 meses. Qual será o valor pago? 


\section{Solução.}

No exemplo dado o valor emprestado é o valor inicial, portanto, o capital $C$, à taxa $i$ de $4 \%$ e o período do empréstimo é de 6 meses. Assim,

$$
\begin{aligned}
C_{n} & =C \cdot(1+i)^{n} \\
& =2000 \cdot(1+0,04)^{6} \\
& =2530,63804
\end{aligned}
$$

O valor da dívida ao fim do período será de $\mathrm{R} \$ 2.530,63$.

Exemplo 3.10. Um cliente não consegue efetuar o pagamento de seu cartão, realizando-o somente após 4 meses no valor de $R \$ 3.513,84$. Sabendo que a administradora do cartão cobra a taxa de $10 \%$ a.m. pelo atraso, responda:

(a) Qual a dívida inicial do cartão?

(b) Qual seria o valor da divida se fosse adotado o regime de capitalização simples?

(c) Faça a comparação entre os valores das dividas nos dois regimes.

(d) Após 12 meses a comparação seria igual?

\section{Solução.}

(a) O valor do pagamento é o valor final, ou seja, o montante ao final da movimentação financeira, e deseja-se encontrar o valor inicial, o capital $C$. Pela fórmula 3.6:

$$
\begin{aligned}
C_{n} & =C \cdot(1+i)^{n} \\
3513,84 & =C \cdot(1,1)^{4} \\
C & =\frac{3513,84}{1,4641}=2400 .
\end{aligned}
$$

O valor da dívida no vencimento do cartão era de $\mathrm{R} \$ 2.400,00$.

(b) No regime de capitalização simples, o montante após 4 meses da dívida inicial de $\mathrm{R} \$$ 2.400,00, seria:

$$
\begin{aligned}
c_{n} & =C \cdot(1+i n) \\
& =2400 \cdot(1+0,1 \cdot 4) \\
& =3360
\end{aligned}
$$

O valor da dívida à época do pagamento seria de $\mathrm{R} \$ 3.360,00$. 
(c) Comparando os montantes encontrados para o regime de juros compostos em relação ao simples tem-se:

$$
\frac{3513,84}{3360}=1,04578571
$$

ou seja, o Montante no regime de juros compostos é aproximadamente 4,578\% maior que o Montante calculado a juros simples.

(d) Fazendo a comparação para os montantes após 12 meses:

No regime de juros simples:

$$
c_{12}=C \cdot(1+0,1 \cdot 12)=2,2 \cdot C
$$

No regime de juros compostos:

$$
C_{12}=C \cdot(1+0,1)^{12} \approx 3,1384 \cdot C
$$

Comparando as duas

$$
\frac{C_{12}}{c_{12}} \approx 1,42656
$$

Logo, após um ano, o montante nos juros compostos será 42,656\% maior que o montante calculado no regime de juros simples.

\subsubsection{Juros Compostos, PG e funções exponenciais}

Em uma aplicação financeira, o crescimento do montante a cada período completo obedece a uma taxa de crescimento constante, assim como um decrescimento (considere como um "crescimento negativo"), o que caracteriza uma Progressão Geométrica.

Assim, quando o professor inicia o assunto Progressões Geométricas, vale apresentar o regime de capitalização composta e enriquecer este assunto com exercícios como os exemplos 3.9 e 3.10, vinculando o assunto ao ensino de PG, ao invés de tratá-lo isoladamente.

Como a Progressão Geométrica é discreta, ou seja, sua variável independente $n$ é natural, comparando a períodos, os montantes seriam os termos a cada período completo. Sendo o termo geral dado por $a_{n}=a_{0} \cdot q^{n}$ (essa notação é melhor para abordagem de montantes que a notação convencional: $\left.a_{n}=a_{1} \cdot q^{n-1}\right)$ e no cálculo do montante, $C_{n}=C_{0} \cdot(1+i)^{n}$, note que o primeiro termo é $a_{0}=C_{0}$, enquanto a razão $q=(1+i)$ e o número de períodos é dado por $n$.

Exemplo 3.11. Um capital de $R \$ 3.000,00$ foi aplicado durante 5 meses, rendendo juros de $R \$ 215,96$. Qual a taxa de juros praticada? 


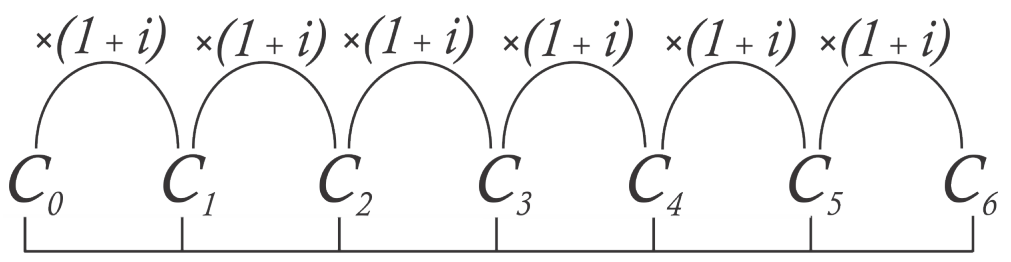

Figura 3.6: montantes período a período como termos de uma PG

\section{Solução.}

Como o valor dos juros foi de $\mathrm{R} \$ 215,96$ e $M=C+J$, o montante foi de $\mathrm{R} \$ 3.215,96$. Assim,

$$
\begin{aligned}
C_{5} & =C_{0} \cdot(1+i)^{5} \\
3215,96 & =3.000 \cdot(1+i)^{5} \\
1,07198667 & =(1+i)^{5} \\
(1,07198667)^{\frac{1}{5}} & =(1+i) \\
1,01399982 & =1+i \\
i & =0,01399982 \%
\end{aligned}
$$

A taxa de juros é de aproximadamente 1,4\% a.m.

Como a progressão geométrica associa a cada $n$ natural um termo $C_{n}$, fica subentendido um comportamento discreto dos montantes. Embora possam ser resolvidas situaçõesproblema que envolvem períodos fracionários, torna-se essencial a abordagem de regime de capitalização composta em funções exponenciais. Esta proposta permite o aluno perceber os juros compostos como uma aplicação matemática de assuntos essenciais e não como fórmulas soltas para memorizar.

No exemplo a seguir, torna-se familiar ao aluno a necessidade de se trabalhar com funções exponenciais. Considere a fórmula 3.6, do cálculo de montante a juros compostos, na notação de funções, $C: \mathbb{R} \rightarrow \mathbb{R}$, sendo $C(n)=C \cdot(1+i)^{n}$, em que $C=C(0)$, então:

$$
C(n)=C \cdot(1+i)^{n}
$$

Há dois casos a se considerar: a função exponencial é crescente, para $(1+i)>1 \Rightarrow$ $i>0$, ou seja, a taxa é positiva e seu gráfico é crescente. O outro caso é dado para a função exponencial decrescente, para $0<(1+i)<1 \Rightarrow-1<i<0$, ou seja, para a taxa negativa (quando há desconto) o Montante sofre depreciação.

O gráfico 1 representa uma aplicação que sofre acréscimo (taxa positiva, mais comum), enquanto o gráfico 2 indica uma aplicação que sofre decréscimo (taxa negativa), como 


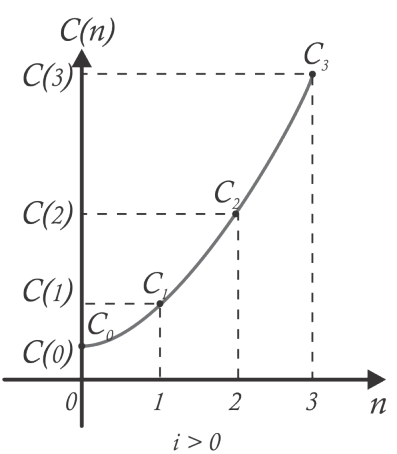

Gráfico 1

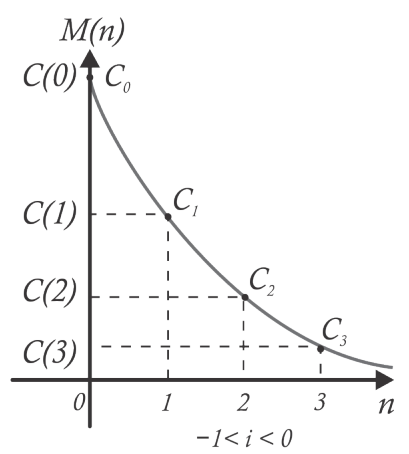

Gráfico 2

Figura 3.7: O Montante a juros compostos como uma função exponencial

descontos ou depreciação de um bem.

Exemplo 3.12. Mateus comprou um carro seminovo de $R \$ 32.000,00$ que sofre depreciação de aproximadamente 5,8\% a.a. Qual será o valor do carro após 4 anos?

\section{Solução.}

Note que a taxa é negativa, $i=-5,8 \%$ e o número de períodos de 4 anos, com capital $C_{0}=C=32000$. Assim,

$$
\begin{aligned}
& C(n)=C_{0} \cdot(1+i)^{n} \\
& C(n)=32000 \cdot(1-0,058)^{4} \\
& C(n)=25197,2758
\end{aligned}
$$

Em 4 anos o valor do carro será de aproximadamente $\mathrm{R} \$ 25.197,27$.

Exemplo 3.13. Um investidor aplica todo o lucro de sua empresa em um fundo que rende juros de 2,5\% a.m. Quanto tempo, aproximadamente, deve esperar para retirar o dobro do que investiu, sabendo que os juros são calculados diariamente?

\section{Solução.}

Sabe-se que o investidor deseja retirar o dobro do capital $C$ após $n$ meses. Assim, $C(n)=2 \cdot C$.

$$
\begin{aligned}
C(n) & =C_{0} \cdot(1+i)^{n} \\
2 \cdot C_{0} & =C_{0} \cdot(1+0,025)^{n} \\
2 & =(1,012)^{n} \\
\log 2 & =n \cdot \log (1,025) \\
n & \approx 28,071
\end{aligned}
$$


O investidor deve aguardar aproximadamente 2 anos, 4 meses e 2 dias.

Exemplo 3.14. O valor de um bem sofre uma depreciação (desvalorização) de 8\% a.a. Qual o prazo máximo para venda deste bem se o proprietário não quer vendê-lo por menos de $25 \%$ do valor inicial?

\section{Solução.}

Como o valor do bem, que inicialmente é $C_{0}$, sofre desvalorização, $i=-0,08$ e desejase que o montante final seja de $C(n)=\frac{C_{0}}{4}$,tem-se:

$$
\begin{aligned}
C(n) & =C_{0} \cdot(1+i)^{n} \\
\frac{C_{0}}{4} & =C_{0} \cdot(1-0,08)^{n} \\
\frac{1}{4} & =(0,92)^{n} \\
\ln 2^{-2} & =n \cdot \ln (0,92) \\
n & \approx 16,6259
\end{aligned}
$$

O proprietário deve vender o bem antes de, aproximadamente, 16 anos, 7 meses e 16 dias.

\subsubsection{Capitalização composta com taxa de juros variáveis}

Na dedução da fórmula do Montante no regime de capitalização composta, foi considerada uma taxa de juros constante. No entanto são muito comuns situações em que a taxa de juros sofre alterações durante os períodos da operação financeira.

Considere um capital $C$ aplicado a juros compostos por $n$ períodos, sendo $i_{k}(1 \leq$ $k \leq n$ ) a taxa referente ao período $k$, ou seja, o primeiro período tem taxa $i_{1}$, o segundo período tem taxa $i_{2}$ e assim sucessivamente até o n-ésimo período que tem taxa $i_{n}$. Assim,

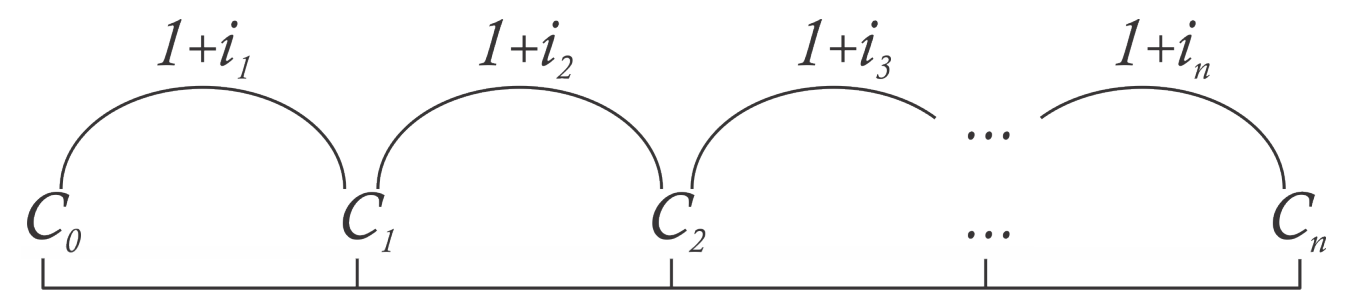

Figura 3.8: O Montante a juros compostos com taxas variáveis 


$$
\begin{aligned}
& \text { período } 0 \quad C_{0}=C \\
& \text { período } 1 \quad C_{1}=C+C \cdot i_{1}=C \cdot\left(1+i_{1}\right) \\
& \text { período } 2 \quad C_{2}=C_{1} \cdot\left(1+i_{2}\right) \\
& =C \cdot\left(1+i_{1}\right)\left(1+i_{2}\right) \\
& \text { período } 3 \quad C_{3}=C_{2} \cdot\left(1+i_{3}\right) \\
& =C \cdot\left(1+i_{1}\right)\left(1+i_{2}\right)\left(1+i_{3}\right) \\
& \text { período } \mathrm{n} \quad C_{n}=C_{n-1}+C_{n-1} \cdot i_{n} \\
& =C \cdot\left(1+i_{1}\right) \cdot\left(1+i_{2}\right) \cdot\left(1+i_{3}\right) \cdots\left(1+i_{n}\right)
\end{aligned}
$$

Assim, para encontrar o montante $M_{n}$ regido a juros compostos com taxas variáveis $\left(i_{1}, i_{2}, \cdots, i_{n}\right)$, tem-se:

$$
C_{n}=C \cdot\left(1+i_{1}\right) \cdot\left(1+i_{2}\right) \cdot\left(1+i_{3}\right) \cdots\left(1+i_{n}\right)
$$

Exemplo 3.15. Um empresário investe $R \$ 8.000,00$ na compra de ações de uma empresa na bolsa durante 10 meses. No primeiro trimestre houve um aumento de 2\% a.m. No quarto mês houve um aumento de 2,4\%, com queda de 1,2\% no quinto e sexto meses. Nos meses restantes houve crescimento de $1 \%$.

\section{Solução.}

Como as taxas de juros foram variáveis, usa-se a fórmula 3.7.

$$
\begin{aligned}
C(n) & =C \cdot\left(1+i_{1}\right) \cdot\left(1+i_{2}\right) \cdot\left(1+i_{3}\right) \cdots\left(1+i_{10}\right) \\
C(n) & =8000 \cdot(1+0,02)^{3} \cdot(1+0,024) \cdot(1-0,012)^{2} \cdot(1+0,01)^{4} \\
& =8830,92
\end{aligned}
$$

\subsubsection{Taxas Proporcionais x Taxas Equivalentes}

Uma taxa de $i \%$ ao ano, proporcionalmente pode ser escrita como $\frac{i}{4} \%$ a.t. $(1$ ano tem 4 trimestres), $\frac{i}{6} \%$ a.b. ( 1 ano tem 6 bimestres), $\frac{i}{12} \%$ a.m. ( 1 ano tem 12 meses) ou mesmo $\frac{i}{360} \%$ a.d. (quando se considera calendário comercial de 360 dias). No entanto, para fins de cálculo, $i \%$ a.a. equivale a $\frac{i}{12} \%$ a.m.? 
Definição 3.6 (Taxas proporcionais). São ditas taxas proporcionais aquelas que reduzidas ao mesmo periodo têm proporcionalmente mesmo valor. Como exemplo, 1 ano tem doze meses, então i\% a.a. e $\frac{i}{12} \%$ a.m. são taxas proporcionais.

Definição 3.7 (Taxas equivalentes). São ditas taxas equivalentes aquelas que reduzidas ao mesmo perído produzem mesmo montante, a partir de um mesmo capital.

Exemplo 3.16. Se um capital de $R \$ 5.000,00$ for aplicado durante 3 meses a uma taxa de $10 \%$ a.m., o montante obtido é o mesmo que o produzido por uma taxa trimestral de 30\%? Proporcionalmente, 30\% a.t. é o mesmo que 10\% a.m. (chamam-se estas de taxas proporcionais).

\section{Solução.}

Para juros simples a resposta é sim, pois, neste caso, o montante $M=C(1+i n)$. Note que $C \cdot(1+0,1 \cdot 3)=C \cdot(1+0,3 \cdot 1)$. No entanto, para juros compostos, não acontece o mesmo.

Situação 1 (30\% a.t.): $M=5.000,00 \cdot(1,3)^{1}=6500$

Situação 2 (10\% a.m.): $M=5.000,00 \cdot(1,1)^{3}=6655$

Então, para juros compostos, taxas proporcionais não são equivalentes. Comparando os montantes produzidos à taxa mensal e à taxa trimestral, o primeiro foi $33,1 \%$ maior (pois $\frac{6655}{6500}=1,0331$ ).

Observação 3.5. Note que 10\% a.m. é uma taxa maior que $30 \%$ a.t. Diz-se, neste caso, que a taxa de $30 \%$ a.t. capitalizada mensalmente é de $10 \%$ a.m. e vice-versa. No entanto, note que as taxas não são equivalentes. Façam-se as taxas equivalentes de $10 \%$ a.m. $e$ $30 \%$ a.t.

Deseja-se descobrir uma taxa de $I$ a.m. equivalente à taxa $i$ de $30 \%$ a.t. Assim, se $M_{3}=C \cdot(1+I)^{3}$ e $m_{1}=C \cdot(1+i)^{1}$, deseja-se produzir $m_{1}=M_{3}$.

$$
\begin{aligned}
C \cdot(1+I)^{3} & =C \cdot(1+i)^{1} \\
(1+I)^{3} & =1,3 \\
(1+I) & =(1,3)^{\frac{1}{3}} \\
I & \approx 0,0914
\end{aligned}
$$

Portanto $9,14 \%$ a.m. equivale a $30 \%$ a.t. 
Mesmo raciocínio para descobrir uma taxa $I$ a.t. equivalente à taxa $i$ de $10 \%$ a.m.

$$
\begin{aligned}
C \cdot(1+I)^{1} & =C \cdot(1+i)^{3} \\
(1+I) & =(1,1)^{3} \\
I & =0,331
\end{aligned}
$$

Logo, a taxa de $10 \%$ a.m. é o mesmo que $33,1 \%$ a.t.

Teorema 3.2. Se a taxa de juros relativamente a um período de tempo é igual a $i$, a taxa de juros relativamente a n períodos de tempo é I tal que

$$
1+I=(1+i)^{n}
$$

Demonstração. Considere um investimento de $n$ períodos e uma taxa $i$ capitalizada periodicamente e deseja-se encontrar uma taxa equivalente $I$ capitalizada uma única vez. Estas taxas são equivalentes quando o montante gerado pelas duas taxas seja o mesmo. Assim, considere $M$ o montante gerado por $I$ e $m$ o montante gerado pela taxa $i$. Assim, $M=m$, então:

$$
\begin{aligned}
M & =m \\
C \cdot(1+I) & =C \cdot(1+i)^{n} \\
1+I & =(1+i)^{n}
\end{aligned}
$$

Exemplo 3.17. Um banco cobra taxa de juros de 12\% a.m. Qual será a taxa equivalente ao ano?

\section{Solução.}

A taxa $i$ de $12 \%$ a.m. equivale à taxa $I$ a.a. Assim, pela fórmula $3.8,1+I=$ $(1+0,12)^{12}, \log \mathrm{I} \approx 2,9=290 \%$ a.a..

Exemplo 3.18. Lena investe seu dinheiro a juros de $15 \%$ a.a., capitalizado mensalmente. Qual a taxa anual de juros?

\section{Solução.}

Como a capitalização é mensal e a taxa de juros é anual, cobra-se uma taxa de juros de $\frac{15 \%}{12}=1,25 \%$ a.m. Assim, para determinar a taxa $I$ a.a. equivalente à taxa $i$ a.m., tem-se: $1+I=(1+0,0125)^{12}$, ou seja, $I \approx 16,075 \%$ a.a. 


\subsection{Estudo de Casos}

A Matemática Financeira da maneira como é abordada hoje na Educação Básica, não consegue cumprir seu principal papel, ou seja, aplicar seus conceitos a situações do cotidiano. Não mostra a aplicação na realidade do aluno que não é preparado para tomar decisões de maneira consciente.

Serão apresentados alguns casos que podem inspirar várias outras situações problema a fim de enriquecer o curso de Matemática Financeira.

\subsubsection{Cartão de crédito}

O cartão de crédito é hoje o meio mais utilizado para pagamento de compras e movimenta grande parcela das vendas. Seguem algumas informações sobre cartões de crédito disponibilizadas pelo Banco Central do Brasil ${ }^{1}$.

Os serviços de pagamentos vinculados a cartão de crédito emitidos por instituições financeiras ou instituições de pagamento estão sujeitos à regulamentação baixada pelo Conselho Monetário Nacional e pelo Banco Central do Brasil, nos termos dos arts. $4^{\circ}$ e 10 da Lei 4.595, de 1964, e da Lei 12.865, de 2013.

Os bancos podem cobrar basicamente cinco tarifas referentes à prestação de serviços de cartão de crédito, considerados serviços essenciais: anuidade, emissão de segunda via do cartão, pelo seu uso no saque em espécie, pelo seu uso para pagamento de contas (por exemplo, faturas e boletos de cobranças de produtos e serviços) e no pedido de avaliação emergencial do limite de crédito.

É permitido pagar um valor inferior ao valor total da fatura, observado que o pagamento mínimo é de $15 \%$ do seu total. É importante saber que ao não realizar o pagamento total da fatura, o cliente estará contratando uma operação de crédito, sujeita à cobrança de juros sobre o saldo não liquidado.

A tabela 3.1 é uma parcial da exibida no portal do Banco Central do Brasil, vide Referência [1].

Na figura 3.9 está uma imagem de fatura de cartão de crédito, com destaque em dois campos.

Problema 3.1. Estudando a tabela, qual a diferença entre as taxas anuais equivalentes do banco com maior taxa de juros e o banco de menor taxa?

Solução. Calculando as taxas equivalentes dos bancos de maior taxa (Cetelem) como $I_{c}$ e de menor taxa (Banco Semear) como $I_{s}$, considere as respectivas taxas mensais: $i_{c}$ e $i_{s}$.

\footnotetext{
${ }^{1}$ Vide Referência [1]
} 


\begin{tabular}{|c|l|c|}
\hline Posição & Instituição & taxa de juros a.m. \\
\hline 1 & Banco Semear & 1,44 \\
\hline 7 & Caixa Econômica Federal & 5,47 \\
\hline 10 & Banco do Nordeste do Brasil S.A. & 8,43 \\
\hline 11 & Banco do Estado do RS S.A. & 9,64 \\
\hline 12 & Banco do Brasil & 10,46 \\
\hline 23 & Banco Santander (Brasil) S.A. & 14,54 \\
\hline 28 & Banco Bradesco S.A. & 15,00 \\
\hline 44 & Itaú Unibanco BM S.A. & 17,95 \\
\hline 48 & Banco Cetelem S.A. & 19,29 \\
\hline
\end{tabular}

Tabela 3.1: Trecho retirado de [1] taxas de Cartões de Crédito

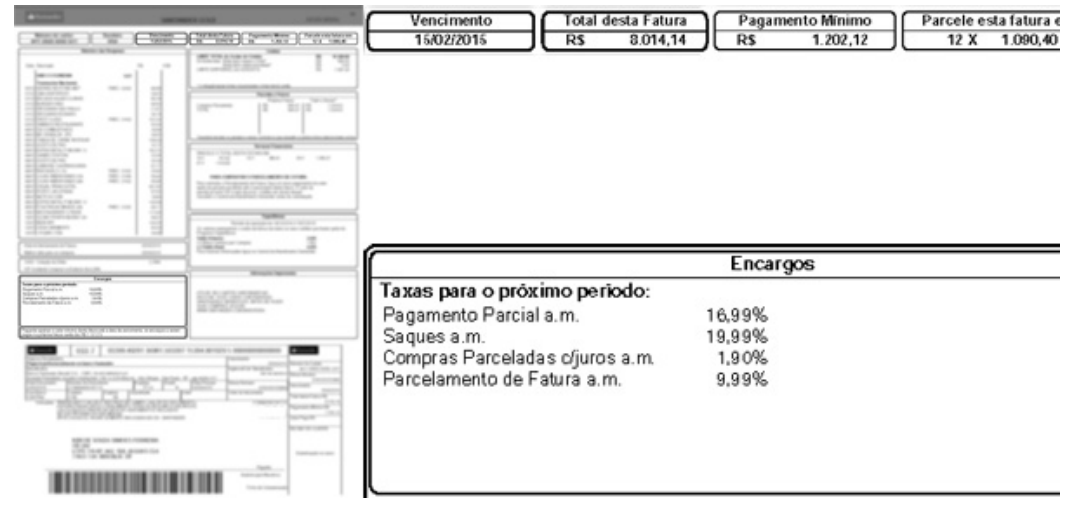

Figura 3.9: Exemplo de imagem de fatura de cartão de crédito

Assim, $I_{s}+1=(1+0,0144)^{12} \Rightarrow I_{s} \approx 18,72 \%$ e $I_{c}+1=(1+0,1929)^{12} \Rightarrow I_{c} \approx 730,32 \%$. Logo, comparando as taxas equivalentes, $\frac{I_{c}}{I_{s}}=39=3900 \%$. Logo, a taxa anual cobrada pelo banco Cetelem é 39 vezes maior que a cobrada no banco Semear (ou 3.900\%).

Problema 3.2. Lima é cliente do Banco Itaú Unibanco (posição 44 na tabela) e a fatura do cartão de crédito é de $R \$ 8.000,00$. Como receberia uma boa quantia em três meses, conseguiu um empréstimo, em outro banco, para pagar em 90 dias a juros de 3\% a.m. Quanto o cliente economizou com esta decisão?

\section{Solução.}

Calculam-se as dívidas nos dois casos: deixar a dívida do cartão de crédito $\left(M_{i}\right)$ ou tomar um empréstimo para quitar a dívida $\left(M_{e}\right)$. 
$1^{\circ}$ caso: Pagando a fatura em atraso após 3 meses, o montante será dado por:

$$
\begin{aligned}
& M_{i}=8000 \cdot(1+0,1795)^{3} \\
& M_{i}=13127,55
\end{aligned}
$$

$2^{\circ}$ caso: Tomando um empréstimo para quitar a dívida após 3 meses:

$$
\begin{aligned}
& M_{e}=8000 \cdot(1+0,03)^{3} \\
& M_{e}=8741,81
\end{aligned}
$$

Note que, fazendo o empréstimo, Lima terá uma economia de $\mathrm{R} \$$ 4.385,74 (dado por $\left.M_{i}-M_{e}\right)$.

Problema 3.3. Um cliente recebeu a fatura exibida na figura 3.9. O valor desta conta é de $R \$$ 8.014,14. Se ele decidir pagar o valor minimo (equivalente a 15\% da fatura), gerando uma cobrança de 16,99\% a.m. para o crédito rotativo, quitando o débito ao final do $3^{\circ}$ mês, qual será seu gasto final e a taxa de juros mensal equivalente ao valor pago? Faça uma comparação com o caso de inadimplência que o cliente deve pagar $15 \%$ a.m. de juros.

\section{Solução.}

No mês 0 (à vista) o pagamento mínimo é de $\mathrm{R} \$ 1.202,12$ (equivalente a $15 \%$ de $\mathrm{R} \$$ $8.014,14)$, transferindo a dívida de $\mathrm{R} \$ 6.812,02$ para o mês seguinte.

mês 1 O valor da nova fatura é de $6812,02 \cdot(1+0,1699)=7969,38$. Após o pagamento do valor mínimo de $\mathrm{R} \$ 1.195,40$ sobram $\mathrm{R} \$ 6.773,97$ para o mês seguinte.

mês $2 \mathrm{O}$ valor da nova fatura é de $6773,97 \cdot 1,1699=7924,87$. Após o pagamento do valor mínimo de $\mathrm{R} \$ 1.188,73$, tendo $\mathrm{R} \$ 6.736,14$ para o último mês.

mês $3 \mathrm{O}$ valor da fatura que será liquidada é de $6736,14 \cdot 1,1699=7880,61$, efetuando este pagamento o cliente tem um gasto total de:

$$
1202,12+1195,40+1188,73+7880,61=11466,86
$$

Comparando com o valor original da fatura, o valor pago foi aproximadamente $43 \%$ maior que a inicial. Considerando $I$ a taxa trimestral (43\%) e $i$ a taxa mensal, 
tem-se pela fórmula 3.8:

$$
\begin{aligned}
1+I & =(1+i)^{3} \\
1,43 & =(1+i)^{3} \\
i & =0,12662317
\end{aligned}
$$

Aproximadamente $12,662 \%$ de juros. Note que a taxa de juros cobrada não ficou muito distante do caso da inadimplência, 15\% (situação que o cliente pagaria uma vez ao final do $3^{\circ}$ mês).

\subsubsection{Cheque Especial}

Segundo o Banco Central (vide Referência [2]), o cheque é uma ordem de pagamento à vista e um título de crédito.

A operação com cheque envolve três agentes:

O emitente (emissor ou sacador), que é aquele que emite o cheque;

O beneficiário, que é a pessoa a favor de quem o cheque é emitido;

O sacado, que é o banco onde está depositado o dinheiro do emitente.

O chamado cheque especial é um produto que decorre de uma relação contratual em que é fornecida ao cliente uma linha de crédito para cobrir cheques que ultrapassem o valor existente na conta. O banco cobra juros por esse empréstimo.

Também, retirado do site do Banco Central do Brasil (vide Referência [3]) a taxa de juros cobrada por algumas principais instituições financeiras do país, apresentadas na tabela 3.2 .

Problema 3.4. Fernanda tem conta em dois bancos: Banco Santander (posição 29 da tabela 3.2) e Caixa Econômica (posição 17 da tabela 3.2). No Banco Santander tem uma divida de $R \$ 12.000,00$ no cheque especial. Ao vender seu carro, vai receber em quatro meses a quantia de $R \$ 15.000,00$. Decidiu fazer uma transferência da dívida, passando a quantia de $R \$ 12.000,00$ da conta na Caixa para o Banco Santander, ficando com o cheque especial total para pagamento em quatro meses na conta da Caixa. Qual será a economia que terá feito com esta decisão?

\section{Solução.}

Calculando as dívidas nos dois casos, cheque especial do Santander ou usar o cheque especial da Caixa. 


\begin{tabular}{|c|l|c|}
\hline Posição & Instituição & taxa de juros a.m. \\
\hline 1 & Banco Indusval S.A. & 1,94 \\
\hline 2 & Banco Sofisa S.A. & 2,03 \\
\hline 14 & Banco de Brasília S.A. - BRB & 6,51 \\
\hline 17 & Caixa Econômica Federal & 7,89 \\
\hline 20 & Banco do Brasil & 9,15 \\
\hline 24 & Itaú Unibanco S.A. & 10,06 \\
\hline 25 & Banco Bradesco S.A. & 10,08 \\
\hline 27 & HSBC Bank Brasil & 12,70 \\
\hline 29 & Banco Santander S.A. & 13,28 \\
\hline
\end{tabular}

Tabela 3.2: Trecho retirado de [2] taxas de Cheques Especiais

$1^{\circ}$ caso: Deixando o valor no cheque especial do Santander $\left(M_{s}\right)$, a dívida em 4 meses será de: $M_{s}=12000 \cdot(1+0,1328)^{4}=19.760 .33$.

$2^{\circ}$ caso: Transferindo a dívida para o cheque especial da Caixa $\left(M_{c}\right)$, a dívida em 4 meses será de: $M_{c}=12000 \cdot(1+0,0789)^{4}=16.259,45$.

Note que a economia foi de $\mathrm{R} \$ 3.500,88\left(M_{s}-M_{c}\right)$ ou de aproximadamente $29,17 \%$ da dívida.

Problema 3.5. Quais as taxas anuais equivalentes dos bancos BRB (posição 14) e HSBC (posição 27)? Faça as comparações entre as taxas dos bancos.

Solução. Calculando as taxas equivalentes dos bancos BRB (Banco de Brasília) como $I_{b}$ e do banco HSBC como $I_{h}$, tem-se, $I_{b}+1=(1+0,0651)^{12} \Rightarrow I_{b} \approx 113,15 \%$ a.a. e $I_{h}+1=(1+0,1270)^{12} \Rightarrow I_{h} \approx 319,84 \%$ a.a.. Logo, comparando as taxas equivalentes,

$$
\frac{I_{h}}{I_{b}} \approx 2,827=282,7 \%
$$

Ou seja, a taxa do banco HSBC é maior que o dobro da taxa anual do banco BRB.

As taxas de cheque especial praticadas pelas instituições financeiras levam muitas vezes o cliente a apelar a uma forma de taxa diminuída, o empréstimo pessoal, consignado ou outra modalidade.

Problema 3.6 (Empréstimo x Cheque Especial). Gustavo, cliente do Banco Bradesco (posição 25 da tabela 3.2), tem uma divida de $R \$ 5.000,00$ no cheque especial. Recebendo uma oferta de empréstimo de um familiar a uma taxa de 2,5\% a.m. Qual será a economia sabendo que tem $R \$ 1.200,00$ para pagar por mês? 


\section{Solução.}

Façam-se dois casos, no primeiro Gustavo usará mensalmente a quantia de $\mathrm{R} \$ 1.200,00$ para abater a dívida de cheque especial no banco Itau, cuja taxa é de 10,08\% a.m..

$1^{\circ}$ caso: Gustavo paga $\mathrm{R} \$ 1.200,00$ para quitar o cheque especial. Assim,

mês 0: $\quad$ a dívida será de $5.000-1.200=3.800$

mês 1: a dívida sofreu aumento de 10,06\%, então após o pagamento, $3.800 \cdot(1,1008)$, subtraído o pagamento de $\mathrm{R} \$ 1200,00$, a dívida fica em $\mathrm{R} \$ 2.983,04$.

mês $2: \quad$ a dívida será de $2.983,04 \cdot(1,1008)-1200=2.083,73$.

mês 3: a dívida será de $2.083,73 \cdot(1,1008)-1200=1.093,76$.

mês 4: a dívida será de $1.093,76 \cdot(1,1008)-1200=1.204,01$.

mês 5: $\quad$ a dívida será de $1.204,01 \cdot(1,1008)-1200=125,37$.

mês 6: a dívida será de 125,37, após pagamento terá sobrado $\mathrm{R} \$ 1.074,63$ no sexto mês.

Logo, ao final de 6 meses Gustavo gastará $\mathrm{R} \$ 7.325,37$.

$2^{\circ}$ caso: Gustavo paga $\mathrm{R} \$ 1.200,00$ como primeira parcela do empréstimo.

mês 0: a dívida será de $5.000-1.200=3.800$

mês 1: a dívida sofreu aumento de $2,5 \%$. Então, após o pagamento, $3.800 \cdot(1,025)-$ $1200=2.695,00$.

mês 2: $\quad$ a dívida será de $2.695,00 \cdot(1,025)-1200=1.562,37$.

mês 3: $\quad$ a dívida será de $1.562,37 \cdot(1,025)-1200=401,42$.

mês 4: a dívida sofreu aumento de $2,5 \%$, passando a ser de $\mathrm{R} \$ 411,45$. Com o pagamento de $\mathrm{R} \$ 1.200,00$, sobram 788,55 . Neste caso, Gustavo gastaria um total de $\mathrm{R} \$$ $5.211,45$.

Comparando os gastos nos dois casos, tem-se $\frac{5211,45}{7325,37}=0,7114248154018159$, que é aproximadamente $28,85 \%$ de economia se escolher o segundo caso ao invés do primeiro. 


\section{Capítulo}

\section{O dinheiro no tempo: empréstimos e financiamentos}

A operação fundamental da Matemática Financeira é o empréstimo. Uma pessoa ou instituição de posse de um capital $C$ o empresta a outro por certo número de períodos de tempo, recebendo, ao final, o capital acrescido dos juros, chamado de Montante. Este é representado por M. A razão $i=\frac{J}{M}$ é a taxa constante, sempre referida ao período da operação, chamada taxa de juros.

Como os montantes $\left(C_{n}\right)$ de cada período formam uma PG, conforme o estudo apresentado nos capítulos 2 e 3 , é possível encontrar um termo posterior a partir de um anterior e vice-versa.

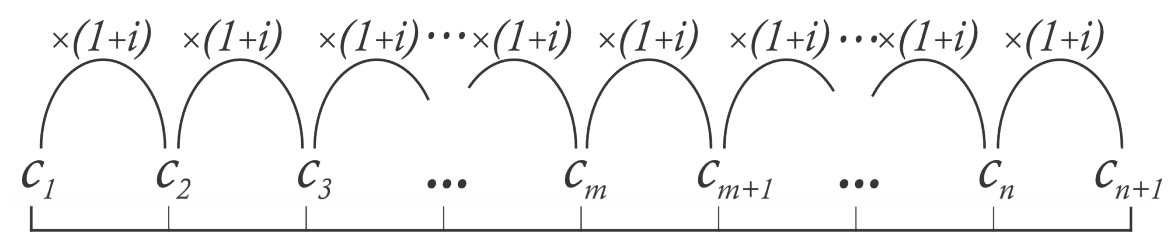

Figura 4.1: Montantes a cada período

Note que: 


$$
\begin{aligned}
C_{n} & =C_{0} \cdot(1+i)^{n} \Rightarrow C_{0}=\frac{C_{n}}{(1+i)^{n}} \\
C_{5} & =C_{2} \cdot(1+i)^{3} \Rightarrow C_{2}=\frac{C_{5}}{(1+i)^{3}} \\
C_{10} & =C_{4} \cdot(1+i)^{6} \Rightarrow C_{4}=\frac{C_{10}}{(1+i)^{6}} \\
C_{n} & =C_{m} \cdot(1+i)^{n-m} \Rightarrow C_{m}=\frac{C_{n}}{(1+i)^{n-m}}
\end{aligned}
$$

\subsection{Valor Atual e Valor Futuro}

É importante perceber que o problema fundamental da Matematica Financeira é o deslocamento do dinheiro no tempo, ou seja, observar que o valor de uma quantia depende da época a que está referida. Daqui a um ano, R \$ 100,00 não terão o mesmo valor de hoje. A partir de um investimento certo que rende 5\% a.m. é possível notar que pagando hoje $\mathrm{R} \$ 100,00, \mathrm{R} \$ 105,00$ daqui a um mês ou $\mathrm{R} \$ 110,25$ daqui a dois meses não haverá diferença no valor, mesmo que se refiram a épocas diferentes.

Enfatizando esta abordagem neste capítulo, será usada a partir deste ponto a seguinte notação: $A$ : valor atual (equivalente ao Capital) e $F$ : valor futuro (em substituição ao Montante).

Exemplo 4.1. Henrique tomou um empréstimo de $R \$ 4.000,00$ a juros de $5 \%$ a.m. Um mês depois pagou $R \$ 2.000,00$ e no terceiro mês liquidou sua dívida. Qual o valor do último pagamento?

\section{Solução.}

Os esquemas a seguir são equivalentes, $\mathrm{R} \$ 4.000,00$ hoje equivalem à soma das parcelas de $\mathrm{R} \$ 2.000,00$ e $P$ (veja a figura 4.2 ).

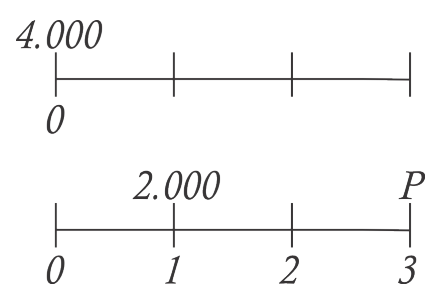

Figura 4.2: Deslocando as parcelas para a data 0

Assim, para igualar os dois esquemas, deslocam-se todas as parcelas para uma mesma 
data, por exemplo, a data 0 . Como a taxa $i=0,05$, tem-se:

$$
\begin{aligned}
4000 & =\frac{2000}{1+0,05}+\frac{P}{(1+0,05)^{3}} \\
4000 \cdot(1,05)^{3} & =2000 \cdot(1,05)^{2}+P \\
P & =2425,50
\end{aligned}
$$

Logo, o pagamento final foi de $\mathrm{R} \$ 2.425,50$.

Observação 4.1. Para obter o valor futuro, basta multiplicar o valor atual por $(1+i)^{n}$, isto é, $F=A \cdot(1+i)^{n}$, sendo $n$ o número de períodos para "chegar" ao valor futuro. Analogamente, para encontrar o valor atual basta dividir o valor futuro por $(1+i)^{n}$.

Para a resolução do exemplo, pode se deslocar todas as quantias para qualquer data, para a data 1 , por exemplo, tem-se:

$$
\begin{aligned}
4000 \cdot(1,05) & =2000+\frac{P}{(1,05)^{2}} \\
P & =2425,50
\end{aligned}
$$

Note que a quantia de $\mathrm{R} \$ 4.000,00$ foi deslocada em um mês à frente e $P$ retrocedeu em dois meses.

Assim, deslocando todas as parcelas e valores para o mesmo período, é possível comparar os valores.

Exemplo 4.2. Uma loja oferece duas opções de pagamento:

(i) à vista com $10 \%$ de desconto;

(ii) em duas prestações mensais iguais, sem desconto, a primeira sendo paga no ato da compra.

Qual a taxa de juros embutidos na venda a prazo?

\section{Solução.}

Considerando o valor do produto como $V$, faz-se o esquema ilustrado na figura 4.3.

Assim, deslocando as parcelas para a data 0, tem-se:

$$
\begin{aligned}
\frac{V}{2}+\frac{1}{(1+i)} \cdot \frac{V}{2} & =0,9 \mathrm{~V} \\
\frac{V(2+i)}{2 \cdot(1+i)} & =0,9 \mathrm{~V} \\
i & =\frac{1}{4}=25 \%
\end{aligned}
$$




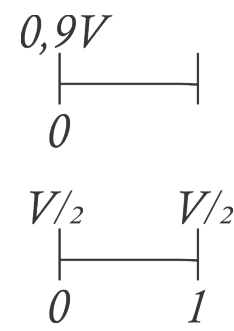

Figura 4.3: Opções de pagamento (exemplo 4.2)

Nesta condição de pagamento está embutida uma taxa de $25 \%$ a.m..

\subsection{Financiamentos}

Um conjunto de quantias é chamado de renda, série ou anuidade. A estas quantias é dado o nome de pagamentos ou termos. Caso os pagamentos sejam iguais, a série é dita uniforme.

A modalidade financeira na qual se divide um determinado valor emprestado em vários pagamentos é chamada como financiamento. Observe a figura 4.4.

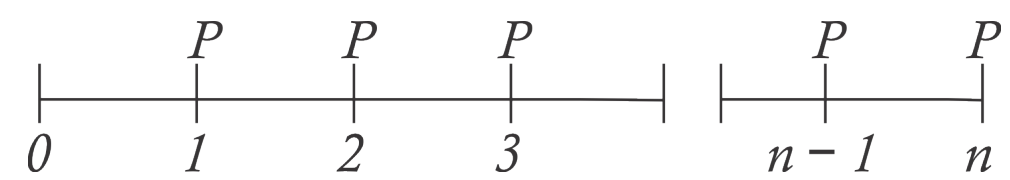

Figura 4.4: Deslocando as parcelas para a data 0 encontra-se o valor atual

Teorema 4.1. ${ }^{1}$ O valor de uma série uniforme de $n$ pagamentos iguais a $P$, uma unidade de tempo antes do primeiro pagamento, é, sendo $i$ a taxa de juros, igual a

$$
A=\frac{P \cdot\left[1-(1+i)^{-n}\right]}{i}
$$

Demonstração. A é o valor atual, equivale à soma de todas as parcelas deslocadas para a data 0. Assim,

$$
\begin{aligned}
A & =P \cdot(1+i)^{-1}+P \cdot(1+i)^{-2}+P \cdot(1+i)^{-3}+\cdots+P \cdot(1+i)^{-n} \\
& =P \cdot(1+i)^{-1} \cdot\left[1+(1+i)^{-1}+(1+i)^{-1}+\cdots+(1+i)^{-n+1}\right]
\end{aligned}
$$

Note que $A$ equivale à soma dos termos de uma $\mathrm{PG}$ decrescente de primeiro termo $P$. $(1+i)^{-1}$ e razão $(1+i)^{-1}$. Da fórmula dos termos de uma PG decrescente (fórmula 2.6,

\footnotetext{
${ }^{1}$ Retirado de [7]
} 
página 40), tem-se:

$$
\begin{aligned}
S_{n} & =\frac{a_{1} \cdot\left(1-q^{n}\right)}{1-q} \\
A & =\frac{P \cdot(1+i)^{-1} \cdot\left[1-(1+i)^{-n}\right]}{1-\frac{1}{1+i}} \\
A & =\frac{P}{1+i} \cdot \frac{1-(1+i)^{-n}}{1} \cdot \frac{1+i}{i} \\
A & =\frac{P \cdot\left[1-(1+i)^{-n}\right]}{i}
\end{aligned}
$$

Corolário 4.1. ${ }^{2}$ O valor de uma série uniforme na época do último pagamento é:

$$
F=\frac{P \cdot\left[(1+i)^{n}-1\right]}{i}
$$

Demonstração. Da fórmula do montante (fórmula 3.6, pág. 53), $F=A \cdot(1+i)^{n}$. Da fórmula 4.1, $A=\frac{P \cdot\left[1-(1+i)^{-n}\right] \cdot(1+i)^{n}}{i}$, então: $F=\frac{P \cdot\left[(1+i)^{n}-1\right]}{i}$

Observação 4.2. As fórmulas apresentadas acima podem ser omitidas, caso se trabalhe com este assunto como uma aplicação da soma dos termos de uma Progressão Geométrica.

Exemplo 4.3. Felipe deseja comprar um carro em 6 meses. Para isso recebeu duas propostas de venda, em uma delas ele poderia pagar o carro em seis prestações de $R \$$ 4.000,00 a juros de 4\% a.m.. Na segunda opção de pagamento Felipe poderia pagar o valor total ao final dos seis meses.

(a) Qual o valor do carro à vista?

(b) Qual o valor do carro ao final dos 6 meses?

\section{Solução por PG.}

Considere o esquema da figura 4.5 para resolução do exemplo.

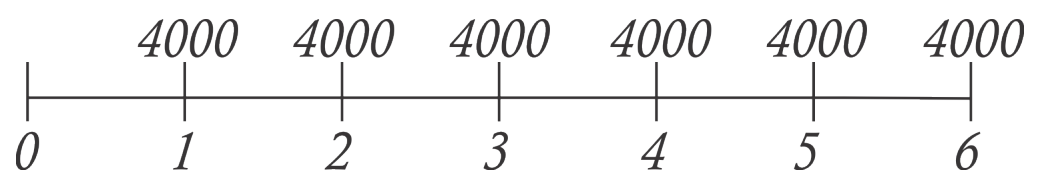

Figura 4.5: Deslocando as parcelas para as datas 0 (valor atual) e 6 (valor futuro)

\footnotetext{
${ }^{2}$ Retirado de [7]
} 
(a) Deseja-se saber o valor do carro à vista, ou seja, o valor atual da série de pagamentos.

$$
\begin{aligned}
& A=\frac{4000}{1,04}+\frac{4000}{(1,04)^{2}}+\frac{4000}{(1,04)^{3}}+\frac{4000}{(1,04)^{4}}+\frac{4000}{(1,04)^{5}}+\frac{4000}{(1,04)^{6}} \\
& A=3846,15+3698,22+3555,98+3419,21+3287,70+3161,25 \\
& A \approx 20968,55
\end{aligned}
$$

O valor atual será de $\mathrm{R} \$ 20.968,55$. Usando a fórmula 2.8 da página 42 , da soma dos termos de uma $\mathrm{PG}, S_{n}=\frac{a_{1} \cdot\left(1-q^{n}\right)}{1-q}$, encontra-se a fórmula equivalente à 4.1 do valor atual.

(b) Para encontrar o valor ao final do prazo, valor futuro, considera-se uma PG de razão $q=1,04$, ou seja, deslocando a primeira parcela para a última data, ela sofre cinco aumentos sucessivos, enquanto a segunda parcela quatro e assim sucessivamente.

$$
\begin{aligned}
& F=4000 \cdot\left[1+1,04+(1,04)^{2}+(1,04)^{3}+(1,04)^{4}+(1,04)^{5}\right] \\
& F=26531,90
\end{aligned}
$$

O valor futuro será de $\mathrm{R} \$ 26.531,90$.

\section{Solução pelas fórmulas 4.1 e 4.2}

O valor atual é dado por: $A=\frac{P \cdot\left[1-(1+i)^{-n}\right]}{i}=\frac{4000 \cdot\left[1-(1+0,04)^{-6}\right]}{0,04}, \log$, $A=20968,55$

O valor futuro é dado por $F=\frac{P \cdot\left[(1+i)^{n}-1\right]}{i}=\frac{4000 \cdot\left[(1+0,04)^{6}-1\right]}{0,04}$, logo, $F=26531,90$.

Exemplo 4.4. Um investidor transfere em sua aplicação financeira, ao fim de cada mês, a importância de R\$2.500,00, a juros de 2\% a.m. Quanto terá acumulado ao final do ano?

\section{Solução.}

Deseja-se saber o valor futuro, vide figura 4.6.

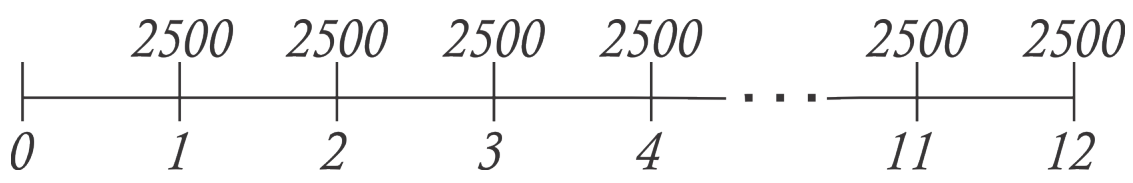

Figura 4.6: Deslocam-se as parcelas para o período 12 (valor futuro)

Pela fórmula $4.2, F=\frac{P \cdot\left[(1+i)^{n}-1\right]}{i}=\frac{2500 \cdot\left[(1,02)^{12}-1\right]}{0,02}$, logo, o valor retirado ao final da aplicação será de $\mathrm{R} \$ 33.530,22$. 
Exemplo 4.5 (AUDITOR FISCAL DA PREVIDENNCIA SOCIAL). Obtenha o valor mais próximo da quantia que deve ser depositada ao fim de cada mês, considerando uma taxa de rendimento de $2 \%$ a.m., juros compostos, com o objetivo de se obter $R \$ 50.000,00$ ao fim de dez meses.

(a) $R \$ 5.825,00$

(b) $R \$ 5.000,00$

(c) $R \$ 4.782,00$

(d) $R \$ 4.566,00$

(e) $R \$ 3.727,00$

\section{Solução.}

Sabe-se o valor Futuro $(F=50000)$, a taxa $(i=0,02)$ e o número de períodos $(n=10)$. Deseja-se descobrir o valor do pagamento $P$.

Pela fórmula 4.2, usada para cálculo do valor futuro, tem-se:

$$
\begin{aligned}
F & =\frac{P \cdot\left[(1+i)^{n}-1\right]}{i} \\
50000 & =\frac{P \cdot\left[(1+0,02)^{10}-1\right]}{0,02} \\
P & \approx 4566,32
\end{aligned}
$$

Logo, a opção correta é a letra (d).

Os esquemas adotados nos exemplos de financiamento indicam que o cliente tem um saldo devedor (dívida) que deve ser abatido (amortizado) até o fim do tempo total.

Os sistemas de financiamento mais praticados no mercado brasileiro são o Sistema de Amortização Constante (SAC) e o Sistema Francês, também chamado Tabela Price.

No Sistema de Amortização constante, os pagamentos decrescem de forma suave a cada período, enquanto na Tabela Price, as prestações são constantes.

Para análise dos dois casos torna-se necessário o uso de planilhas, sendo ferramentas de grande importância aplicativos editores de planilhas eletrônicas como o Microsoft Excel (pago) ou o BrCalc do BrOffice (distribuição gratuita).

\subsubsection{Sistema de Amortização Constante(SAC)}

No Sistema de Amortização Constante o saldo devedor é dividido em partes iguais, sendo abatida (amortizada) cada uma delas por pagamento. Assim, a cobrança de juros 
sobre o saldo devedor diminui a cada pagamento, o que provoca uma redução gradativa das parcelas.

Exemplo 4.6. Uma dívida de $R \$ 100,00$ é paga com juros de $10 \%$ a.m., em cinco meses, pelo SAC. Faça a planilha de amortização.

\section{Solução.}

Como as amortizações são iguais, em cada parcela será abatido o equivalente a $\frac{1}{5}$ da dívida inicial (Saldo Devedor no mês 0). Considere a tabela dada a seguir, onde $D_{k}$ representa o saldo devedor no período $k, A_{k}$ valor de abatimento da parcela $k, J_{k}$ o valor pago de juros e $P_{k}$ o valor da parcela no período $k$.

\begin{tabular}{|r|c|c|r|r|}
\hline $\mathrm{k}$ & $D_{k}$ & $A_{k}$ & $J_{k}\left(10 \%\right.$ de $\left.D_{k-1}\right)$ & $P_{k}\left(A_{k}+J_{k}\right)$ \\
\hline 0 & 100 & - & - & - \\
\hline 1 & 80 & 20 & $10 \%$ de $100: 10,00$ & $20+10=30$ \\
\hline 2 & 60 & 20 & $10 \%$ de $80: 8,00$ & $20+8=28$ \\
\hline 3 & 40 & 20 & $10 \%$ de $60: 6,00$ & $20+6=26$ \\
\hline 4 & 20 & 20 & $10 \%$ de $40: 4,00$ & $20+4=24$ \\
\hline 5 & 0 & 20 & $10 \%$ de $20: 2,00$ & $20+2=22$ \\
\hline
\end{tabular}

Tabela 4.1: Planilha no Sistema SAC

Teorema 4.2 (Sistema de Amortização Constante). ${ }^{1}$ No SAC, sendo $n$ o número de pagamentos e $i$ a taxa de juros, $A_{k}=\frac{D_{0}}{n}, D_{k}=\frac{n-k}{n} \cdot D_{0}, J_{k}=i \cdot D_{k-1}$ e $P_{k}=A_{k}+J_{k}$.

Demonstração. Se a dívida $D_{0}$ é amortizada em $n$ quotas iguais, cada quota vale $A_{k}=\frac{D_{0}}{n}$ e o estado da dívida (saldo devedor), após $k$ amortizações, é $D_{k}=D_{0}-k \cdot A_{k}=D_{0} \cdot \frac{n-k}{n}$.

As duas últimas fórmulas são triviais.

Analisando o Exemplo 4.6, observa-se que pelo fato de a amortização ser constante, de $R \$ 20,00$, e a cada período a dívida (saldo devedor) é reduzida por esta parcela de amortização, os valores mensais das dívidas formam uma Progressão Aritmética de primeiro termo 100 e razão -20. Da mesma forma, os juros equivalem a 10\% das dívidas em cada período, ou seja, cada juro equivale a $10 \%$ de um termo de uma PA, assim, tem primeiro termo igual a 10 e razão -2. Assim os valores das parcelas também formam uma PA, sendo de primeiro termo 30 e razão -2 .

Considere as Progressões Aritméticas, iniciando no termo de índice 1.

\footnotetext{
${ }^{1}$ Retirado de [7]
} 


$$
\begin{aligned}
& D_{k}=\left(D_{1}, D_{2}, D_{3}, D_{4}, D_{5}\right)=(80,60,40,20,0) \\
& J_{k}=\left(J_{1}, J_{2}, J_{3}, J_{4}, J_{5}\right)=(10,8,6,4,2) \\
& P_{k}=\left(P_{1}, P_{2}, P_{3}, P_{4}, P_{5}\right)=(30,28,26,24,22)
\end{aligned}
$$

Verifique a mesma tabela do exemplo 4.6. Considere $A_{k}=A=20$.

\begin{tabular}{|r|c|c|c|r|}
\hline $\mathrm{k}$ & $D_{k}$ & $A_{k}$ & $J_{k}\left(10 \%\right.$ de $\left.D_{k-1}\right)$ & $P_{k}\left(A_{k}+J_{k}\right)$ \\
\hline 0 & 100 & - & - & - \\
\hline 1 & $D_{1}=100+\left(-A_{0}\right)$ & $A_{0}$ & $J_{1}=0,1 \cdot D_{0}=10,00$ & $P_{1}=J_{1}+A_{0}=10+A_{0}$ \\
\hline 2 & $D_{2}=100+2 \cdot\left(-A_{0}\right)$ & $A_{0}$ & $J_{2}=0,1 \cdot D_{1}=8,00$ & $P_{2}=J_{2}+A_{0}=8+A_{0}$ \\
\hline 3 & $D_{3}=100+3 \cdot\left(-A_{0}\right)$ & $A_{0}$ & $J_{3}=0,1 \cdot D_{2}=6,00$ & $P_{3}=J_{3}+A_{0}=6+A_{0}$ \\
\hline 4 & $D_{4}=100+4 \cdot\left(-A_{0}\right)$ & $A_{0}$ & $J_{4}=0,1 \cdot D_{3}=4,00$ & $P_{4}=J_{4}+A_{0}=4+A_{0}$ \\
\hline 5 & $D_{5}=100+5 \cdot\left(-A_{0}\right)$ & $A_{0}$ & $J_{5}=0,1 \cdot D_{4}=2,00$ & $P_{5}=J_{5}+A_{0}=2+A_{0}$ \\
\hline
\end{tabular}

Tabela 4.2: Note que os campos $D_{k}, J_{k}$ e $P_{k}$ formam PA's

Tratando as sequências $D_{k}, J_{k}$ e $P_{k}$, note que:

$D_{k}$ é uma progressão aritmética de $1^{\circ}$ termo $D_{1}=100-A$ e razão $\left(-A_{0}\right)$, assim, sua forma geral é dada por $D_{k}=\left(100-A_{0}\right)+(k-1)\left(-A_{0}\right)$.

$J_{k}$ é uma progressão aritmética de $1^{\circ}$ termo $J_{1}=10$ e razão $\left(-0,1 \cdot A_{0}\right)$, assim, seu termo geral é dada por $J_{k}=10+(k-1) \cdot\left(-0,1 \cdot A_{0}\right)$.

$P_{k}$ é uma progressão aritmética de $1^{\circ}$ termo 30 (ou seja, $P_{1}+A_{0}=10+A_{0}$ ) e razão $-A_{0}$. Seu termo geral é dado por $P_{k}=\left(10+A_{0}\right)+(k-1)\left(-0,1 \cdot A_{0}\right)$.

Teorema 4.3. Dado um financiamento no sistema de amortização constante (SAC), com amortização representada por $A_{k}=A_{0}=\frac{D_{0}}{n}$, sendo uma divida $D_{0}$ que será quitada em $n$ periodos a taxa de juros $i$. As dividas tomadas periodo a período, assim como os juros e o valor da prestação, são dadas, respectivamente, pelas fórmulas (considere $k \in \mathbb{N} e$ $k \leq n)$ :

$$
\begin{aligned}
D_{k} & =D_{1}+(k-1)\left(-A_{0}\right)=A_{0} \cdot(n-k) \\
J_{k} & =J_{1}+(k-1) \cdot\left(-A_{0} \cdot i\right)=A_{0} \cdot i \cdot(n-k+1) \\
P_{k} & =P_{1}+(k-1)\left(-A_{0} \cdot i\right)=A_{0} \cdot i \cdot(1+i+i n-i k)
\end{aligned}
$$

Demonstração. A essência deste teorema está no destaque dos juros, prestações e dívidas como Progressões Aritméticas. Logo, deseja-se mostrar que a dívida, o juro e a prestação de um período $k \in \mathbb{N}$ obedece a uma lei, ou seja, é um termo geral de uma PA.

Da demonstração do Teorema 4.2, tem-se: $D_{k}=D_{0}-k \cdot A_{k}$, como $k \in \mathbb{N}, D_{k}$ é uma sequência cujo termo geral é o de uma Progressão Aritmética. Considere $A_{k}=\frac{D_{0}}{n}=A_{0}$ 
e consequentemente $D_{0}=A_{0} \cdot n$.

Assim, como a dívida sofre periodicamente uma redução de $A_{0}$, é uma PA de $1^{\circ}$ termo $D_{1}$, sendo $D_{1}=D_{0}-A_{0}=A_{0} \cdot n-A_{0}$ e termo geral $D_{k}=D_{1}+(k-1) \cdot\left(-A_{0}\right)$. Assim,

$$
D_{k}=D_{1}+(k-1) \cdot\left(-A_{0}\right)=A_{0} \cdot n-A_{0}+(k-1)\left(-A_{0}\right)=A_{0} \cdot(n-k)
$$

Como os juros de cada período referem-se à sua respectiva dívida do período anterior, formam uma PA de $1^{\circ}$ termo $J_{1}=i \cdot D_{0}=A_{0} \cdot i \cdot n$ e razão $-A_{0} \cdot i$. Assim,

$$
J_{k}=J_{1}+(k-1) \cdot\left(-A_{0} \cdot i\right)=A_{0} \cdot i \cdot(n-k+1)
$$

Como a prestação é a soma da amortização e o juro, e sendo os juros termos de uma PA de razão - ai e amortização constante igual a $A_{0}$, tem-se:

$$
\begin{aligned}
P_{k} & =J_{k}+A_{0}=A_{0} \cdot i \cdot(n-k+1)+A_{0} \\
P_{k} & =A_{0} \cdot i \cdot n-A_{0} \cdot i \cdot k+A_{0} \cdot i+A_{0} \\
P_{k} & =A_{0} \cdot(1+i+i n-i k)
\end{aligned}
$$

Observação 4.3. Cada uma das fórmulas foi apresentada em duas versões, usando a notação de PA e, a partir desta, uma fórmula simplificada, cabendo ao aluno escolher qual modelo seguir.

Observação 4.4. O último Teorema apresentado possibilita descobrir-se qual o valor de uma prestação qualquer de um financiamento, assim como a divida em determinado período e o juro cobrado, sem a necessidade da construção de planilhas.

Do teorema 4.3, conclui-se que as dívidas, prestações e juros formam progressões aritméticas. Como se conhece um meio de somar um número qualquer de termos de uma PA, demonstra-se o corolário dado a seguir.

Corolário 4.2. No $S A C$, a soma das $k$ primeiras parcelas $\left(S_{p, k}\right)$ e de seus respectivos juros $\left(S_{j, k}\right)$ em um financiamento de duração de $n$ períodos à taxa de juros i são dadas por:

$$
\begin{aligned}
S_{j, k} & =\frac{\left(j_{1}+j_{k}\right) \cdot k}{2}=\frac{A_{0} \cdot i \cdot k \cdot(2 n-k+1)}{2} \\
S_{p, k} & =S_{j, k}+A_{0} \cdot n=\frac{2 \cdot A_{0} \cdot n \cdot(i k+1)+A_{0} \cdot i \cdot k(1-k)}{2}
\end{aligned}
$$


Demonstração. Como os juros encontrados formam uma Progressão Aritmética, pela fórmula da Soma dos $n$ termos (fórmula 2.2), indicando a soma dos juros por $S_{j, k}$ e $S_{p, k}$, a soma das parcelas, tem-se:

$$
\begin{aligned}
S_{j, k} & =\frac{\left(J_{1}+J_{k}\right) \cdot k}{2}=\frac{\left[A_{0} \cdot i \cdot n+A_{0} \cdot i \cdot(n-k+1)\right] \cdot k}{2} \\
S_{j, k} & =\frac{A_{0} \cdot i \cdot k \cdot(2 n-k+1)}{2}
\end{aligned}
$$

Como a parcela $P_{k}=J_{k}+A_{0}$, a soma das parcelas equivale à soma dos juros $\left(S_{j, k}\right)$ adicionada à soma das amortizações $\left(A_{0} \cdot n=D_{0}\right)$. Logo,

$$
\begin{aligned}
S_{p, k} & =S_{j, k}+A_{0} \cdot n=\frac{A_{0} \cdot i \cdot k \cdot(2 n-k+1)}{2}+A_{0} \cdot n \\
S_{p, k} & =\frac{2 \cdot A_{0} \cdot i \cdot k \cdot n-A_{0} \cdot i \cdot k^{2}+A_{0} \cdot i \cdot k+2 \cdot A_{0} \cdot n}{2} \\
S_{p, k} & =\frac{2 \cdot A_{0} \cdot n \cdot(i k+1)+A_{0} \cdot i \cdot k \cdot(1-k)}{2}
\end{aligned}
$$

Nas fórmulas apresentadas no Corolário 4.2 encontra-se o total dos juros e das parcelas fazendo $k=n$. Assim, a soma total dos juros $\left(S_{j, n}\right)$ é dada por $S_{j, n}=\frac{A_{0} \cdot i \cdot n \cdot(n+1)}{2}$ e total das parcelas $S_{p, n}=\frac{A_{0} \cdot n \cdot(i n+i+2)}{2}$.

Exemplo 4.7. Fernanda deseja comprar uma casa no valor de $R \$ 450.000,00$. Como já possui $R \$ 300.000,00$, deseja financiar sua divida no sistema SAC, em 12 parcelas, à taxa de 3,2\% a.m.. Responda:

(a) Qual o valor da primeira e da última parcela?

(b) Qual o valor pago de juros na sexta parcela?

(c) Após finalizar o financiamento, qual o gasto total de juros e das parcelas?

\section{Solução pela planilha de amortização.}

Os valores das parcelas são dados na tabela 4.3 , verificando as colunas $J_{k}$ e $P_{k}$, responde-se aos itens.

(a) A primeira parcela é de $\mathrm{R} \$ 17.300,00$ e a última vale $\mathrm{R} \$ 12.900,00$.

(b) Na sexta parcela os juros equivalem a $\mathrm{R} \$ 2.800,00$.

(c) O gasto de Juros é de $\mathrm{R} \$ 31.200,00$ e das parcelas é de $\mathrm{R} \$ 181.200,00$. 


\begin{tabular}{|c|c|c|r|r|}
\hline $\mathrm{k}$ & $D_{k}$ & $A_{k}$ & $J_{k}$ & $P_{k}$ \\
\hline 0 & 150000 & - & - & - \\
\hline 1 & 137500 & 12500 & 4800 & 17300 \\
\hline 2 & 125000 & 12500 & 4400 & 16900 \\
\hline 3 & 112500 & 12500 & 4000 & 16500 \\
\hline 4 & 100000 & 12500 & 3600 & 16100 \\
\hline 5 & 87500 & 12500 & 3200 & 15700 \\
\hline 6 & 75000 & 12500 & 2800 & 15300 \\
\hline 7 & 62500 & 12500 & 2400 & 14900 \\
\hline 8 & 50000 & 12500 & 2000 & 14500 \\
\hline 9 & 37500 & 12500 & 1600 & 14100 \\
\hline 10 & 25000 & 12500 & 1200 & 13700 \\
\hline 11 & 12500 & 12500 & 800 & 13300 \\
\hline 12 & 0 & 12500 & 400 & 12900 \\
\hline total & - & 150000 & 31200 & 181200 \\
\hline
\end{tabular}

Tabela 4.3: Resolução do exemplo 4.7

\section{Solução pelo Teorema 4.3 e Corolário 4.2.}

Sabendo que as quantias de dívidas, juros e pagamentos são progressões aritméticas (Teorema 4.3), o uso das fórmulas apresentadas no Teorema 4.3 e Corolário 4.2 são suficientes para a resolução do exemplo.

(a) O valor da primeira parcela é dado por:

$$
\begin{aligned}
& P_{k}=J_{k}+A_{0} \\
& P_{1}=0,032 \cdot 150.000+\frac{150.000}{12}=17.300,00
\end{aligned}
$$

A última parcela é dada por $P_{12}$

$$
\begin{aligned}
P_{k} & =P_{1}+(k-1) \cdot\left(-A_{0} \cdot i\right) \\
P_{12} & =17300+(12-1) \cdot\left(-\frac{150000}{12} \cdot 0,032\right)=12900
\end{aligned}
$$

Ou, pelo uso da segunda fórmula no Teorema 4.3,

$$
\begin{aligned}
P_{k} & =A_{0} \cdot(1+i+i n-i k) \\
P_{12} & =12500 \cdot(1+0,032+0,032 \cdot 12-0,032 \cdot 12)=12900
\end{aligned}
$$


A primeira parcela saiu por $R \$ 17.300,00$, enquanto a última saiu por $R \$ 12.900,00$.

(b) O valor pago de juros na sexta parcela é dado por $J_{6}$, na resolução a seguir.

$$
\begin{aligned}
& J_{6}=J_{1}+5 \cdot\left(-A_{0} \cdot i\right)=A_{0} \cdot i \cdot n+5 \cdot\left(-A_{0} \cdot i\right) \\
& J_{6}=150000 \cdot 0,032 \cdot 12+5 \cdot(-150000 \cdot 0,032)=2800
\end{aligned}
$$

Ou, simplesmente, pela fórmula do Teorema 4.3,

$$
J_{6}=A_{0} \cdot i \cdot(n-k+1)=12500 \cdot 0,032 \cdot(12-12+1)=2800
$$

O valor gasto de juros na sexta parcela é de $\mathrm{R} \$ 2.800,00$.

(c) A soma dos juros é calculada por $S_{j, 12}$, assim, tem-se:

$$
S_{j, 12}=\frac{\left(J_{1}+J_{12}\right) \cdot 12}{2}
$$

Ou, pela fórmula 4.6 do Corolário 4.2 ,

$$
\begin{aligned}
S_{j, k} & =\frac{A_{0} \cdot i \cdot k \cdot(2 n-k+1)}{2} \\
S_{j, 12} & =\frac{12500 \cdot 0,032 \cdot 12 \cdot(2 \cdot 12-12+1)}{2} \\
S_{j, 12} & =31200
\end{aligned}
$$

A soma das parcelas equivale à soma dos termos de uma PA, ou simplesmente, à soma de todos os juros e todas as amortizações, assim, pelo Corolário 4.2, tem-se:

$$
\begin{aligned}
S_{p, k} & =S_{j, k}+A_{0} \cdot n \\
S_{p, k} & =31200+150000=181200
\end{aligned}
$$

Logo, a soma de todas as parcelas totalizaram $\mathrm{R} \$ 181.200,00$.

\subsubsection{Sistema Francês de Amortização (Tabela Price)}

Como apresentado anteriormente, neste sistema o valor da parcela é constante. Da fórmula, $D_{0}=\frac{P \cdot\left[1-(1+i)^{-n}\right]}{i}$, isolando a parcela $P$, tem-se:

$$
P=\frac{D_{0} \cdot i}{1-(1+i)^{-n}}
$$


Exemplo 4.8. Fazendo simulações de financiamentos de veículos, Leonardo encontra uma condição vantajosa. Com $10 \%$ de entrada para o valor do carro, pode financiar o restante em 36 meses a uma taxa promocional de 1\% a.m.. Qual o valor máximo pode financiar sendo que a parcela não deve ultrapassar $R \$ 1.200,00$ e que entrada deve ter?

Solução. Considerando uma parcela de $\mathrm{R} \$ 1.200,00$ em 36 vezes, à taxa de $1 \%$ a.m., tem-se:

$$
\begin{aligned}
P & =\frac{i \cdot D_{0}}{1-(1+i)^{-n}} \\
1200 & =\frac{0,01 \cdot D_{0}}{1-(1+0,01)^{-36}} \\
D_{0} & =\frac{1200 \cdot\left[1-(1,01)^{-36}\right]}{0,01} \\
D_{0} & =36129,00604
\end{aligned}
$$

O valor que Leonardo pode tomar para o financiamento é de aproximadamente $\mathrm{R} \$ 36.129,00$. Como deve dar 10\% de entrada, a dívida inicial deve ser de no máximo $90 \%$ do valor do automóvel $(x)$, assim:

$$
\begin{aligned}
0,9 x & =36129 \\
x & =40143,33
\end{aligned}
$$

O carro deve ter valor de no máximo $\mathrm{R} \$ 40.143,33$ e Leonardo deve ter de entrada $\mathrm{R} \$$ 4.014,33.

Exemplo 4.9. Uma divida de $R \$ 100,00$ é paga pelo sistema francês em 5 meses, com juros de $10 \%$ a.m.. Faça a planilha de amortização.

\section{Solução.}

Inicialmente calcula-se a prestação:

$$
P=\frac{D_{0} \cdot i}{1-(1+i)^{-n}}=\frac{100 \cdot 0,1}{1-(1+0,1)^{-5}}=26,38
$$

Em seguida, é construída a planilha de amortização, Tabela 4.4.

Teorema 4.4 (Sistema Francês de Amortização ${ }^{3}$ ). Considerando um financiamento de uma divida $D_{0}$, no sistema francês de amortização, sendo $i$ a taxa de juros e $n$ o número

\footnotetext{
${ }^{3}$ Retirado de [7]
} 


\begin{tabular}{|c|c|c|r|r|}
\hline $\mathrm{k}$ & $D_{k}$ & $A_{k}\left(P_{k}-J_{k}\right)$ & $J_{k}\left(10 \%\right.$ de $\left.D_{k-1}\right)$ & $P_{k}$ \\
\hline 0 & 100,00 & 0 & 0 & 0 \\
\hline 1 & 83,62 & 16,38 & 10,00 & 26,38 \\
\hline 2 & 65,60 & 18,02 & 8,36 & 26,38 \\
\hline 3 & 45,78 & 19,82 & 6,56 & 26,38 \\
\hline 4 & 23,98 & 21,80 & 4,58 & 26,38 \\
\hline 5 & 0,00 & 23,98 & 2,40 & 26,38 \\
\hline
\end{tabular}

Tabela 4.4: Resolução do exemplo 4.9

de pagamentos, tem-se:

$$
\begin{aligned}
P_{k} & =\frac{i \cdot D_{0}}{1-(1+i)^{-n}} \\
D_{k} & =\frac{D_{0} \cdot\left[1-(1+i)^{-(n-k)}\right]}{1-(1+i)^{-n}} \\
J_{k} & =i \cdot D_{k-1} \\
A_{k} & =P_{k}-J_{k}
\end{aligned}
$$

Demonstração. A primeira fórmula é simplesmente o teorema 4.1 e as duas últimas são triviais. Quanto à segunda, observe que a dívida $D_{k}$ será liquidada, por $n-k$ pagamentos, sucessivos iguais a $P_{k}$. Portanto, novamente pelo teorema 4.1, tem-se $\frac{P_{k} \cdot\left[1-(1+i)^{-(n-k)}\right]}{i}$.

Substituindo o valor de $P_{k}$, obtém-se a segunda fórmula.

No Sistema de Amortização Constante, verificou-se que as dívidas, os juros e as parcelas são progressões aritméticas, o que visivelmente não acontece na Tabela Price. No entanto, considere a planilha apresentada na tabela 4.5, baseado na tabela 4.4, comparando cada valor com seu antecessor.

Analisando os valores encontrados percebe-se que as dívidas e os juros não podem representar progressões geométricas. No entanto, o campo amortização sugere esta possibilidade.

Dado o teorema a seguir, verifica-se que as amortizações realmente formam uma Progressão Geométrica.

Para verificar se uma sequência realmente forma uma Progressão Geométrica deve-se ter a razão entre dois termos consecutivos sempre constante. Assim, considere: $A_{k-1}, A_{k}$ e $A_{k+1}$. 


\begin{tabular}{|c|c|c|r|r|}
\hline $\mathrm{k}$ & $D_{k+1} / D k$ & $A_{k+1} / A_{k}$ & $J_{k+1} / J_{k}$ & $P_{k+1} / P_{k}$ \\
\hline 1 & 0,8362 & 1,1001221 & 0,836 & 1 \\
\hline 2 & 0,784501315 & 1,099889012 & 0,784688995 & 1 \\
\hline 3 & 0,697865854 & 1,099899092 & 0,698170732 & 1 \\
\hline 4 & 0,523809524 & 1,1 & 0,524017467 & 1 \\
\hline
\end{tabular}

Tabela 4.5: Comparando as quantias mensais com suas antecessoras

$$
\begin{aligned}
A_{k-1} & =P_{k-1}-J_{k-1} \\
& =\frac{i \cdot D_{0}}{1-(1+i)^{-n}}-\frac{i \cdot D_{0} \cdot\left[1-(1+i)^{-(n-k+2)}\right]}{1-(1+i)^{-n}} \\
& =\frac{i \cdot D_{0} \cdot(1+i)^{-n+k-2}}{1-(1+i)^{-n}} \\
A_{k} & =P_{k}-J_{k} \\
& =\frac{i \cdot D_{0}}{1-(1+i)^{-n}}-\frac{i \cdot D_{0} \cdot\left[1-(1+i)^{-(n-k+1)}\right]}{1-(1+i)^{-n}} \\
& =\frac{i \cdot D_{0} \cdot(1+i)^{-n+k-1}}{1-(1+i)^{-n}} \\
& =P_{k+1}-J_{k+1} \\
A_{k+1} & \frac{i \cdot D_{0}}{1-(1+i)^{-n}}-\frac{i \cdot D_{0} \cdot\left[1-(1+i)^{-(n-k)}\right]}{1-(1+i)^{-n}} \\
& =\frac{i \cdot D_{0} \cdot(1+i)^{-n+k}}{1-(1+i)^{-n}}
\end{aligned}
$$

Fazendo as razões entre os termos consecutivos $A_{k} / A_{k-1}$ e $A_{k+1} / A_{k}$, tem-se:

$$
\begin{aligned}
\frac{A_{k}}{A_{k-1}} & =\left[\frac{i \cdot D_{0} \cdot(1+i)^{-n+k-1}}{1-(1+i)^{-n}}\right]:\left[\frac{i \cdot D_{0} \cdot(1+i)^{-n+k-2}}{1-(1+i)^{-n}}\right] \\
& =\frac{i \cdot D_{0} \cdot(1+i)^{-n+k-1}}{i \cdot D_{0} \cdot(1+i)^{-n+k-2}}=1+i \\
\frac{A_{k+1}}{A_{k}} & =\left[\frac{i \cdot D_{0} \cdot(1+i)^{-n+k}}{1-(1+i)^{-n}}\right]:\left[\frac{i \cdot D_{0} \cdot(1+i)^{-n+k-1}}{1-(1+i)^{-n}}\right] \\
& =\frac{i \cdot D_{0} \cdot(1+i)^{-n+k}}{i \cdot D_{0} \cdot(1+i)^{-n+k-1}}=1+i
\end{aligned}
$$


Como $\frac{A_{k}}{A_{k-1}}=\frac{A_{k+1}}{A_{k}}=1+i$, a sequência $A_{k}$ é uma Progressão Geométrica de razão $(1+i)$. Pelo Teorema 4.4,

$$
\begin{aligned}
A_{1} & =P-J_{1} \\
A_{1} & =P-i \cdot D_{0} \\
A_{1} & =\frac{i \cdot D_{0}}{1-(1+i)^{-n}}-i \cdot D_{0} \\
A_{1} & =\frac{i \cdot D_{0}}{1-(1+i)^{-n}} \cdot(1+i)^{-n}
\end{aligned}
$$

Como a prestação $P_{k}=\frac{i \cdot D_{0}}{1-(1+i)^{-n}}=P$ é fixa, pode-se escrever a parcela de amortização na forma: $A_{1}=P \cdot(1+i)^{-n}$

Teorema 4.5. Em um financiamento calculado pela tabela price, de taxa $i$, parcela $P$, de $n$ periodos são dadas as fórmulas:

$$
\begin{aligned}
A_{k} & =A_{1} \cdot(1+i)^{k-1} \\
A_{k} & =P \cdot(1+i)^{-n+k-1} \\
J_{k} & =P \cdot\left[1-(1+i)^{-n+k-1}\right] \\
D_{k} & =\frac{P}{i} \cdot\left[1-(1+i)^{k-n}\right]
\end{aligned}
$$

Demonstração. Como provado anteriormente, as amortizações formam uma progressão geométrica de primeiro termo $A_{1}=P \cdot(1+i)^{-n}$, como a razão desta PG é $(1+i)$, tem-se:

$$
\begin{aligned}
& A_{k}=A_{1} \cdot(1+i)^{k-1} \\
& A_{k}=P \cdot(1+i)^{-n+k-1}
\end{aligned}
$$

Assim, como $J_{k}=P-A_{k}$, pelo Teorema 4.4, tem-se:

$$
\begin{aligned}
& J_{k}=P-A_{k} \\
& J_{k}=P-P \cdot(1+i)^{-n+k-1} \\
& J_{k}=P \cdot\left[1-(1+i)^{-n+k-1}\right]
\end{aligned}
$$

Da mesma forma, pelo Teorema $4.4, D_{k}=D_{k-1}-A_{k}$ e a parcela $P$ é dada por $P=$ 
$\frac{i \cdot D_{0}}{1-(1+i)^{-n}}$. Assim

$$
\begin{aligned}
D_{k} & =D_{k-1}-A_{k} \\
& =D_{k-1}-\left(P-J_{k}\right) \\
& =D_{k-1}-P+i \cdot D_{k-1} \\
& =D_{k-1} \cdot(1+i)-P \\
& =\frac{D_{0}}{1-(1+i)^{-n}} \cdot(1+i) \cdot\left[1-(1+i)^{-n+k-1}\right]-P
\end{aligned}
$$

Como $P=\frac{i \cdot D_{0}}{1-(1+i)^{-n}} \Longrightarrow \frac{P}{i}=\frac{D_{0}}{1-(1+i)^{-n}}$. Assim,

$$
\begin{aligned}
& =\frac{P}{i} \cdot(1+i) \cdot\left[1-(1+i)^{-n+k-1}\right]-P \\
& =\frac{P+P \cdot i-P \cdot(1+i)(1+i)^{-n+k-1}-P \cdot i}{i} \\
& =\frac{P}{i} \cdot\left[1-(1+i)^{k-n}\right]
\end{aligned}
$$

Exemplo 4.10 (Revisitando o Exemplo 4.7). Fernanda deseja comprar uma casa no valor de $R \$$ 450.000,00. Como já possui $R \$$ 300.000,00, deseja financiar sua dívida no sistema frâncês de amortização, em 12 parcelas, à taxa de 3,2\% a.m.. Responda:

(a) Qual o valor das parcelas?

(b) Qual o valor pago de juros na sexta parcela?

(c) Qual a dívida após o pagamento da quinta parcela?

(d) Qual o valor de amortização da décima parcela?

\section{Solução pela planilha de amortização.}

Inicialmente calcula-se o valor da prestação.

$$
\begin{aligned}
P & =\frac{D_{0} \cdot i}{1-(1+i)^{-n}} \\
& =\frac{150.000 \cdot 0,032}{1-(1+0,032)^{-12}} \\
& =15249,78
\end{aligned}
$$

Para responder as perguntas basta conferir a tabela. 


\begin{tabular}{|c|c|c|r|r|}
\hline $\mathrm{k}$ & $D_{k}$ & $A_{k}$ & $J_{k}$ & $P_{k}$ \\
\hline 0 & $150.000,00$ & - & - & - \\
\hline 1 & $139.550,22$ & $10.449,78$ & $4.800,00$ & $15.249,78$ \\
\hline 2 & $128.766,04$ & $10.784,18$ & $4.465,61$ & $15.249,78$ \\
\hline 3 & $117.636,77$ & $11.129,27$ & $4.120,51$ & $15.249,78$ \\
\hline 4 & $106.151,36$ & $11.485,41$ & $3.764,38$ & $15.249,78$ \\
\hline 5 & $94.298,42$ & $11.852,94$ & $3.396,84$ & $15.249,78$ \\
\hline 6 & $82.066,18$ & $12.232,24$ & $3.017,55$ & $15.249,78$ \\
\hline 7 & $69.442,51$ & $12.623,67$ & $2.626,12$ & $15.249,78$ \\
\hline 8 & $56.414,89$ & $13.027,62$ & $2.222,16$ & $15.249,78$ \\
\hline 9 & $42.970,38$ & $13.444,51$ & $1.805,28$ & $15.249,78$ \\
\hline 10 & $29.095,65$ & $13.874,73$ & $1.375,05$ & $15.249,78$ \\
\hline 11 & $14.776,92$ & $14.318,72$ & 931,06 & $15.249,78$ \\
\hline 12 & - & $14.776,92$ & 472,86 & $15.249,78$ \\
\hline total & - & $150.000,00$ & $32.997,42$ & $182.997,42$ \\
\hline
\end{tabular}

Tabela 4.6: Resolução do exemplo 4.10

(a) O valor de cada parcela é de $\mathrm{R} \$ 15.249,78$.

(b) Na sexta parcela o valor dos juros é de $\mathrm{R} \$ 3.017,55$.

(c) Após o pagamento da quinta parcela a dívida é de $\mathrm{R} \$ 94.298,42$.

(d) A décima parcela tem amortização de $\mathrm{R} \$ 13.874,73$.

\section{Solução pelas fórmulas dos Teoremas 4.4 e 4.5 .}

(a) O valor da parcela foi calculado pela fórmula dada no Teorema 4.4, $\mathrm{R} \$ 15.249,78$.

(b) O valor pago de juros na sexta parcela é dado pela fórmula dos juros.

$$
\begin{aligned}
& J_{k}=P \cdot\left[1-(1+i)^{-n+k-1}\right] \\
& J_{6}=15249,78 \cdot\left[1-(1+0,032)^{-12+6-1}\right]=3017,548
\end{aligned}
$$

O valor dos juros na sexta parcela é de $\mathrm{R} \$ 3.017,55$. 
(c) A dívida após o pagamento da quinta parcela é calculado por sua respectiva fórmula.

$$
\begin{aligned}
& D_{k}=\frac{P}{i} \cdot\left[1-(1+i)^{k-n}\right] \\
& D_{5}=\frac{15249,78}{0,032} \cdot\left[1-(1+0,032)^{5-12}\right]=94298,42
\end{aligned}
$$

O saldo devedor após a quinta parcela é de $\mathrm{R} \$ 94.298,42$.

(d) A amortização da décima parcela é dada por:

$$
\begin{aligned}
A_{k} & =P \cdot(1+i)^{-n+k-1} \\
A_{10} & =15249,78 \cdot(1+0,032)^{-12+10-1} \\
A_{10} & =13874,72827
\end{aligned}
$$

O valor amortizado na décima parcela é de $\mathrm{R} \$ 13.874,73$.

Observação 4.5. Comparando os exemplos 4.7 e 4.10 e suas respectivas tabelas $(4.3$ e 4.6), note que na primeira os juros decaem em velocidade inferior à da segunda. Daí a preferência por instituições financeiras em oferecer empréstimos com parcelas fixas, geralmente baseadas na tabela Price.

Como a sequência das amortizações é caracterizada por uma PG, é possível determinar a soma das primeiras $k$ parcelas, assim como seus respectivos juros e amortizações.

Corolário 4.3. No sistema francês de amortização, sendo $i$ a taxa de juros e n o número de pagamentos, calculam-se a soma das $k$ primeiras parcelas $S_{p, k}$, amortizações $S_{a, k}$ e dos juros $S_{j, k}$, respectivamente, pelas fórmulas:

$$
\begin{aligned}
S_{p, k} & =k \cdot P \\
S_{a, k} & =\frac{P \cdot(1+i)^{-n} \cdot\left[(1+i)^{k}-1\right]}{i} \\
S_{j, k} & =S_{p, k}-S_{a, k}
\end{aligned}
$$

Demonstração. A demonstração da fórmula da soma das parcelas é trivial, como são $k$ parcelas iguais a $P$, a soma destes pagamentos é igual a $k \cdot P$.

Como as amortizações formam uma progressão geométrica, a soma é dada por $S_{a, k}$. 
Da soma dos $k$ primeiros termos de uma PG, tem-se:

$$
\begin{aligned}
S_{k} & =\frac{a_{1} \cdot\left(q^{k}-1\right)}{q-1} \\
S_{a, k} & =\frac{A_{1} \cdot\left[(1+i)^{k}-1\right]}{(1+i)-1} \\
S_{a, k} & =\frac{P \cdot(1+i)^{-n} \cdot\left[(1+i)^{k}-1\right]}{i}
\end{aligned}
$$

Observação 4.6. A partir das fórmulas apresentadas no Corolário 4.3 é possivel determinar a soma total das parcelas $\left(S_{p}\right)$, amortizações $\left(S_{a}\right)$ e juros $\left(S_{j}\right)$, fazendo $k=n$. Desta forma,

$$
\begin{aligned}
S_{p} & =n \cdot P \\
S_{a} & =\frac{P \cdot\left[1-(1+i)^{-n}\right]}{i}=D_{0} \\
S_{j} & =S_{p}-S_{a}=n \cdot P-D_{0}
\end{aligned}
$$

Exemplo 4.11. Ao adquirir um automóvel de $R \$ 36.000,00$ pelo sistema de financiamento francês, Théo deu uma entrada de $R \$ 12.000,00$, financiando $R \$ 24.000,00$ à taxa de 1,36\% a.m. em 48 parcelas.

(a) Qual o valor das parcelas?

(b) Qual a quantia de amortização paga na $12^{a}$ parcela?

(c) Qual a divida após o pagamento da metade das parcelas?

(d) Qual terá sido o total gasto de juros ao final do financiamento?

\section{Solução.}

(a) O valor da parcela é de $\frac{0,0136 \cdot 24000}{1-(1+0,0136)^{-48}}=684,11$.

(b) A amortização da $12^{\mathrm{a}}$ parcela é dada por $A_{12}$.

$$
A_{12}=684,11 \cdot(1,0136)^{-48+12-1}=415,013
$$

Assim, a quantia amortizada é de $\mathrm{R} \$ 415,01$. 
(c) A dívida após metade das parcelas pagas é dada por $D_{24}$.

$$
D_{24}=\frac{684,11}{0,0136} \cdot\left[1-(1+0,0136)^{24-48}\right]=13928,41335
$$

A dívida em dois anos é de $\mathrm{R} \$ 13.928,41$.

(d) Como o valor da parcela é a soma entre o juro e a amortização, então a soma dos juros é igual à soma das parcelas subtraída da soma das amortizações.

$$
\begin{aligned}
S_{j} & =S_{p}-S_{a}=48 \cdot P-D_{0} \\
& =48 \cdot 684,11-24000=8837,28
\end{aligned}
$$

O total gasto de juros foi de $\mathrm{R} \$ 8.837,28$.

\subsection{Estudo de casos}

Analisando dilemas da vida real, a partir dos conteúdos apresentados neste capítulo seguem situações-problema que podem e devem fazer parte da vida de qualquer estudante do Ensino Médio.

\subsection{1 À vista ou a prazo?}

As facilidades oferecidas pelas instituições de crédito ou no comércio de modo geral levam a uma reflexão. Se um indivíduo possui um valor total, ele deve comprar à vista ou investir a quantia e sacar mês a mês para pagar as parcelas? A resposta não é sempre a mesma, observe as condições oferecidas no problema a seguir.

Problema 4.1. Rafael pretende comprar um notebook que custa $R \$ 3.600,00$. A loja oferece as seguintes condições:

Condição (1) $10 \%$ de desconto à vista;

Condição (2) 4 parcelas mensais iguais, sendo a primeira em 30 dias.

Condição (3) 12 parcelas mensais iguais, sendo a primeira à vista.

Qual a melhor condição, sabendo que Rafael conhece um investimento que rende 6\% a.m. ( equivale a dizer que para ele o dinheiro vale $6 \%$ a.m.). Se ele não efetuar o pagamento à vista deverá investir, retirando mensalmente a quantia para pagamento. 


\section{Solução.}

Condição (1) O valor do notebook com 10\% de desconto a vista é dado por: $0,9 \cdot 3600=$ 3240 , teve uma economia de $\mathrm{R} \$ 360,00$.

Investindo esta quantia, tem-se:

$$
\begin{aligned}
& C_{n}=C_{0} \cdot(1+i)^{n} \\
& C_{n}=360 \cdot 1,06^{4} \\
& C_{n}=454,49
\end{aligned}
$$

Teria um lucro de $\mathrm{R} \$ 454,49$.

Condição (2) Considere 4 parcelas mensais iguais de $\mathrm{R} \$ 900,00$, sendo a primeira em 30 dias (lembre-se cada uma das quatro parcelas ficam aplicadas rendendo $6 \%$ a.m.), vide figura 4.7. Note que cada uma das quantias ficou aplicada por seu respectivo número de períodos (a primeira ficou durante 1 período, a segunda, terceira e quarta, respectivamente durante 2,3 e 4 períodos).

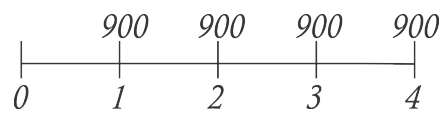

Figura 4.7: Parcelas que estão aplicadas

Assim, deseja-se saber qual a quantia obtida ao final dos quatro meses, $F=900 \cdot(1,06)+900 \cdot(1,06)^{2}+900 \cdot(1,06)^{3}+900 \cdot(1,06)^{4}$ Note que se deseja efetuar a soma de uma PG de 4 termos, primeiro termo $900 \cdot(1,06)$ e razão 1,06. Logo,

$$
\begin{aligned}
& F=\frac{a_{1}\left(q^{n}-1\right)}{q-1} \\
& F=\frac{900 \cdot(1,06) \cdot\left[(1,06)^{4}-1\right]}{1,06-1} \\
& F=4173,38
\end{aligned}
$$

Note que nessa opção Rafael, investindo em sua aplicação financeira, recebe um lucro de $\mathrm{R} \$ 573,38$, valor maior que o obtido na compra à vista.

Condição (3) Considerando que Rafael tem $\mathrm{R} \$ 3.600,00$ para aplicar, rendendo $6 \%$ a.m., dividindo em doze partes, tem-se que a primeira parcela não fica investida, 
a segunda permanece por um mês, a terceira por dois, até a última por onze meses.

Assim, se Rafael aplicar o valor que possui e retirar quantias mensalmente para pagamento das parcelas, tem-se:

$300+300 \cdot(1,06)+300 \cdot(1,06)^{2}+300 \cdot(1,06)^{3}+\cdots+300 \cdot(1,06)^{10}+300 \cdot(1,06)^{11}$

O total investido equivale ao valor futuro, em onze meses.

$$
S_{n}=\frac{300 \cdot\left[(1,06)^{12}-1\right]}{1,06-1}=5060,98
$$

Logo, comprando o notebook e deixando o dinheiro investido, ele terá um ganho de $\mathrm{R} \$ 1.460,98$ (equivalente a 5060,98 - 3600).

\subsubsection{Empréstimo Pessoal}

O empréstimo é um contrato entre o cliente e a instituição financeira pelo qual ele recebe uma quantia que deverá ser devolvida ao banco em prazo determinado, acrescida dos juros acertados. Os recursos obtidos no empréstimo não têm destinação específica.

O empréstimo consignado é uma modalidade em que o desconto da prestação é feito diretamente na folha de pagamento ou de benefício previdenciário do contratante. A consignação em folha de pagamento ou de benefício depende de autorização prévia e expressa do cliente à instituição financeira concedente do empréstimo.

A tabela abaixo é um trecho da listagem das instuições financeiras que oferecem empréstimo pessoal, disponível no Portal do Banco Central na Internet, vide [3].

Problema 4.2. Renato é cliente do Banco do Brasil e recebeu do banco duas opções de empréstimo: 12 vezes a juros de 4,28\% a.m. ou empréstimo consignado (com desconto no contra-cheque) em 6 vezes, com taxa de 2,2\% a.m. O empréstimo é uma modalidade que oferece pagamentos fixos, geralmente baseado na tabela price (Sistema Francês).

Qual será o valor da parcela nos dois casos, sabendo que ele deseja retirar um empréstimo de $R \$ 4.000,00$ ?

\section{Solução.}

Pela fórmula 4.8, calculam-se os pagamentos: 


\begin{tabular}{|c|l|c|}
\hline Posição & Instituição & taxa de juros a.m. \\
\hline 1 & BCO BNP PARIBAS BRASIL S A & 1,43 \\
\hline 7 & BANCO BONSUCESSO S.A. & 1,9 \\
\hline 19 & BCO CITIBANK S.A. & 3,62 \\
\hline 21 & BRB - BCO DE BRASILIA S.A. & 3,8 \\
\hline 24 & CAIXA ECONOMICA FEDERAL & 3,95 \\
\hline 30 & BCO DO BRASIL S.A. & 4,28 \\
\hline 31 & BV FINANCEIRA S.A. CFI & 4,4 \\
\hline 34 & BCO SANTANDER (BRASIL) S.A. & 4,6 \\
\hline 35 & HSBC BANK BRASIL SA BCO MULTIP & 4,64 \\
\hline 64 & CREFISA S.A. CFI & 20,22 \\
\hline
\end{tabular}

Tabela 4.7: Trecho retirado de [3], taxas de empréstimos pessoais

Empréstimo simples

$$
\begin{aligned}
P & =\frac{D_{0} \cdot i}{\left[1-(1+i)^{-n}\right]} \\
P & =\frac{4000 \cdot 0,0428}{\left[1-(1,0428)^{-12}\right]}=433,16
\end{aligned}
$$

Empréstimo consignado

$$
\begin{aligned}
P & =\frac{D_{0} \cdot i}{\left[1-(1+i)^{-n}\right]} \\
P & =\frac{4000 \cdot 0,022}{\left[1-(1,022)^{-6}\right]}=718,93
\end{aligned}
$$

\subsubsection{Custo Efetivo Total (CET)}

O Custo Efetivo Total (CET) é a taxa equivalente ao cálculo de todos os encargos e despesas que incidem sobre operações de crédito e de arrendamento mercantil financeiro, ofertadas a pessoas físicas, microempresas ou empresas de pequeno porte.

Quando uma pessoa física ou empresa contrata um financiamento, por exemplo, incide sobre o valor financiado o IOF (Imposto sobre Operações Financeiras) assim como encargos e taxas particulares daquela aplicação e instituição, todas devem ser explicitadas no momento do contrato, por lei. Calculando estes encargos, encontra-se a taxa real de juros que está sendo praticada na aplicação financeira, esta taxa real denomina-se Custo Efetivo Total. 
O cálculo desta taxa leva em consideração que o valor financiado é inferior ao valor inicialmente desejado, ou seja, deve-se retirar as taxas e encargos sobre a quantia acordada. Esta quantia real, que será de posse do cliente equivale à dívida inicial de um cálculo que leva em consideração a parcela inicial (a partir da taxa dada e parcela obtida sobre o valor inicialmente desejado).

Veja alguns exemplos de despesas que podem ser inseridas nas operações financeiras e nem sempre são divulgadas pela instituição, mas estão incluídas no CET:

(i) Taxas de juros

(ii) Taxas de análise de crédito

(iii) Tac - Tarifa de abertura de cadastro

(iv) Taxas administrativas em geral

(v) Seguros em geral

(vi) Tarifas em geral

(vii) Tributos em geral

Todas as despesas cobradas do cliente devem constar no CET. Desta forma é possível conhecer a taxa de juros real, que vai além do valor financiado e sua respectiva taxa de juros.

Problema 4.3. Considere um cliente de um banco que toma um empréstimo, em 12 parcelas iguais (ou seja, tabela price), de $R \$ 10.000,00$ e taxa IOF de $R \$ 317,00$ e uma taxa de administração da instituição no valor de $R \$ 83,00$. A taxa de juros cobrada pela instituição é de 3,8\%. Considere que o cliente não deseja arcar com valor superior a $R \$$ 10.000,00 no financiamento.

(a) Qual o valor da parcela considerando a taxa de juros dada?

(b) Qual a taxa percentual correspondente ao Custo Efetivo Total (CET)?

Solução.

(a) O valor da parcela pedida aqui seria a parcela inicial, ou seja, aquela calculada ao considerar o empréstimo de $\mathrm{R} \$ 10.000,00$ em 12 parcelas iguais à juros de 3,8\% a.m. 
Assim,

$$
\begin{aligned}
P & =\frac{D_{0} \cdot i}{1-(1+i)^{-n}} \\
P & =\frac{1000 \cdot 0,038}{1-(1+0,038)^{-12}}=1053,19356
\end{aligned}
$$

Logo, a parcela será de $\mathrm{R} \$ 1.053,19$.

(b) Para descobrir a CET da aplicação recorre-se à resolução de polinômios de grau $n$, sendo $n$ o número de parcelas. Assim, considerando $D_{r}$ como dívida real, $P$ o valor calculado da parcela, indica-se este cálculo por:

$$
\begin{aligned}
D_{r} & =\frac{P}{(C E T+1)}+\frac{P}{(C E T+1)^{2}}+\frac{P}{(C E T+1)^{3}}+\cdots \frac{P}{(C E T+1)^{12}} \\
9600 & =\frac{1053,19}{(C E T+1)}+\frac{1053,19}{(C E T+1)^{2}}+\frac{1053,19}{(C E T+1)^{3}}+\cdots \frac{1053,19}{(C E T+1)^{12}}
\end{aligned}
$$

Realizando o cálculo com auxílio de uma calculadora financeira, encontra-se a taxa real de $4,51 \%$.

O cálculo do CET é realizado com auxílio de uma calculadora financeira ou planilha eletrônica, sendo necessária a resolução de polinômios de grau qualquer, o que não é objetivo deste trabalho. Deseja-se apenas ter uma ideia do custo real de um financiamento.

\subsubsection{Financiamento de Carros: leasing ou financiamento}

Segundo o portal do Banco Central do Brasil, o leasing é um contrato denominado na legislação brasileira como arrendamento mercantil. As partes desse contrato são denominadas arrendador e arrendatário, conforme sejam, de um lado, um banco ou sociedade de arrendamento mercantil e, de outro, o cliente. O objeto do contrato é a aquisição, por parte do arrendador, de bem escolhido pelo arrendatário para sua utilização. O arrendador é, portanto, o proprietário do bem, sendo que a posse e o usufruto, durante a vigência do contrato, são do arrendatário. O contrato de arrendamento mercantil pode prever ou não a opção de compra, pelo arrendatário, do bem de propriedade do arrendador.

O leasing é uma operação com características legais próprias, não se constituindo operação de financiamento. Nas operações de financiamento, o bem é de propriedade do mutuário, ainda que alienado, já no ato da compra.

O prazo mínimo de arrendamento é de dois anos para bens com vida útil de até cinco anos e de três anos para os demais. Assim, para analisar um financiamento, deve-se 
construir uma planilha. A partir de editores de planilhas eletrônicas é possível automatizar o processo.

Problema 4.4. Fazendo uma simulação de financiamento de veículos, Lima registrou as informações dadas na tabela 4.8. Ele possui $\mathbf{R} \$ 5.500,00$ para dar como entrada para a compra de um carro de $R \$ 45.500,00$.

\begin{tabular}{|r|l|c|c|c|}
\hline Valor do veículo & $\mathrm{R} \$ 45.500,00$ & Parcelas & Taxa mensal & Prestação \\
\hline Valor de entrada & $\mathrm{R} \$ 5.500,00$ & 24 & $1,99 \%$ & $\mathrm{R} \$ 2.224,39$ \\
\hline Valor financiado & $\mathrm{R} \$ 40.000,00$ & 30 & 2,12 & $\mathrm{R} \$ 1.911,81$ \\
\hline Ano Modelo & 2015 & 36 & $2,25 \%$ & $\mathrm{R} \$ 1.719,55$ \\
\hline Estado & $\mathrm{DF}$ & 42 & 2,39 & $\mathrm{R} \$ 1.600,00$ \\
\hline Carro & $0 \mathrm{~km}$ & 48 & $2,39 \%$ & $\mathrm{R} \$ 1.484,40$ \\
\hline
\end{tabular}

Tabela 4.8: Simulação de um financiamento

(a) Considerando o plano de 48 vezes, Lima encontrou um valor diferente para a parcela. Analisando o contrato percebeu uma série de encargos contratuais. Qual o percentual que estas taxas interferem no valor financiado?

(b) Optando pelo plano de 36 parcelas, qual será o valor necessário para quitar a dívida após 2 anos de pagamentos?

\section{Solução.}

(a) Utilizando a fórmula 4.8, é possível encontrar a dívida inicial $D_{0}$.

$$
\begin{aligned}
& D_{0}=\frac{P \cdot\left[1-(1+i)^{-n}\right]}{i} \\
& D_{0}=\frac{1484,40 \cdot\left[1-(1+0,0239)^{-48}\right]}{0,0239} \\
& D_{0}=42.119,77
\end{aligned}
$$

Comparando a dívida encontrada com a dívida inicial, há um aumento de aproximadamente $5,3 \%$ de encargos em relação à dívida de $\mathrm{R} \$ 40.000,00$, que é o valor restante para o carro.

(b) Para pagamento da dívida encontra-se o termo $D_{24}$, usando a fórmula 4.16 do Teorema 
4.5 .

$$
\begin{aligned}
D_{k} & =\frac{P}{i} \cdot\left[1-(1+i)^{k-n}\right] \\
D_{24} & =\frac{1.719,55}{0,0225} \cdot\left[1-(1+0,0225)^{24-36}\right]=17908,73292
\end{aligned}
$$

Assim, se o cliente quiser pagar a dívida após dois anos de pagamentos, deve desembolsar R $\$ 17.908,73$.

Problema 4.5. Uma prática muito comum, sugerida por gerentes de lojas e mesmo especialistas, é a indicação de financiar um valor em mais prestações e pagar uma dupla de parcelas extremas (primeira e última, segunda e penúltima e assim sucessivamente) sendo mais vantajoso que dividir na metade do prazo.

Verifique, considerando um financiamento de $R \$ 10.000,00$, dividido em dez parcelas iguais ou dividida em 20, pagando sempre uma dupla de pagamentos extremos. Considere uma taxa de 2\% a.m., na Tabela Price.

\section{Solução.}

Na condição de 10 vezes, o pagamento é dado pela fórmula 4.8: $P=\frac{10000 \cdot 0,02}{\left[1-(1,02)^{-10}\right]} \Rightarrow$ $P=1113,26$. O valor total pago é de $\mathrm{R} \$ 11.132,60$.

Na condição de 20 vezes, $P=\frac{10000 \cdot 0,02}{\left[1-(1,02)^{-20}\right]} \Rightarrow P=611,57$

Note que o valor total pago nas dez prestações é de $\mathrm{R} \$ 11.132,60$. Pagando as parcelas extremas, verifique o esquema exibido na figura 4.8 .

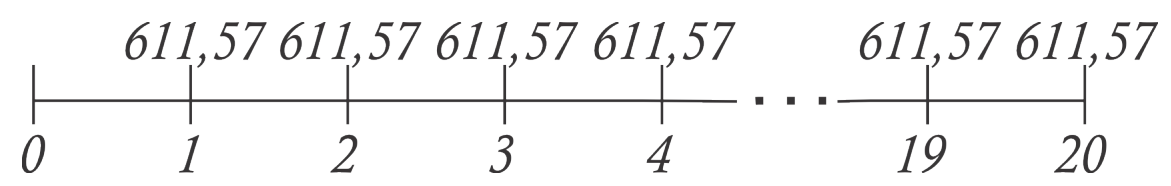

Figura 4.8: parcelas no tempo

Assim, as parcelas serão pagas segundo as extremidades: primeira e última, segunda e penúltima e assim sucessivamente. Veja a figura Ou seja, considerando o pagamento $P$, faz-se:

A soma $S$ das parcelas é dada por

$$
\begin{aligned}
& S=\left[P_{1}+\frac{P_{20}}{(1,02)^{19}}\right]+\left[P_{2}+\frac{P_{19}}{(1,02)^{17}}\right]+\left[P_{3}+\frac{P_{18}}{(1,02)^{15}}\right]+\left[P_{4}+\frac{P_{17}}{(1,02)^{13}}\right]+\cdots+\left[P_{10}+\frac{P_{11}}{(1,02)^{1}}\right] \\
& \text { Como } P_{1}=P_{2}=\cdots P_{20}=P, \text { então } S=10 \cdot P+\left[\frac{P}{(1,02)^{19}}+\frac{P}{(1,02)^{17}}+\frac{P}{(1,02)^{15}}+\cdots+\frac{P}{(1,02)^{1}}\right] .
\end{aligned}
$$




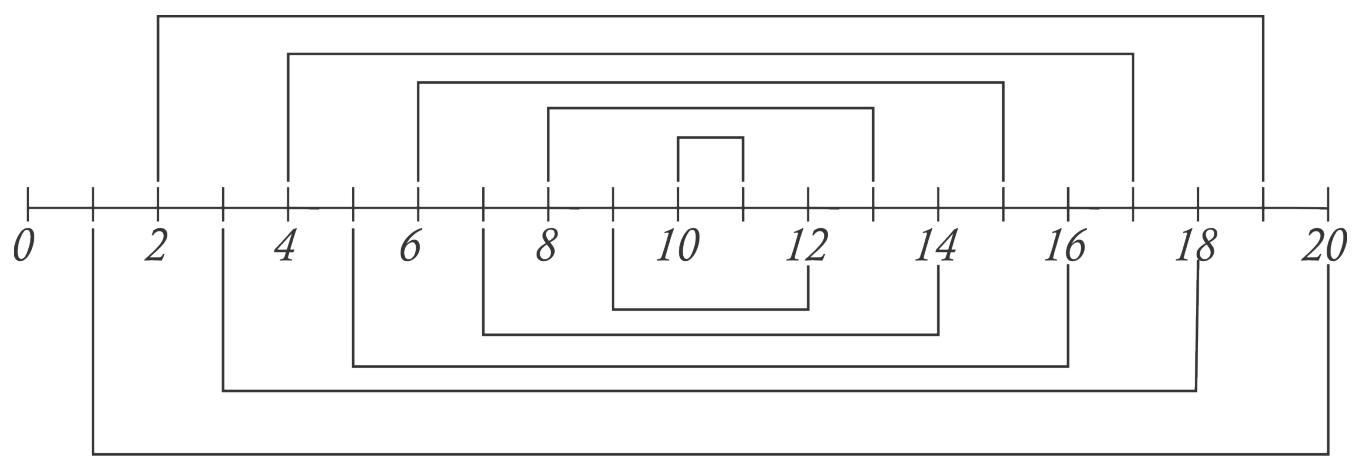

Figura 4.9: parcelas no tempo

Assim,

$$
\begin{aligned}
S & =10 \cdot P+\frac{P}{1,02} \cdot\left[1+\frac{1}{(1,02)^{2}}+\frac{1}{(1,02)^{4}}+\frac{1}{(1,02)^{6}}+\cdots+\frac{1}{(1,02)^{18}}\right] \\
& =10 \cdot P+\frac{P}{1,02} \cdot\left[\frac{1-\left[(1,02)^{-2}\right]^{10}}{1-(1,02)^{-2}}\right] \\
& =10 \cdot P+\frac{0,32703}{0,039608} \\
& \approx 18,25667 \cdot P
\end{aligned}
$$

Como o valor da parcela $P$ é de $\mathrm{R} \$ 611,57$, o valor total é de $\mathrm{R} \$ 11.165,23$. Comparando as duas condições, tem-se um aumento de 0,293 \% em relação à condição de 10 parcelas, ou seja, os valores são muito próximos.

Analisando o primeiro período da segunda condição $P+\frac{P}{(1,02)^{19}}$, fazendo $P=611,57$, o gasto no primeiro período será de $\mathrm{R} \$ 1.031,37$, enquanto o décimo período (maior gasto) será de $P+\frac{P}{(1,02)^{1}}=1211,14$.

Observe que a segunda opção pode ser vantajosa em determinadas condições, como exemplo, se o cliente tem hoje a quantia de $\mathrm{R} \$ 1.200,00$ livre para gasto, mas deseja uma maleabilidade para algum possível imprevisto, a opção de menor parcela pode ser interessante.

\subsubsection{Financiamento Imobiliário}

O financiamento imobiliário vem sendo o meio mais utilizado pelo brasileiro na compra de um imóvel. O comprador dispõe de uma porcentagem mínima do valor do imóvel e toma o restante financiado.

De modo geral, a modalidade mais oferecida pelas instituições financeiras é o Sistema de Amortização Constante. 
Como os prazos contratados costumam ser muito grandes, chegando a prazos como 30 anos (360 pagamentos mensais), torna-se necessário o uso de planilhas eletrônicas e mesmo as simulações disponibilizadas pelas próprias instituições.

\begin{tabular}{|c|l|c|c|}
\hline Posição & Instituição & $\%$ a.m. & $\%$ a.a. \\
\hline 1 & BCO SANTANDER (BRASIL) S.A. & 0,92 & 11,62 \\
\hline 2 & CAIXA ECONOMICA FEDERAL & 0,96 & 12,17 \\
\hline 3 & BCO DO BRASIL S.A. & 1,01 & 12,88 \\
\hline
\end{tabular}

Tabela 4.9: Trecho retirado de [3], financiamento imobiliário com taxas reguladas

Problema 4.6 (Analisando um Financiamento Imobiliário). A tabela 4.10 mostra as condições de uma simulação de financiamento, na qual o cliente possui $R \$ 80.000,00$ e deseja financiar a quantia de $R$ \$320.000,00 para compra de um imóvel pelo Sistema de Amortização Constante por 20 anos. A tabela 4.11 exibe os valores do primeiro ano de financiamento.

Condições da simulação:

\begin{tabular}{|l|c|}
\hline Valor de financiamento & $\mathrm{R} \$ 320.000,00$ \\
\hline Prazo & 240 meses \\
\hline Valor da entrada & $\mathrm{R} \$ 80.000,00$ \\
\hline Juros & $8,6488 \%$ a.a \\
\hline
\end{tabular}

Tabela 4.10: Condições da simulação

Faça um estudo de caso, respondendo as questões a seguir.

(a) Quanto é amortizado a cada mês? e qual o valor pago de juros no primeiro mês?

(b) A taxa de juros dada na tabela 4.10 é capitalizada anualmente ou mensalmente?

(c) Construa uma planilha para o primeiro ano, exibindo as amortizações mensais, juros, valor da prestação (livre dos encargos) e saldo devedor.

(d) Após 10 anos de financiamento, ou seja, na abertura do $11^{\circ}$ ano, quais os valores da divida, do pagamento de juros e o valor da parcela?

(e) Ao final do financiamento qual o valor total do gasto em juros?

Valores do primeiro ano de financiamento:

\section{Solução.}




\begin{tabular}{|r|c|c|c|c|c|r|}
\hline $\mathrm{N}^{\mathrm{o}}$ & Vencimento & Prestação & FGHAB(seg) & Tarifas & Encargo & Saldo Devedor \\
\hline 1 & $24 / 05 / 2015$ & $3.639,68$ & 94,16 & 25,00 & $3.758,84$ & $318.666,67$ \\
\hline 2 & $24 / 06 / 2015$ & $3.630,07$ & 93,88 & 25,00 & $3.748,95$ & $317.333,34$ \\
\hline 3 & $24 / 07 / 2015$ & $3.620,46$ & 93,59 & 25,00 & $3.739,05$ & $316.000,01$ \\
\hline 4 & $24 / 08 / 2015$ & $3.610,85$ & 93,31 & 25,00 & $3.729,16$ & $314.666,68$ \\
\hline 5 & $24 / 09 / 2015$ & $3.601,24$ & 93,02 & 25,00 & $3.719,26$ & $313.333,35$ \\
\hline 6 & $24 / 10 / 2015$ & $3.591,63$ & 92,74 & 25,00 & $3.709,37$ & $312.000,02$ \\
\hline 7 & $24 / 11 / 2015$ & $3.582,02$ & 92,46 & 25,00 & $3.699,48$ & $310.666,69$ \\
\hline 8 & $24 / 12 / 2015$ & $3.572,41$ & 92,17 & 25,00 & $3.689,58$ & $309.333,36$ \\
\hline 9 & $24 / 01 / 2016$ & $3.562,80$ & 91,89 & 25,00 & $3.679,69$ & $308.000,03$ \\
\hline 10 & $24 / 02 / 2016$ & $3.553,19$ & 91,60 & 25,00 & $3.669,79$ & $306.666,70$ \\
\hline 11 & $24 / 03 / 2016$ & $3.543,58$ & 91,32 & 25,00 & $3.659,90$ & $305.333,37$ \\
\hline 12 & $24 / 04 / 2016$ & $3.533,97$ & 91,04 & 25,00 & $3.650,01$ & $304.000,04$ \\
\hline
\end{tabular}

Tabela 4.11: Condições da simulação

O valor pago mensalmente é aquele que consta na coluna Encargo, da tabela 4.11, equivalente ao valor da prestação (Amortização + Juros) com encargos extras, sendo $F G H A B$ (espécie de seguro) e uma tarifa de $\mathrm{R} \$ 25,00$.

(a) Considerando a prestação do primeiro mês, leva-se em consideração o Saldo Devedor do mês Zero que é de $\mathrm{R} \$ 320.000,00$.

Assim, como as amortizações são constantes, em cada uma das 240 prestações será amortizado $\frac{320.000}{240}=1.333,33$. Logo, no primeiro mês, basta descontar a prestação da amortização (Prestação = Amortização + Juros), ou seja, 3.639, 68 - 1.333, $33=$ 2.306, 35. Assim, o valor gasto de juros na primeira parcela é de $\mathrm{R} \$ 2.306,35$.

(b) Deseja-se saber a taxa de juros cobrada mensalmente. Sabendo que a taxa $i$ é dada pela razão $\frac{\text { Juros }}{\text { Dívida }}$, conhecendo o juro cobrado do primeiro mês em (a), tem-se: $i=$ $\frac{2.306,35}{320.000}=0,00720733$.

Para determinar se a taxa é proporcional ou equivalente, é necessário descobrir inicialmente a taxa proporcional, dada por $i=\frac{8,6488}{12}=0,00720733$, ou seja, 0,720733\% mesmo valor encontrado na comparação do juro do primeiro mês sobre o saldo devedor do mês zero.

Desta forma, pode-se afirmar que a taxa de juros é capitalizada anualmente. Se a 
capitalização fosse mensal, a taxa anual equivalente seria:

$$
\begin{aligned}
1+I & =(1+0,00720733)^{12} \\
I & \approx 0,09
\end{aligned}
$$

A taxa anual $I$ seria $9 \%$ a.a. se fosse capitalizada mensalmente.

\begin{tabular}{|c|c|c|c|c|}
\hline $\mathrm{k}$ & $D_{k}$ & $A_{k}$ & $J_{k}$ & $P_{k}$ \\
\hline- & $320.000,00$ & - & - & - \\
\hline 1 & $318.666,67$ & $1.333,33$ & $2.306,35$ & $3.639,68$ \\
\hline 2 & $317.333,34$ & $1.333,33$ & $2.296,74$ & $3.630,07$ \\
\hline 3 & $316.000,01$ & $1.333,33$ & $2.287,13$ & $3.620,46$ \\
\hline 4 & $314.666,68$ & $1.333,33$ & $2.277,52$ & $3.610,85$ \\
\hline 5 & $313.333,35$ & $1.333,33$ & $2.267,91$ & $3.601,24$ \\
\hline 6 & $312.000,02$ & $1.333,33$ & $2.258,30$ & $3.591,63$ \\
\hline 7 & $310.666,69$ & $1.333,33$ & $2.248,69$ & $3.582,02$ \\
\hline 8 & $309.333,36$ & $1.333,33$ & $2.239,08$ & $3.572,41$ \\
\hline 9 & $308.000,03$ & $1.333,33$ & $2.229,47$ & $3.562,80$ \\
\hline 10 & $306.666,70$ & $1.333,33$ & $2.219,86$ & $3.553,19$ \\
\hline 11 & $305.333,37$ & $1.333,33$ & $2.210,25$ & $3.543,58$ \\
\hline 12 & $304.000,04$ & $1.333,33$ & $2.200,64$ & $3.533,97$ \\
\hline
\end{tabular}

Tabela 4.12: Planilha de Amortização do $1^{\circ}$ Ano

(c) Para construir a planilha de amortização do primeiro ano, basta utilizar a amortização mensal de $\mathrm{R} \$ 1.333,33$ e a taxa de juros encontrada de 0,720733\% a.m. Ilustrada na tabela 4.12 .

(d) Após dez anos de financiamento desejam-se encontrar valores que não constam na tabela, ou seja, valores após dez anos de financiamento sem a necessidade da construção da planilha completa. Desta forma, apela-se ao Teorema 4.3, encontrando-se:

$$
\begin{aligned}
D_{k} & =A_{0} \cdot(n-k) \\
D_{121} & =1333,33 \cdot(240-121)=158.666,27
\end{aligned}
$$


O valor da $121^{\mathrm{a}}$ parcela é dada por:

$$
\begin{aligned}
P_{k} & =A_{0} \cdot(1+i+i n-i k) \\
P_{121} & =1333,33 \cdot(1+0,00720733+0,00720733 \cdot 240-0,00720733 \cdot 121) \\
P_{121} & =2486,499917
\end{aligned}
$$

Assim, na parcela de número 121, o valor foi de $\mathrm{R} \$ 2.486,50$. O valor referente a juros é de $J_{k}=P_{k}-a$, ou então:

$$
\begin{aligned}
J_{k} & =A_{0} \cdot i \cdot(n-k+1) \\
J_{121} & =1333,33 \cdot 0,00720733 \cdot 240-121+1=1133,95042
\end{aligned}
$$

Os juros acarretam um gasto de aproximadamente $\mathrm{R} \$ 1133,95$.

(e) Ao final do financiamento o gasto total de juros é representado por:

$$
\begin{aligned}
S_{j} & =\frac{A_{0} \cdot i \cdot n \cdot(n+1)}{2} \\
S_{j} & =\frac{1333,33 \cdot 0,00720733 \cdot 240 \cdot(240+1)}{2} \\
S_{j} & =555827,90
\end{aligned}
$$

O total de juros é de $\mathrm{R} \$ 555.827,90$.

Observação 4.7. Note que o total de juros pago no primeiro ano foi de $R \$ 27.041,90$, enquanto o total amortizado foi de $R \$ 15.999,96$. O gasto de juros no primeiro ano equivale a $169 \%$ do que foi gasto para amortizar o saldo devedor.

Observação 4.8. Na tabela 4.10, o valor pago (encargo) tem acréscimo de taxas adicionais como um seguro e uma tarifa característica da instituição. Ao final do financiamento (240 prestações) será gasto um total de $R \$ 6.000,00$ somente de tarifas (equivale a 0,01875\%), enquanto o seguro, que é calculado sobre o saldo devedor (calculando por volta 0,02946\% da divida). Ou seja, somente a soma dos gastos com o seguro equivale a aproximadamente $0,0002946 \cdot S_{d}$ (sendo $S_{d}$ a soma das dívidas). Como $S_{d}=\frac{\left(D_{1}+D_{n}\right) \cdot n}{2}$, então a soma dos seguros equivale a $0,0002946 \cdot S_{d}=11265,504$. Desta forma, confere-se um gasto extra de $R \$ 17.265,50$ em gastos inesperados.

Note que é essencial perceber que existem variáveis que não aparecem nas fórmulas de Matemática, como taxas de administração, índices de correção (que podem alterar uma 
taxa percentual inicial) e mesmo outras tarifas. Assim, qualquer decisão que envolva um gasto, principalmente um financiamento deve ser muito bem pensada. 


\section{Conclusão}

A Matemática Financeira é um assunto essencial para a vida de qualquer cidadão, é utilizada diariamente, ainda que muitas vezes as pessoas não percebam. Uma das maiores indagações do aluno ao professor de Matemática é a aplicação prática dos assuntos estudados durante as aulas. O professor não pode deixar de utilizar temas de larga aplicação como a Matemática Financeira, que tem uma enorme variedade de contextos, presentes em vários tópicos da Matemática, como razão, proporção, funções e progressões e apresentá-la de modo a desobrigar o aluno a decorar uma série de fórmulas, principalmente se ela estiver diluída dentro dos tópicos que serão ministrados. Dessa forma, o aluno perceberá a importância do conteúdo em seu cotidiano e o aprendizado será mais eficaz.

Existe, ainda, a intenção de sugerir a reflexão sobre um possível curso de Matemática Financeira dentro do próprio currículo da Educação Básica, inserindo conceitos e situações reais que fazem parte da vivência de qualquer cidadão comum.

De qualquer modo, é apresentada uma forma para repensar a Matemática Financeira, trazendo-a para a realidade do aluno, usando-a como aplicações de vários assuntos trabalhados no Ensino Regular, assim como para enriquecer o que é apresentado.

Ainda que esta proposta seja apenas uma fagulha para motivar o professor a fazer diferente, se ele repensar o ensino deste assunto tão atual e importante, a meta deste trabalho terá sido alcançada. 


\section{Referências Bibliográficas}

[1] B. C. Brasil. http://www.bcb.gov.br/?cartaodecreditofaq, 2015.

[2] B. C. Brasil. http://www.bcb.gov.br/?chequesfaq, 2015.

[3] B. C. Brasil. http://www.bcb.gov.br/pt-br/sfn/infopban/txcred/txjuros/paginas/default.aspx, 2015.

[4] G. Iezzi, S. Hazzan, and D. Degenszajn. Fundamentos de Matemática Elementar, volume 11 of Fundamentos de Matemática Elementar. Atual Editora, SÃ£o Paulo, 1 edition, 2004.

[5] E. L. Lima, P. C. P. C. Carvalho, E. Wagner, and A. C. Morgado. A Matemática do Ensino Médio, volume 1 of Coleção do Professor de Matemática. SBM, Rio de Janeiro, 9 edition, 2006.

[6] E. L. Lima, P. C. P. C. Carvalho, E. Wagner, and A. C. Morgado. A Matemática do Ensino Médio, volume 2 of Coleção do Professor de Matemática. SBM, Rio de Janeiro, 6 edition, 2006.

[7] A. C. Morgado, E. Wagner, and S. C. Zani. Progressões e Matemática Financeira. Coleção do Professor de Matemática. SBM, 2001.

[8] I. P. d. Sá. Matemática Financeira para Educadores Críticos. Editora Ciência Moderna, 2011.

[9] W. Spinelli and M. H. Queiroz. Matemática Comercial e Financeira. Editora Ática, 2011. 